UNIVERSIDADE DE SÃO PAULO INSTITUTO DE GEOCIENNCIAS

\title{
CONDUTIVIDADE HIDRÁULICA OBTIDA PELO MÉTODO DO PERFIL INSTANTÂNEO UTILIZANDO CURVA DE RETENÇÃO E SONDA DE NÊUTRONSE PELO MODELO DE GENUCHTEN
}

Ana Lúcia Olmedo Berretta

Orientador: Prof. Dr. Fábio Taioli

DISSERTAÇÃO DE MESTRADO

Programa de Pós-Graduação em Recursos Minerais e Hidrogeologia

\author{
SÃO PAULO \\ 1999
}




\title{
CONDUTIVIDADE HIDRÁULICA OBTIDA PELO MÉTODO DO PERFIL INSTANTÂNEO UTILIZANDO CURVA DE RETENÇÃO E SONDA DE NÊUTRONS E PELO MODELO DE GENUCHTEN
}

\section{ANA LÚCIA OLMEDO BERRETTA}

\author{
Orientador: Prof. Dr. Fabio Taioli
}

DISSERTAÇÃO DE MESTRADO

COMISSÃO JULGADORA

Nome

Presidente: Prof. Dr. Fabio Taioli

Examinadores: Prof. Dr. Carlos Alberto Mendonça

Prof. Dr. Paulo Leonel Libardi

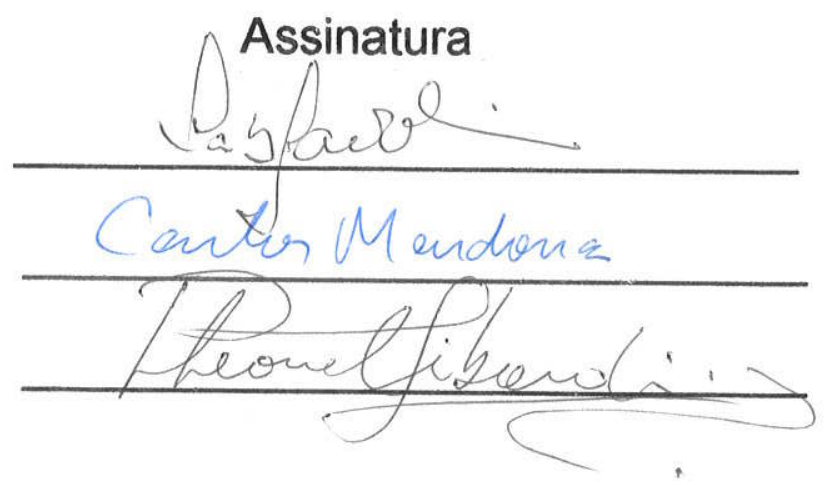




\section{UNIVERSIDADE DE SÃO PAULO \\ INSTITUTO DE GEOCIÊNCIAS}

DEDALUS - Acervo - IGC

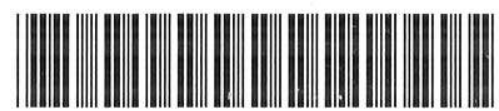

30900004615

\section{CONDUTIVIDADE HIDRÁULICA OBTIDA PELO MÉTODO DO PERFIL INSTANTÂNEO UTILIZANDO CURVA DE RETENÇÃO E SONDA DE NÊUTRONS E PELO MODELO DE GENUCHTEN}

Ana Lúcia Olmedo Berretta

Orientador: Prof. Dr. Fabio Taioli

DISSERTAÇÃO DE MESTRADO

Programa de Pós-Graduação em Recursos Minerais e Hidrogeologia

SÃO PAULO

1999 


\section{SUMÁRIO}

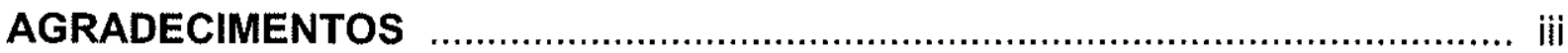

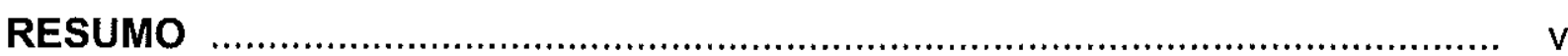

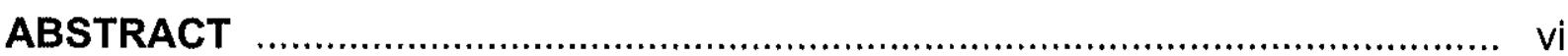

INDICE DE FOTOS ................................................................................... vii

ÍNDICE DE FIGURAS .............................................................................. vii

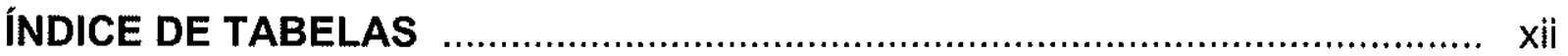

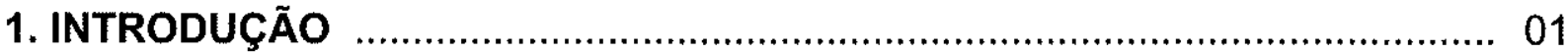

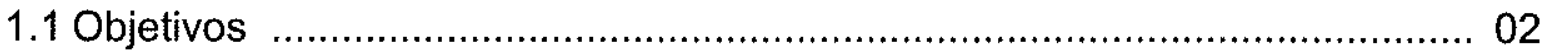

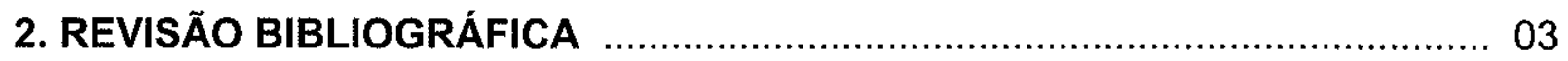

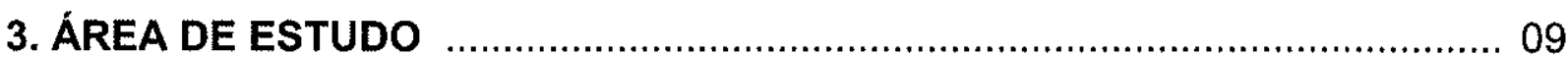

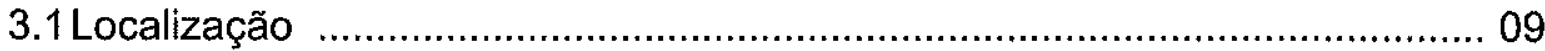

3.2 Clima

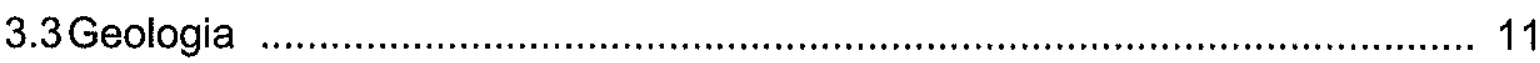

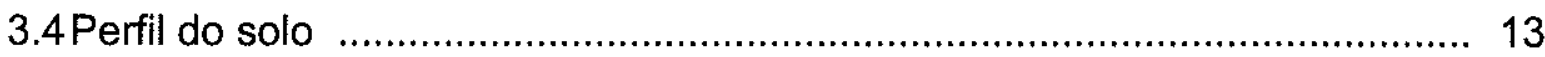

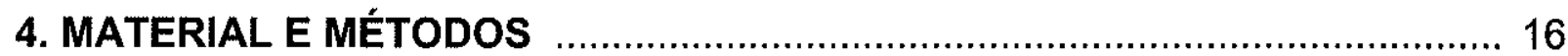

4.1 Curva de retenção ............................................................................... 16

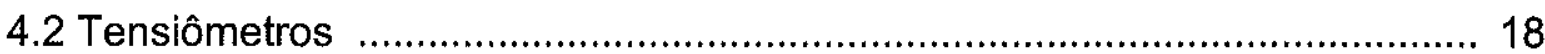

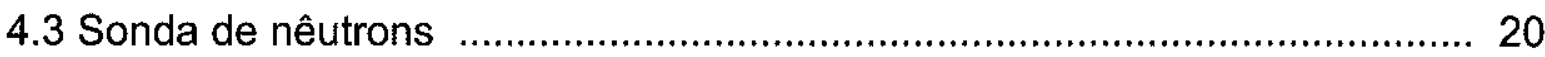

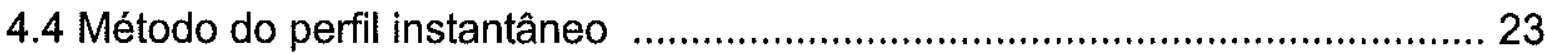

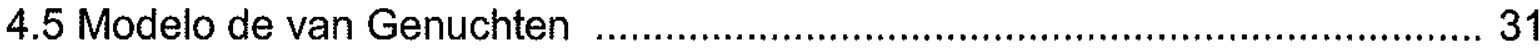

5. RESULTADOS E DISCUSSÃO

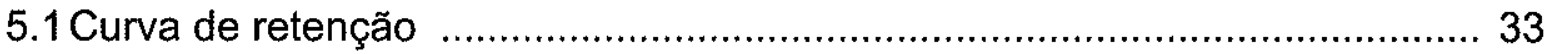

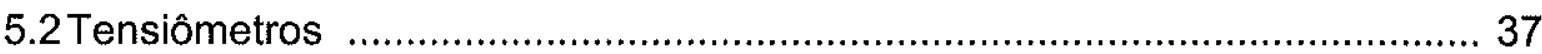

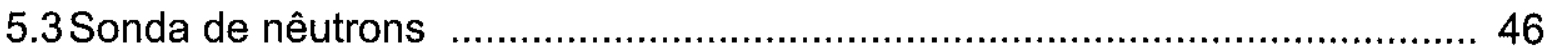

5.4 Método do perfil instantâneo ….......................................................... 55

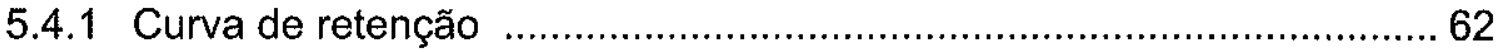




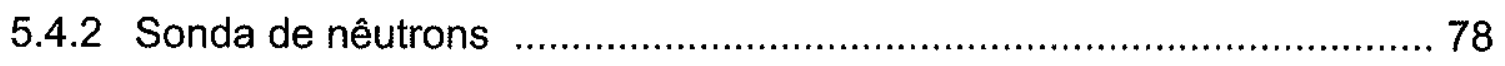

5.5Modelo de van Genuchten ............................................................... 92

5.6Comparação entre $K r$ experimental e $K r$ por van Genuchten .................... 103

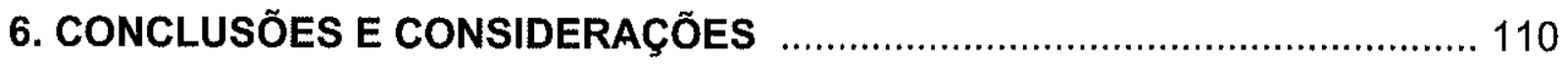

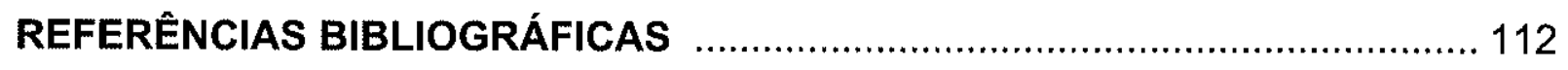




\section{AGRADECIMENTOS}

A importância deste trabalho não está somente nas palavras aqui impressas, mas nos amigos e ensinamentos que obtive ao longo do tempo em que o realizei.

Agradeço ao Prof. Dr. Fábio Taioli, pela orientação e pela força para o término deste trabalho.

Ao Prof. Dr. Paulo Leonel Libardi, que muito admiro, pela orientação e pelo exemplo de profissionalismo.

Ao Rodrigo César Araújo Cunha, pelas sugestões e pelo apoio para que eu continuasse meu trabalho.

À Prof. Dra. Annkarin Aurélia Kimmelmann e Silva, por ter me ensinado a ser perseverante e lutar pelos meus objetivos.

Ao Instituto de Geociências, em especial aos professores do Programa de Recursos Minerais e Hidrogeologia.

Ao Departamento de Ciências Exatas da ESALQ/USP, pela estrutura fornecida para a finalização do trabalho.

Aos alunos de pós-graduação do IGc/USP Jamile Dehaini, Kátia Maria Mellito, Cláudio F. Pires, Douglas Bastianon, Iraldo Braggion, Carbeny Capote Marrero, José Luiz Gomes Zoby, Anísia de Castro, Marta L. N. Almodovar, Francis Priscila Hager, Valdeneide Regina da Silva, Silvia Maria Ferreira, Fernando Roberto de Oliveira, André Bonacin da Silva e Alejandra P. Fuentes, pelos momentos compartilhados, amizade e por terem feito esta jornada mais importante.

Às meninas da secretaria de pós-graduação Ana Paula Cabanal e Magali Poli Fernandes Rizzo, pela eficiência de seu trabalho e pelas risadas compartilhadas.

Aos amigos Peter Marshal Fleming e Leila Menegasse pelo incentivo constante e pelo ombro amigo.

À amiga Fernanda Spironello, Luna, Valter, D. Zenaide e Sr. Osvaldo, minha família "adotiva" em Piracicaba, pela acolhida e pelo incentivo na parte final do trabalho.

Aos pós-graduandos da ESALQ Jeane, Silvia, Luciana, Jean, Marcelo, Karen, Glória, Cláudia, pela simpatia com que me receberam, e ao José Fernandes pelas fotos fornecidas para a ilustração do trabalho desenvolvido em campo.

Ao Conselho Nacional de Desenvolvimento Científico e Tecnológico (CNPQ), pela bolsa de estudo. 
Agradeço especialmente aos meus pais, Nair Olmedo Berretta e Edon Berretta, pelo incentivo constante, pela confiança em meu trabalho e por ensinarem muito mais do que jamais poderei aprender em livros.

Aos meus irmãos Cristina, Regina, Roberto e Vera, pelo estímulo, amizade, compreensão, paciência, confiança... Aos meus cunhados Cláudio, Eduardo e Vânia, e minhas sobrinhas Daniela e Beatriz pelo afeto.

Ao Modesto Hurtado Ferrer, pelo amor, carinho, paciência, compreensão e, sobretudo, por estar sempre a meu lado. 


\section{RESUMO}

No estudo do movimento da água na zona não saturada do perfil do solo, um dos parâmetros mais importantes para a sua compreensão é a condutividade hidráulica. Estimativas confiáveis são difíceis de serem obtidas, uma vez que a condutividade hidráulica do solo é reconhecidamente uma das propriedades físicas do solo de mais alta variabilidade. O trabalho foi desenvolvido em uma Terra Roxa Estruturada Latossólica, em uma área localizada dentro do Campus da Escola Superior de Agricultura "Luiz de Queiroz", Universidade de São Paulo. A condutividade hidráulica do solo em função da umidade foi determinada por meio de dois métodos, um direto e outro indireto, sendo que no método direto de campo a umidade do solo foi obtida por meio de dois procedimentos: pela curva de retenção de água no solo e pela sonda de nêutrons. Descreveu-se o método do perfil instantâneo, resolvendo-se a equação de Richards para a determinação do parâmetro condutividade hidráulica em função da umidade do solo, utilizando-se de tensiômetros para determinação do potencial total da água no solo, e para a determinação da umidade, a sonda de nêutrons e a curva de retenção para cada horizonte do solo estudado. A sonda de nêutrons é pouco sensível a variação de umidade no solo estudado. Apesar da curva de retenção apresentar valores de correlação melhores para a umidade ao longo do tempo de drenagem da água, o solo apresenta uma tendência para pouca variação de umidade até $50 \mathrm{~cm}$ de profundidade, refletindo a presença do horizonte Bt. Como método indireto, utilizouse o modelo de van Genuchten, que ajustou bem a curva de retenção. Os valores obtidos para a condutividade hidráulica relativa tiveram uma boa correlação em relação a condutividade hidráulica relativa experimental obtida pelo método do perfil instantâneo. Entretanto, os valores estimados pelo modelo sempre foram menores do que os obtidos experimentalmente. 


\section{ABSTRACT}

The hydraulic conductivity is one of the most important parameters to understand the movement of water in the unsaturated zone. Reliable estimations are difficult to obtain, once the hydraulic conductivity is highly variable. This study was carried out at "Escola Superior de Agricultura Luiz de Queiroz", Universidade de São Paulo, in a Kandiudalfic Eutrudox soil. The hydraulic conductivity was determined by a direct and an indirect method. The instantaneous profile method was described and the hydraulic conductivity as a function of soil water content was determined by solving the Richards equation. Tensiometers were used to estimate the total soil water potential, and the neutron probe and the soil retention curve were used to estimate soil water content in the direct method. The neutron probe showed to be not adequately sensible to the changes of soil water content in this soil. Despite of the soil retention curve provides best correlation values to soil water content as a function of water redistribution time, the soil water content in this soil did not vary too much till the depth of $50 \mathrm{~cm}$, reflecting the influence of the presence of a Bt horizon. The soil retention curve was well fitted by the van Genuchten model used as an indirect method. The values of the van Genuchten and the experimental relative hydraulic conductivity obtained by the instantaneous profile method provided a good correlation. However, the values estimated by the model were always lower than that ones obtained experimentally. 


\section{ÍNDICE DE FOTOS}

4.1 Detalhe da sonda de nêutrons efetuando medidas no campo

4.2 Parcela experimental pronta para ser inundada, com os dez tensiômetros e o tubo de acesso da sonda instalados em seu centro

4.3 Parcela experimental inundada

4.4 Detalhe dos manômetros de mercúrio dos tensiômetros instalados na parcela experimental

4.5 Colocação da lona sobre a superfície do solo

4.6 Colocação de capim sobre a primeira camada de lona .......

4.7 Início das medidas no tempo zero de redistribuição, feitas pela sonda de nêutrons e pelos tensiômetros 


\section{INDICE DE FIGURAS}

3.1 Parcela experimental circular com dez tensiômetros e um tubo de acesso para a sonda de nêutrons no centro

3.2 Pluviosidade média mensal do ano de 1995

3.3 Mapa geológico da região de Piracicaba

3.4 Horizontes pedológicos do solo estudado

4.1 Câmara de pressão de Richards

4.2 Procedimento da medida de $\phi_{\mathrm{m}}$ com o funil de placa porosa

4.3 Tensiômetro com manômetro de mercúrio instalado no campo.

5.1 Curva de retenção do solo Terra Roxa Estruturada Latossólica, para as profundidades de 10 e $20 \mathrm{~cm}$, representativa do horizonte pedológico Ap

5.2 Curva de retenção do solo Terra Roxa Estruturada Latossólica, para as profundidades de 30 a $70 \mathrm{~cm}$, representativa do horizonte pedológico $\mathrm{Bt}_{1}$

5.3 Curva de retenção do solo Terra Roxa Estruturada Latossólica, para as profundidades de 80 a $100 \mathrm{~cm}$, representativa do horizonte pedológico $\mathrm{Bt}_{2}$

5.4 Gráficos de umidade $(\theta)$ pelo tempo $(t)$ de redistribuição em horas, para as profundidades de 10 e $20 \mathrm{~cm}$, com dados obtidos pela curva de retenção

5.5 Gráficos de umidade $(\theta)$ pelo tempo $(t)$ de redistribuição em horas, para as profundidades de 30 e $40 \mathrm{~cm}$, com dados obtidos pela curva de retenção

5.6 Gráficos de umidade $(\theta)$ pelo tempo $(t)$ de redistribuição em horas, para as profundidades de 50 e $60 \mathrm{~cm}$, com dados obtidos pela curva de retenção

5.7 Gráficos de umidade $(\theta)$ pelo tempo $(t)$ de redistribuição em horas, para as profundidades de 70 e $80 \mathrm{~cm}$, com dados obtidos pela curva de retenção

5.8 Gráficos de umidade $(\theta)$ pelo tempo $(t)$ de redistribuição em horas, para as profundidades de 90 e $100 \mathrm{~cm}$, com dados obtidos pela curva de retenção 
5.9 Gráficos de umidade $(\theta)$ por $\ln t$, para as profundidades de 10

e $20 \mathrm{~cm}$, com dados obtidos pela curva de retenção

5.10 Gráficos de umidade $(\theta)$ por In $t$, para as profundidades de 30 e $40 \mathrm{~cm}$, com dados obtidos pela curva de retenção

5.11 Gráficos de umidade $(\theta)$ por In $t$, para as profundidades de 50 e $60 \mathrm{~cm}$, com dados obtidos pela curva de retenção

5.12 Gráficos de umidade $(\theta$ por In $t$, para as profundidades de 70 e $80 \mathrm{~cm}$, com dados obtidos pela curva de retenção

5.13 Gráficos de umidade $(\theta)$ por In $t$, para as profundidades de 90 e $100 \mathrm{~cm}$, com dados obtidos pela curva de retenção

5.14 Gráficos de umidade $(\theta)$ por In $t$, para as profundidades de 20 e $30 \mathrm{~cm}$, com dados obtidos pela sonda de nêutrons

5.15 Gráficos de umidade $(\theta)$ por In $t$, para as profundidades de 40 e $50 \mathrm{~cm}$, com dados obtidos pela sonda de nêutrons .......

5.16 Gráficos de umidade $(\theta)$ por In $t$, para as profundidades de 60 e $70 \mathrm{~cm}$, com dados obtidos pela sonda de nêutrons

5.17 Gráficos de umidade $(\theta)$ por In $t$, para as profundidades de 80 e $90 \mathrm{~cm}$, com dados obtidos pela sonda de nêutrons

5.18 Gráficos de umidade $(\theta$ ) por $\ln t$, para a profundidade de 100 $\mathrm{cm}$, com dados obtidos pela sonda de nêutrons

5.19 Gráficos de armazenagem $\left(h_{z}\right)$ por In $t$, para as profundidades de 10 e $20 \mathrm{~cm}$, com dados obtidos pela curva de retenção

5.20 Gráficos de armazenagem $\left(h_{z}\right)$ por In $t$, para as profundidades de 30 e $40 \mathrm{~cm}$, com dados obtidos pela curva de retenção

5.21 Gráficos de armazenagem $\left(h_{z}\right)$ por In $t$, para as profundidades de 50 e $60 \mathrm{~cm}$, com dados obtidos pela curva de retenção

5.22 Gráficos de armazenagem $\left(h_{z}\right)$ por In $t$, para as profundidades de 70 e $80 \mathrm{~cm}$, com dados obtidos pela curva de retenção

5.23 Gráficos de armazenagem $\left(h_{z}\right)$ por in $t$, para as profundidades de 90 e $100 \mathrm{~cm}$, com dados obtidos pela curva de retenção 
5.24 Gráficos de gradiente de potencial total ( $g r a d \phi_{t}$ ) pelo tempo de redistribuição $(t)$, para as profundidades de 20 e $30 \mathrm{~cm}$, com dados obtidos pela curva de retenção

5.25 Gráficos de gradiente de potencial total ( $g r a d \phi_{t}$ ) pelo tempo de redistribuição $(t)$, para as profundidades de 40 e $50 \mathrm{~cm}$, com dados obtidos pela curva de retenção

5.26 Gráficos de gradiente de potencial total ( $g r a d ~ \phi_{t}$ ) pelo tempo de redistribuição $(t)$, para as profundidades de 60 e $70 \mathrm{~cm}$, com dados obtidos pela curva de retenção

5.27 Gráficos de gradiente de potencial total ( $g r a d \phi_{t}$ ) pelo tempo de redistribuição $(t)$, para as profundidades de 80 e $90 \mathrm{~cm}$, com dados obtidos pela curva de retenção

5.28 Gráficos de condutividade hidráulica pela umidade $(K(\theta))$, para as profundidades de 20 e $30 \mathrm{~cm}$, com dados obtidos pela curva de retenção

5.29 Gráficos de condutividade hidráulica pela umidade $(K(\theta))$, para as profundidades de 40 e $50 \mathrm{~cm}$, com dados obtidos pela curva de retenção

5.30 Gráficos de condutividade hidráulica pela umidade $(K(\theta))$, para as profundidades de 60 e $70 \mathrm{~cm}$, com dados obtidos pela curva de retenção

5.31 Gráficos de condutividade hidráulica pela umidade $(K(\theta)$, para as profundidades de 80 e $90 \mathrm{~cm}$, com dados obtidos pela curva de retenção

5.32 Gráficos de armazenagem $\left(h_{z}\right)$ por In $t$, para as profundidades de 20 e $30 \mathrm{~cm}$, com dados obtidos pela sonda de nêutrons

5.33 Gráficos de armazenagem $\left(h_{z}\right)$ por In $t$, para as profundidades de 40 e $50 \mathrm{~cm}$, com dados obtidos pela sonda de nêutrons

5.34 Gráficos de armazenagem $\left(h_{z}\right)$ por In $t$, para as profundidades de 60 e $70 \mathrm{~cm}$, com dados obtidos pela sonda de nêutrons

5.35 Gráficos de armazenagem $\left(h_{z}\right)$ por in $t$, para as profundidades de 80 e $90 \mathrm{~cm}$, com dados obtidos pela sonda de nêutrons

5.36 Gráficos de armazenagem $\left(h_{z}\right)$ por In $t$, para a profundidade de $100 \mathrm{~cm}$, com dados obtidos pela sonda de nêutrons 
5.37 Gráficos de condutividade hidráulica pela umidade $(K(\theta))$, para as profundidades de 20 e $30 \mathrm{~cm}$, com dados obtidos pela sonda de nêutrons

5.38 Gráficos de condutividade hidráulica pela umidade $(K(\theta))$, para as profundidades de 40 e $50 \mathrm{~cm}$, com dados obtidos pela sonda de nêutrons

5.39 Gráficos de condutividade hidráulica pela umidade $(K(\theta))$, para as profundidades de 60 e $70 \mathrm{~cm}$, com dados obtidos pela sonda de nêutrons

5.40 Gráficos de condutividade hidráulica pela umidade $(K(\theta))$, para as profundidades de 80 e $90 \mathrm{~cm}$, com dados obtidos pela sonda de nêutrons

5.41 Gráficos de comparação entre $K r$ experimental $(K r(\operatorname{Exp}))$ e $K r$ por van Genuchten $(K r(V G))$, para as profundidades de 20 e $30 \mathrm{~cm}$

5.42 Gráficos de comparação entre $K r$ experimental $(K r(\operatorname{Exp}))$ e $K r$ por van Genuchten $(K r(V G))$, para as profundidades de 40 e $50 \mathrm{~cm}$

5.43 Gráficos de comparação entre $K r$ experimental $(K r(E x p))$ e $K r$ por van Genuchten $(K r(V G))$, para as profundidades de 60 e $70 \mathrm{~cm}$

5.44 Gráficos de comparação entre $K r$ experimental $(K r(E x p))$ e $K r$ por van Genuchten $(K r(V G))$, para as profundidades de 80 e $90 \mathrm{~cm}$ 
5.1 Algumas características físicas do perfil do solo Terra Roxa Estruturada Latossólica

5.2 Valores de potencial mátrico $\left(-\phi_{\mathrm{m}} ; \mathrm{cm}\right.$ água) obtidos ao longo do tempo de drenagem interna do perfil

5.3 Valores de potencial total $\left(-\phi_{t} ; \mathrm{cm}\right.$ água) obtidos ao longo do tempo de drenagem interna do perfil

5.4 Umidade $\left(\mathrm{cm}^{3} / \mathrm{cm}^{3}\right)$ estimada pela curva de retenção da água no solo

5.5 Equações lineares obtidas por regressão da umidade $(\theta)$ versus $\ln t$, para valores obtidos pela curva de retenção

5.6 Umidade $\left(\mathrm{cm}^{3} / \mathrm{cm}^{3}\right)$ estimada pela sonda de nêutrons

5.7 Equações de calibração da sonda para o solo estudado, para cada profundidade

5.8 Equações lineares obtidas por regressão da armazenagem $\left(h_{z}\right)$ versus $\ln t$, com dados obtidos pela sonda de nêutrons

5.9 Armazenagem de água $\left(\mathrm{cm}^{3} / \mathrm{cm}^{2}\right)$ calculada com dados obtidos pela curva de retenção, para cada profundidade ao longo do tempo de drenagem interna do perfil

5.10 Fluxos calculados $(\mathrm{cm} / \mathrm{h})$ com dados obtidos pela curva de retenção, para cada profundidade ao longo do tempo de drenagem interna do perfil

5.11 Equações lineares obtidas por regressão de $h_{z}$ versus $\ln t$ para dados obtidos pela curva de retenção

5.12 Valores de gradiente de potencial total $(\mathrm{cm} / \mathrm{cm})$

5.13 Equações polinomiais obtidas por regressão do gradiente de potencial total ( $g r a d \phi_{t}$ ) versus tempo $(t)$

5.14 Condutividade hidráulica $(\mathrm{cm} / \mathrm{h}$ ) calculada com dados obtidos pela curva de retenção, para cada profundidade ao longo do tempo de drenagem interna do perfil

5.15 Equações potenciais obtidas por regressão dos valores de condutividade hidráulica versus umidade $(K(\theta))$ 
5.16 Valores de condutividade hidráulica saturada $\left(\mathrm{K}_{0}\right)$, calculada com dados obtidos pela curva de retenção, para cada profundidade ao longo do tempo de redistribuição

5.17 Valores de condutividade hidráulica relativa experimental $(K r$ Exp) obtidos pelo procedimento da curva de retenção da água no solo

5.18 Equações lineares obtidas por regressão de armazenagem $\left(h_{z}\right)$ versus $\ln t$ para dados obtidos pela sonda de nêutrons

5.19 Fluxos calculados $(\mathrm{cm} / \mathrm{h})$ para cada profundidade ao longo do tempo de drenagem interna do perfil, com dados obtidos pela sonda de nêutrons

5.20 Condutividade hidráulica calculada $(\mathrm{cm} / \mathrm{h})$ para cada profundidade ao longo do tempo de drenagem interna do perfil, com dados obtidos pela sonda de nêutrons

5.21 Equações lineares obtidas por regressão da condutividade hidráulica versus umidade $(K(\theta))$, com dados obtidos pela sonda de nêutrons

5.22 Saturação efetiva $\left(S_{e}\right)$ calculada para cada profundidade ao longo do tempo de redistribuição

5.23 Valores de condutividade hidráulica relativa $(K r)$ obtidos pelo modelo de van Genuchten (1980)

5.24 Condutividade hidráulica $(\mathrm{cm} / \mathrm{h})$ calculada pelo modelo de van Genuchten (1980)

5.25 Equações lineares obtidas por regressão dos valores de $K r$ $($ Exp) versus $\operatorname{Kr}(V G)$

5.26 Valores escolhidos de $K r(V G)$ e aplicados às equações de regressão $K r(E x p) \times K r(V G)$ para obtenção da relação $K r$ $(\operatorname{Exp}) / K r(V G)$ 


\section{INTRODUÇÃO}

No estudo do movimento da água na zona não saturada do perfil do solo, um dos parâmetros mais importantes para a sua compreensão é a condutividade hidráulica, uma vez que esta caracteriza a capacidade que um meio poroso possui para transmitir água. Pela correta obtenção deste parâmetro pode-se determinar, por exemplo, o movimento de contaminantes presentes na solução da água do solo e estimar seu alcance na água subterrânea.

Estimativas confiáveis são difíceis de serem obtidas, uma vez que a condutividade hidráulica do solo é reconhecidamente uma das propriedades físicas do solo de mais alta variabilidade. Coeficientes de variação da ordem de $100 \%$ para a condutividade hidráulica do solo saturado, e da ordem de $400 \%$ para a condutividade hidráulica do solo a uma umidade $40 \%$ inferior à saturação já foram citados na literatura.

Além de sua importância na agronomia, contribuindo nos estudos de infiltração da água no solo, no movimento da água dentro do perfil de solo e para as raizes das plantas e na drenagem interna da água no solo, há uma grande importância no seu conhecimento na hidrologia, a qual é fundamental nos estudos de recarga de aqüíferos e na contaminação destes por poluentes provenientes da atividade agrícola ou de outras atividades antropogênicas.

A determinação da condutividade hidráulica em solo não saturado pode ser feita em laboratório por métodos desenvolvidos sob condições transientes ou sob condições de regime estacionário, mas pode levar a grandes erros pois as condições físicas do solo são alteradas, uma vez que as amostras de solo sempre sofrem perturbação em sua estrutura, e além disso, podem não ser representativas quando extrapoladas para uma área. Em condições de campo, o método do perfil 
instantâneo é o mais utilizado. Neste método determina-se a condutividade hidráulica em função da umidade do solo $K(\theta)$ e, apesar de apresentar desvantagens, como alto consumo de tempo e investimento de mão-de-obra, sua vantagem está no fato de se basear em medidas diretas no campo.

A relação $k(\theta)$ pode ser obtida por várias maneiras, dentre elas tem-se medidas diretas no campo com o uso da sonda de nêutrons, ou a utilização de outros parâmetros do meio poroso como a curva de retenção da água no solo. A sonda de nêutrons apresenta vantagens por ser um método não destrutivo, e por medir a umidade sempre no mesmo ponto do perfil estudado. Entretanto, o equipamento é caro, possui uma fonte radioativa que necessita ser manuseada cuidadosamente, e necessita ser calibrada para o tipo de solo a ser estudado.

\subsection{Objetivos}

O presente trabalho foi desenvolvido com os seguintes objetivos:

1) determinar a condutividade hidráulica do solo pelo método do perfil instantâneo;

2) determinar a condutividade hidráulica por um método indireto baseado na curva de retenção, especificamente o modelo de van Genuchten (1980);

3) comparar os resultados obtidos para a condutividade em função da umidade $(K(\theta))$ pelos dois métodos apresentados, com 0 intuito de enfatizar os problemas na obtenção dos dados e no seu processamento;

4) comparar os resultados obtidos para $K(\theta)$ pelo método do perfil instantâneo por meio da curva de retenção e pela sonda de nêutrons; 


\section{REVISÃO BIBLIOGRÁFICA}

A primeira equação que quantificou o fluxo de água em meios porosos saturados foi estabelecida por Darcy, 1856, apud Libardi (1995). Através de seu experimento, Darcy mostrou que a quantidade de água que atravessa um meio poroso é proporcional ao gradiente hidráulico, e denominou condutividade hidráulica a constante de proporcionalidade que caracteriza o meio poroso quanto a sua capacidade de transmissão de água.

Foi Buckingham, 1907, apud Libardi (1995) quem introduziu os conceitos para descrição do fluxo de água em meios porosos não saturados, mostrando que nessa condição o fluxo de água também era proporcional a um gradiente de potencial hidráulico, mas que a condutividade hidráulica era função da umidade do solo, e o potencial hidráulico era a soma do potencial gravitacional e do potencial matricial.

Uma nova função na teoria do fluxo de água em solos não saturados também foi introduzida por Buckingham, 1907, apud Libardi (1995) a qual posteriormente foi chamada de difusividade da água por Childs \& Collis-George (1948), apud Libardi (1995). A difusividade foi definida por Buckingham como a razão entre a condutividade hidráulica e a capacidade específica da água, a qual é obtida pela tangente na curva de retenção (umidade do solo versus potencial mátrico) para um dado valor de umidade ou potencial matricial.

Gardner (1970) apresentou um método para determinação da difusividade em função do potencial matricial, baseado na transformação da equação de Richards, assumindo a umidade do solo como função do tempo mas não função da profundidade durante o processo de redistribuição. Nielsen et al. (1972) utilizaramse deste método, e concluíram que este era adequado para propósitos práticos, particularmente durante os estágios iniciais da redistribuição. 
Segundo Prevedello et al. (1987), que propuseram a introdução de novos conceitos de difusividade hidráulica na teoria do fluxo de água em solos não saturados, este conceito trouxe vantagens por apresentar várias soluções disponiveis para a equação diferencial geral que expressa o fluxo, além de dispensar medições de potencial mátrico na quantificação do fluxo na direção horizontal. Entretanto, esses autores ressaltam desvantagens no emprego desta teoria nos processos de movimento de fluxo na direção vertical, uma vez que o tratamento matemático analítico torna-se complexo.

Segundo Libardi (1978), Richards (1931) foi o primeiro pesquisador a apresentar um método de determinação da condutividade hidráulica em condições de fluxo estacionário, no qual utilizava uma pequena coluna de solo entre duas placas de cerâmica, mantendo um gradiente de potencial constante entre elas por meio de colunas de água. Uma vez atingido o regime estacionário, a condutividade hidráulica era então estimada pela equação de Darcy.

Além disso, foi Richards (1931) quem estendeu a equação de BuckinghamDarcy às condições transientes, através da combinação desta equação com a equação da continuidade, obtendo a equação diferencial geral que descreve o movimento não saturado da água em solos, conhecida como equação de Richards.

Em condições de campo, os métodos propostos baseiam-se no método do perfil instantâneo, aplicado para condições de fluxo transiente. A base teórica do método do perfil instantâneo não exige uniformidade das propriedades hidráulicas do sistema de fluxo, e nem que as condições de contorno sejam necessariamente constantes ou conhecidas em detalhes. Consequentemente, tem-se uma alta variabilidade na análise dos dados.

Segundo Klute (1972), este método foi aplicado pela primeira vez em laboratório por Richards \& Weeks (1953), e no campo por Richards et al. (1956). O procedimento utilizado consistia na saturação de um perfil de solo, e sua posterior evaporação e drenagem. O gradiente de potencial e o fluxo de drenagem (ou evaporação) eram estimados a partir de medidas simultâneas do potencial mátrico 
(obtido por meio de tensiômetros instalados em várias profundidades), e da umidade do solo (obtida gravimetricamente), sendo que ao longo do perfil procuravam-se as posições nas quais o fluxo tornava-se igual a zero. Com a finalidade de permitir apenas a drenagem no perfil, Ogata \& Richards (1957) utilizaram o mesmo procedimento cobrindo a superfície do solo com plástico, conseguindo com isso fluxo nulo nessa posição $(z=0)$. Utilizando as mesmas técnicas de Ogata \& Richards (1957), Nielsen et al. (1962) introduziram a sonda de nêutrons para medida da umidade, cuja vantagem principal é a de ser uma técnica não destrutiva.

A partir do trabalho de Nielsen et al. (1962) muitos outros autores têm utilizado esta técnica, entre eles tem-se van Bavel et al. (1968), Hillel et al. (1972), Reichardt \& Libardi (1974), Saunders et al. (1978), Libardi et al. (1980), Prevedello et al. (1981), Luxmore et al. (1981), Prevedello (1987), Souza (1993), Timm (1994), e outros.

Watson (1966) determinou a condutividade hidráulica em função da umidade em colunas de areia, utilizando-se de um procedimento idêntico ao utilizado por Richards \& Weeks (1953), mas empregou a técnica da atenuação de radiação gama para medir a umidade, tensiômetros com transdutor de pressão para medir o potencial mátrico, e fluxo de drenagem vertical.

O trabalho de Hillel et al. (1972) é destacado por Libardi (1978) por apresentar um roteiro simples e completo para a determinação da função condutividade em condições de campo. O procedimento sugerido por Hillel et al. (1972) pode ser aplicado até em perfis de solos heterogêneos, sendo limitado apenas para solos onde o nivel de água se encontra próximo à superfície (Souza, 1993). Este procedimento foi posteriormente simplificado por vários autores.

Black et al. (1969) foram os primeiros a introduzir a hipótese de que a drenagem da água no perfil seria igual em todas as profundidades, ou seja, consideraram o gradiente de potencial hidráulico como sendo unitário. Esta hipótese também foi utilizada por outros autores em métodos simplificados de determinação da condutividade hidráulica, como Davidson et al. (1969), Nielsen et al. (1973), 
Libardi et al. (1980), Chong et al. (1981), que recomendaram sua aplicação em solos identificados como homogêneos.

Bacchi et al. (1991) compararam os métodos simplificados de determinação da condutividade hidráulica de Libardi et al. (1980) e Sisson et al. (1980), e concluíram que para solos homogêneos estes métodos são praticamente equivalentes, na condição de gradiente unitário de potencial hidráulico, apresentando resultados comparáveis ao método de Hillel et al. (1972) utilizado como referência.

Como foi observado por Souza (1993), o coeficiente de variação calculado para os métodos de Hillel et al. (1972), Libardi et al. (1980) e Sisson et al. (1980) é maior no primeiro método em relação aos dois últimos, devido ao fato de que estes consideram o gradiente de potencial total como sendo unitário. Consequentemente, os métodos de Libardi et al. (1980) e Sisson et al. (1980) apresentam menor variabilidade espacial e maior variabilidade temporal em relação ao método de Hillel (1980).

Mais recentemente, Prevedello et al. (1994) conduziu um experimento de redistribuição de água em colunas de solo homogêneo visando avaliar a magnitude dos erros envolvidos na obtenção da condutividade hidráulica em função da umidade adotando-se o gradiente de potencial hidráulico unitário. Foi observado pelos autores que, dentro dos limites de umidade determinados no experimento, os erros na obtenção da condutividade hidráulica foram crescentes com o decréscimo da umidade, chegando a subestimá-la em até $73 \%$.

A metodologia apresentada por Libardi et al. (1980) considera a condutividade hidráulica como sendo uma função exponencial da umidade, e sua determinação é feita por meio de medidas de umidade do solo em função da profundidade e tempo de redistribuição, prevenindo-se a infiltração e evaporação pela superfície do solo. Os métodos da umidade e do fluxo foram desenvolvidos por Libardi et al. (1980) baseados nesta metodologia. 
A determinação da condutividade hidráulica também tem sido feita com a utilização da curva de retenção de água no solo, como apresentam em seus trabalhos Marshall (1958), Millington \& Quirk (1959), Green \& Corey (1971), Campbell (1974), van Genuchten (1980), Talsma (1985), Pauletto et al. (1988) que desenvolveram um método simples para determinação da condutividade em função da umidade a partir da curva de retenção, entre outros.

van Genuchten (1980), por meio de dados obtidos da curva de retenção da água no solo, calculou a condutividade hidráulica analiticamente utilizando um método fundamentado nos modelos apresentados por Burdine (1953) e Mualem (1976).

Segundo Dane (1980), em uma comparação feita entre os métodos propostos por van Genuchten et al. (1980) e por Libardi et al. (1980), mostrou que em solos arenosos os métodos apresentam boa concordância.

Segundo Pauletto (1986), uma outra comparação feita por van Genuchten \& Nielsen (1985), revisando os modelos mais utilizados para o ajuste dos dados experimentais das curvas de retenção, mostra que o modelo de determinação da condutividade hidráulica relativa através da curva de retenção apresentado por van Genuchten et al. (1980) foi o que apresentou a maior validade para a maioria dos solos analisados (95\% dos casos).

Entre os métodos que podem ser utilizados para a determinação da condutividade hidráulica, sejam estes de laboratório ou de campo, diretos ou indiretos, estimativas confiáveis são difíceis de serem obtidas, uma vez esta é reconhecidamente uma das propriedades físicas do solo de mais alta variabilidade. Warrick \& Nielsen (1980) obtiveram um coeficiente de variação da ordem de $100 \%$ para a condutividade hidráulica do solo saturado, e da ordem de $400 \%$ para a condutividade hidráulica do solo a uma umidade $40 \%$ inferior à saturação.

Além de sua importância na agronomia, onde $o$ conhecimento da condutividade hidráulica contribui nos estudos de infiltração da água no solo (Kunze \& Nielsen, 1983; Swartzendruber, 1987; Wolfe et al.,1988), no movimento da água 
dentro do perfil de solo e para as raizes das plantas (Gardner \& Ehlig, 1962; Hainsworth \& Aylmore, 1986, 1989; Jong van Lier \& Libardi, 1997) e na drenagem interna da água no solo (Freire, 1979; Libardi \& Saad, 1994), há uma grande importância no seu conhecimento na hidrologia, onde contribui nos estudos de recarga de aqüíferos (Freeze \& Cherry, 1979) e na contaminação destes por poluentes provenientes da atividade agricola (Casey et al., 1998; Shao \& Horton, 1998) ou de outras atividades antropogênicas. 


\section{3. ÁREA DE ESTUDO}

O trabalho experimental foi conduzido durante os meses de junho e julho de 1995, em uma parcela experimental circular de $5 \mathrm{~m}$ de diâmetro na qual foram instalados um tubo de acesso para a sonda de nêutrons até a profundidade de 1,5 $\mathrm{m}$, e dez tensiômetros a cada $0,10 \mathrm{~m}$, de 0,10 a $1,0 \mathrm{~m}$. A distância entre o tubo de acesso para a sonda e o conjunto de tensiômetros foi de 0,50 m (Figura 3.1).

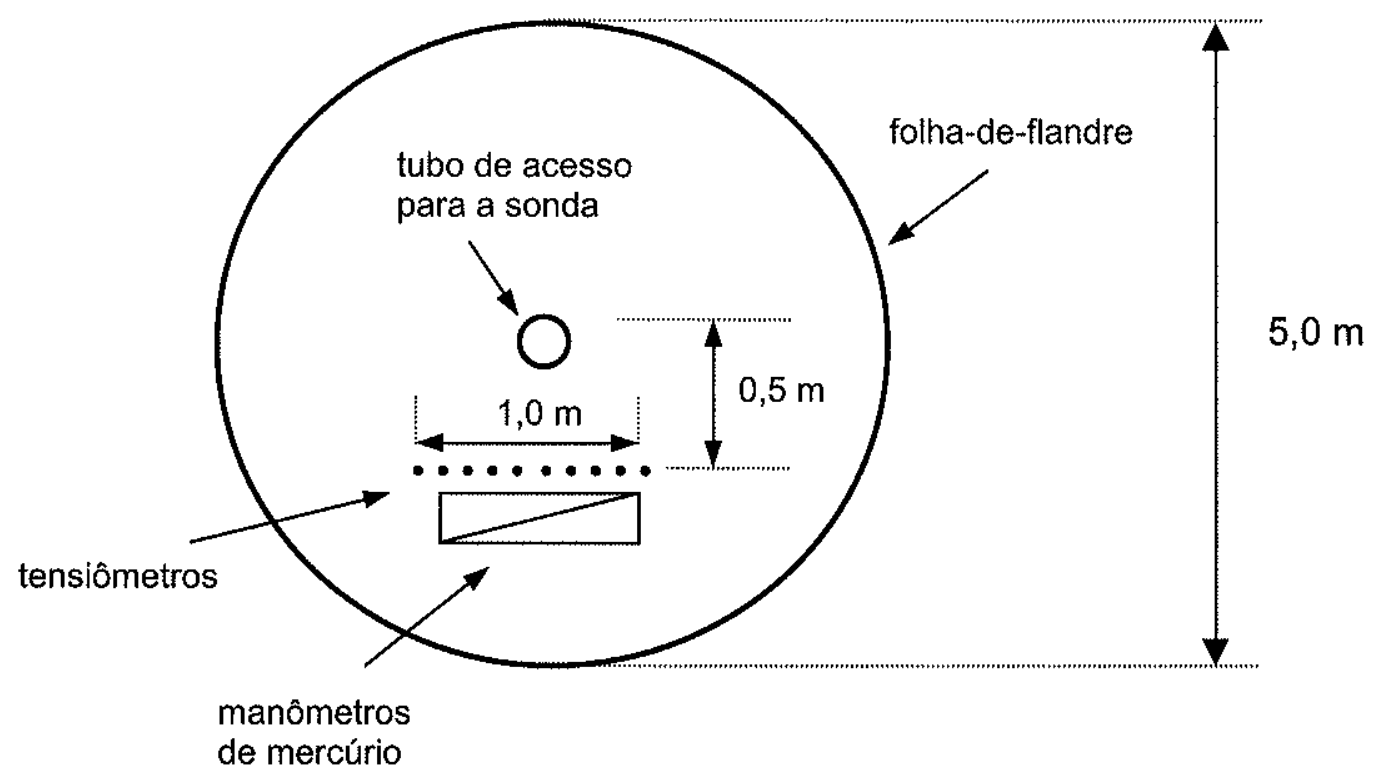

Figura 3.1 Parcela experimental circular com dez tensiômetros e um tubo de acesso para a sonda de nêutrons no centro.

\subsection{Localização}

O experimento foi conduzido em uma área situada nos limites do Campus da Escola Superior de Agricultura "Luiz de Queiroz", Universidade de São Paulo, em 
Piracicaba, São Paulo. As coordenadas geográficas da área estudada são $22^{\circ} 43^{\prime}$ de latitude sul e $47^{\circ} 25^{\prime}$ de longitude oeste, com altitude de $580 \mathrm{~m}$.

\subsection{Clima}

O clima da região é do tipo mesotérmico Cwa, pela classificação climática de Köppen, ou seja, subtropical úmido, com estiagem no inverno, temperatura média do mês mais frio superior a $18^{\circ} \mathrm{C}$ e a do mês mais quente superior a $22^{\circ} \mathrm{C}$ (Camargo et al., 1974). As médias anuais de precipitação são de 1253 mm (Villa Nova, 1989).

Na Figura 3.2 pode-se observar a distribuição da pluviosidade média mensal ao longo do ano de 1995 (ano em que foi desenvolvido o experimento de campo).

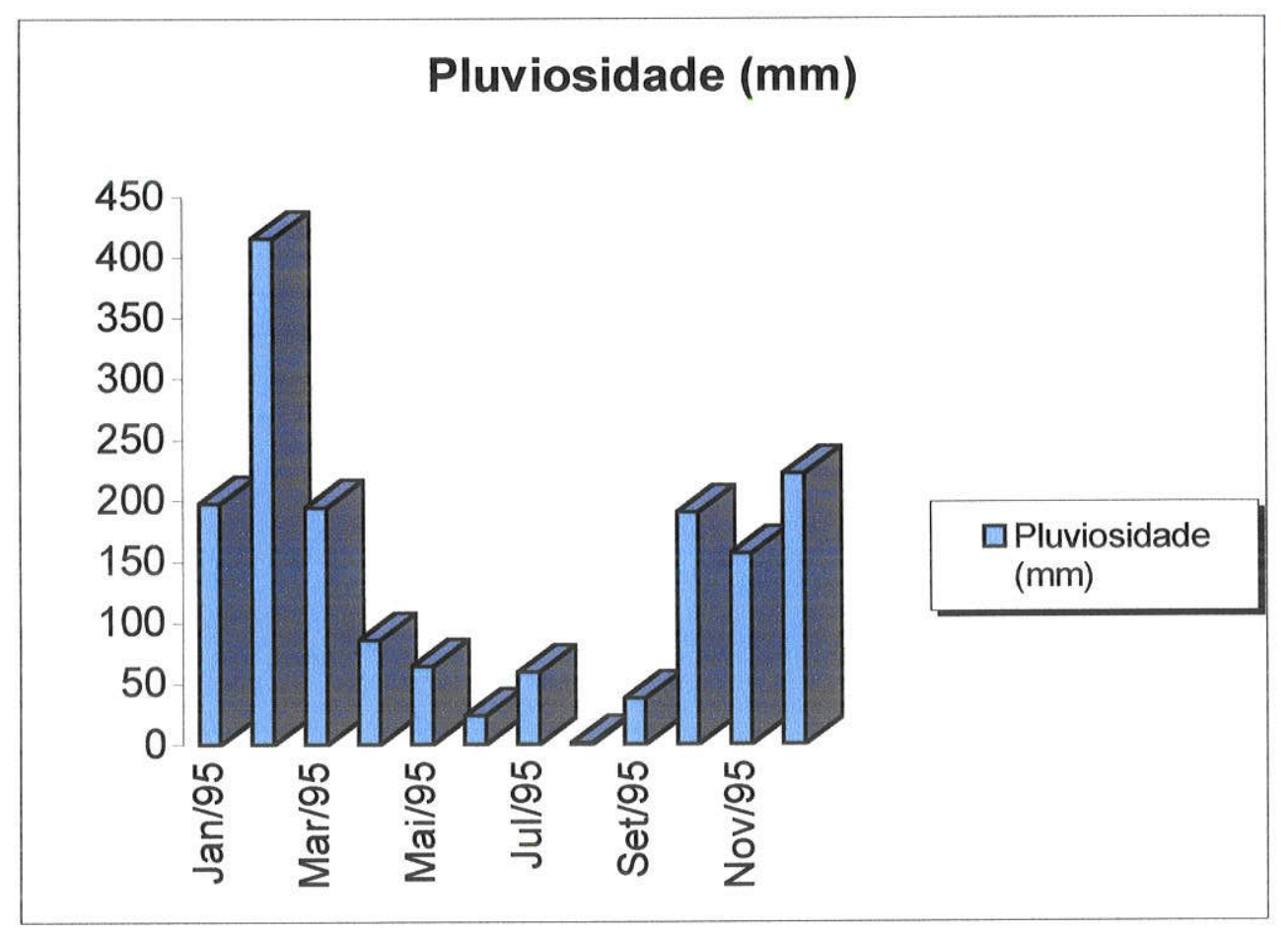

Figura 3.2 Pluviosidade média mensal do ano de 1995. Fonte: http://www.ciagri.usp.br/dfm/seg/postocon.html. 


\subsection{Geologia}

A região de Piracicaba está inserida na Bacia Sedimentar do Paraná (Figura 3.3), cujas unidades litoestratigráficas abrangidas, das mais antigas para as mais recentes, são as seguintes:

- Grupo Passa Dois:

Formação Corumbataí.

Apresenta litologia predominante de siltitos, com menores proporções de arenitos finos a muito finos. Camadas e nódulos de sílex de cor castanha ou esbranquiçada ocorrem em vários pacotes, além de veios delgados de quartzo fibroso e calcita e lâminas de gipsita (Almeida \& Barbosa, 1953).

A Formação Corumbataí é composta pelas seguintes estruturas sedimentares: laminação plano-paralelas, camadas maciças, sedimentos rítmicos (siltitos/argilitos/arenitos finos), concreções discóides, estratificações de pequeno porte e baixo ângulo, marca ondulada, gretas de contração, brechas intraformacionais, estruturas "flaser". Os siltitos são cortados por diques clásticos constituídos de arenitos de granulação fina (Menegon, 1990).

- Grupo São Bento:

Formação Serra Geral.

Apresenta litologia de rochas vulcânicas foleíticas dispostas em derrames basálticos, com coloração cinza a negra, textura afanítica, com intercalações de arenitos intertrapeanos, finos a médios, apresentando estratificação cruzada tangencial. Ocorrem esparsos níveis vitrofíricos não individualizados (IPT, 1981).

A área utilizada para a execução do experimento apresenta um solo de alteração desta unidade litoestratigráfica. 


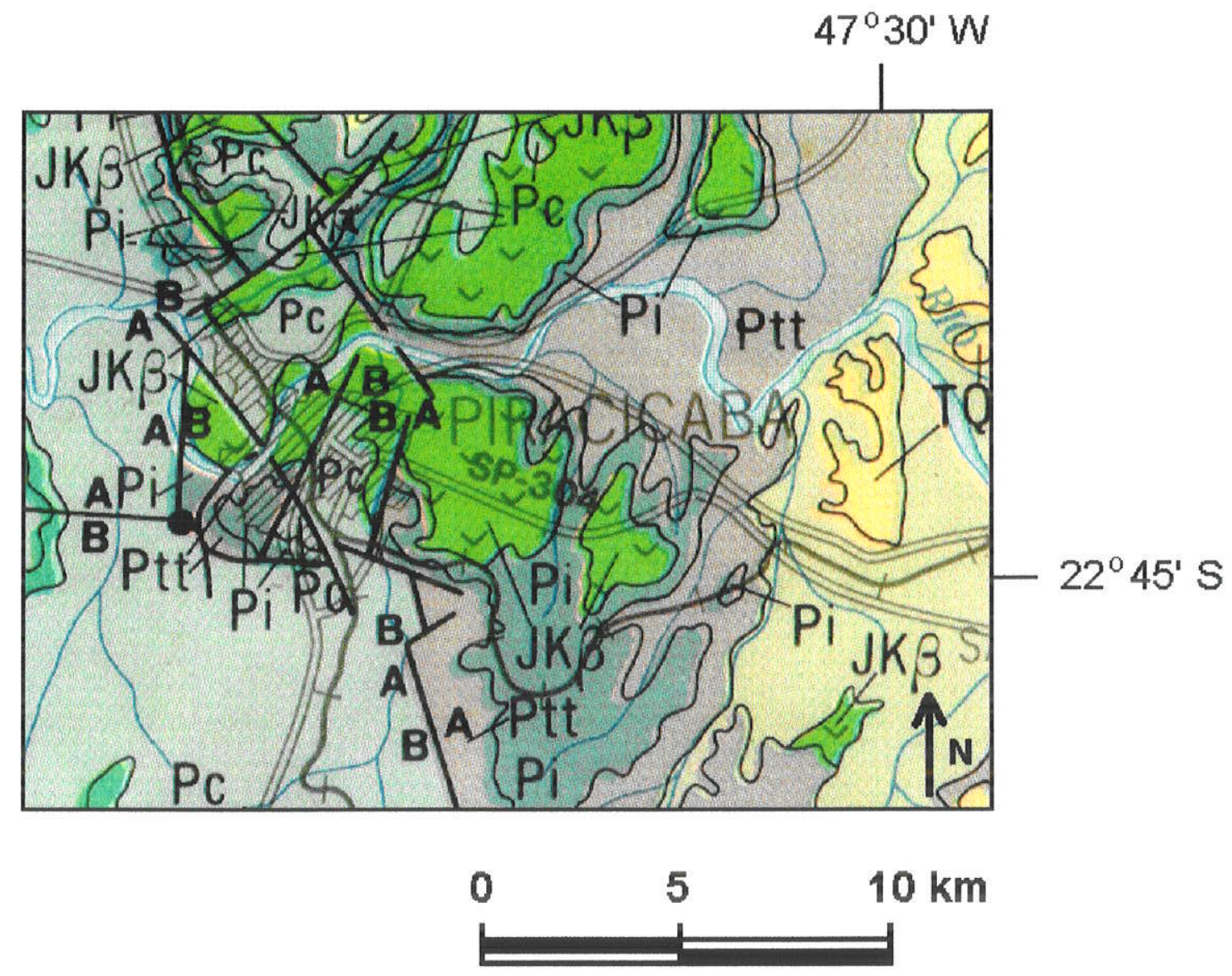

Legenda

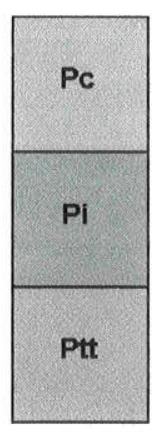

Fm. Corumbataí

Fm. Irati

Grupo Passa Dois

Rochas Intrusivas Básicas
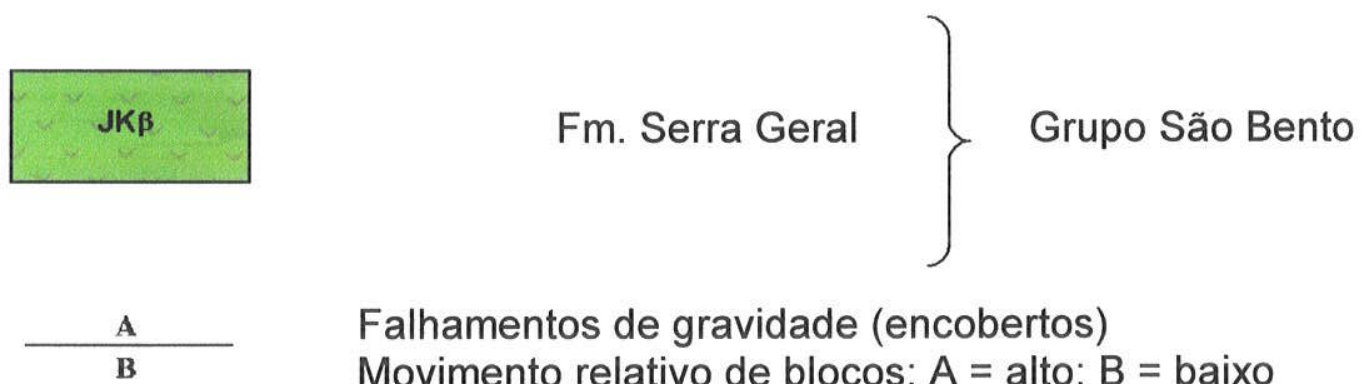

Falhamentos de gravidade (encobertos)

Movimento relativo de blocos: $A=$ alto; $B=$ baixo

Figura 3.3 Mapa geomorfológico da região de Piracicaba. Fonte: IPT (1981). 
$O$ solo estudado apresenta uma seqüência de horizontes $A_{p}-B_{t}-B_{w}$ (Figura 3.4) sendo classificado como Terra Roxa Estruturada Latossólica pela Classificação Brasileira (Brasil, 1960), e como Kandiudalfic Eutrudox, de acordo com a Classificação Americana (USDA, 1975).

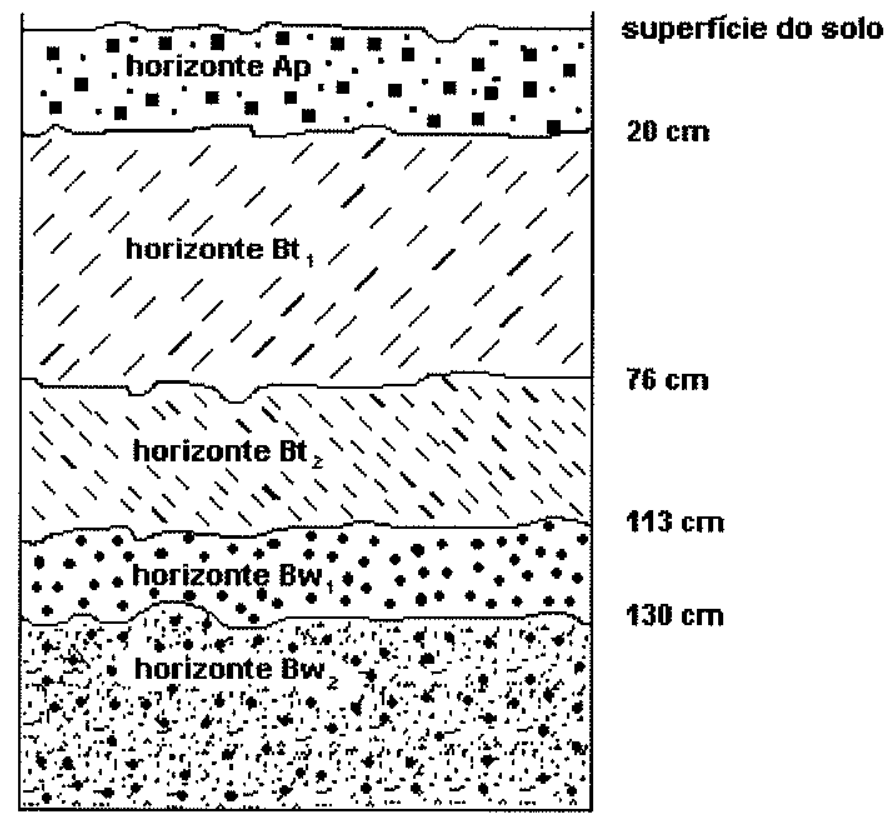

Figura 3.4 Horizontes pedológicos do solo estudado.

Descrição do perfil de solo:

Ap 0-20 cm; 2,5 YR 3/3,5; argiloso; estrutura deformada; cerosidade ausente; friável, plástico, pegajoso; poros médios e pequenos, muito poroso; raízes médias e finas freqüentes; transição clara plana.

$\mathrm{Bt}_{1}$ 20-76 cm; 2,5 YR 3/4; argiloso; estrutura forte que se desfaz em blocos subarredondados pequenos a médios; cerosidade forte; duro, muito plástico, pegajoso; porosidade baixa, poros pequenos; raízes finas poucas; transição gradual plana.

$\mathrm{Bt}_{2}$ 76-113 cm; 2,5 YR 3/4; argiloso; estrutura média a forte, que se desfaz em blocos subangulares médios; cerosidade moderada a fraca; 
consistência dura, muito plástico, pegajoso; muito poroso, poros médios e pequenos; raízes finas raras; transição gradual plana.

$B w_{1}$ 113-130 cm; 2,5 YR 3/5; argiloso; estrutura fraca, que se desfaz em blocos subangulares médios; cerosidade ausente; friável, plástico, pegajoso; poros médios e pequenos, muito poroso; raízes finas raras; transição difusa plana.

$\mathrm{Bw}_{2}$ 130-165 $\mathrm{cm}^{+} ; 2,5$ YR 3/5; argiloso; estrutura fraca que se desfaz em blocos subangulares médios; cerosidade ausente; friável, plástico, pegajoso; muito poroso, poros médios e pequenos; raízes ausentes.

Uma trincheira foi aberta adjacente à parcela experimental, para descrição pedológica e para a retirada de amostras com estrutura indeformada, com a finalidade de determinar a densidade do solo e a curva de retenção nos diferentes horizontes. As características físicas do solo tais como granulometria, densidade e porosidade (Tabela 3.1), foram obtidas por Pauletto (1986).

A densidade do solo (Tabela 3.1) diminui com a profundidade, entretanto a densidade dos sólidos varia muito pouco, podendo-se concluir que a porosidade aumenta com a profundidade. Isso pode ser confirmado pelos valores de porosidade calculados. Pelos valores de densidade apresentados, pode-se observar que a densidade do horizonte $\mathrm{Ap}$ apresenta-se até maior que a do horizonte $\mathrm{Bt}_{1}$, indicando uma compactação na camada superficial $(0-20 \mathrm{~cm})$.

O declive no local é inferior a $0,01 \mathrm{~mm} / \mathrm{mm}$. 
TABELA 3.1 Algumas características físicas do perfil do solo Terra Roxa Estruturada Latossólica.

\begin{tabular}{|c|c|c|c|c|c|c|c|c|c|c|}
\hline \multirow{2}{*}{$\begin{array}{l}\text { Prof. } \\
\text { (m) }\end{array}$} & \multicolumn{5}{|c|}{ Granulometria (mm) (\%) } & \multicolumn{2}{|c|}{$\begin{array}{c}\text { Densidade } \\
\left(\mathrm{g} / \mathrm{cm}^{3}\right)\end{array}$} & \multirow{2}{*}{$\begin{array}{c}\text { Porosidade } \\
(\%) \\
\alpha\end{array}$} & \multicolumn{2}{|c|}{ Poros } \\
\hline & $\begin{array}{c}\text { areia } \\
2-0,05\end{array}$ & $\begin{array}{c}\text { silte } \\
0,05-0,002\end{array}$ & $\begin{array}{c}\text { argila } \\
<0,002\end{array}$ & $\begin{array}{c}\text { argila } \\
\text { disponível } \\
<0,002\end{array}$ & $\begin{array}{l}\text { classe } \\
\text { textural }\end{array}$ & $\begin{array}{c}\text { dos sólidos } \\
\left(\rho_{s}\right)\end{array}$ & $\begin{array}{c}\text { do solo } \\
(\rho)\end{array}$ & & $\begin{array}{c}>0,05 \\
\mathrm{~mm} \\
\%\end{array}$ & $\begin{array}{c}<0,05 \\
\mathrm{~mm} \\
\%\end{array}$ \\
\hline 15 & 30,07 & 17,35 & 52,56 & 27,90 & argiloso & 2,88 & 1,56 & 45,49 & 7,03 & 38,46 \\
\hline 30 & 20,19 & 13,59 & 66,21 & 3,90 & muito argiloso & 2,84 & 1,48 & 47,89 & 6,36 & 41,53 \\
\hline 45 & 19,78 & 12,73 & 67,49 & 2,00 & muito argiloso & 2,87 & 1,43 & 50,17 & 4,67 & 45,50 \\
\hline 60 & 19,87 & 21,37 & 59,04 & 2,70 & argiloso & 2,92 & 1,39 & 52,40 & 6,41 & 45,99 \\
\hline 75 & 20,96 & 19,68 & 59,36 & 3,00 & argiloso & 2,88 & 1,41 & 51,04 & 8,06 & 42,98 \\
\hline 90 & 22,36 & 14,49 & 63,15 & 2,90 & muito argiloso & 2,90 & 1,37 & 52,76 & 10,50 & 42,26 \\
\hline 105 & 22,89 & 16,89 & 60,21 & 1,00 & muito argiloso & 2,90 & 1,30 & 55,17 & 10,71 & 44,46 \\
\hline 150 & 25,33 & 15,12 & 59,55 & 2,00 & argiloso & 2,91 & 1,16 & 60,14 & 11,28 & 48,86 \\
\hline 195 & 22,96 & 16,16 & 60,88 & 1,90 & muito argiloso & 2,92 & 1,26 & 56,85 & 10,11 & 46,74 \\
\hline
\end{tabular}

Fonte: Pauletto (1986). 


\section{MATERIAL E MÉTODOS}

\subsection{Curva de retenção}

A curva característica de retenção da água em um solo é a relação entre a quantidade de água que este solo pode reter a um dado valor de potencial mátrico. Em laboratório, utilizando-se de amostras de solo, pode-se obter a curva por meio da câmara de pressão de placa porosa (Figura 4.1) ou por meio do funil de placa porosa (Figura 4.2). Sua obtenção consiste na aplicação de várias tensões em uma amostra de solo (saturada ou não) em contato com uma placa porosa até o equilíbrio da umidade na amostra, relacionando-se cada tensão com a umidade correspondente.

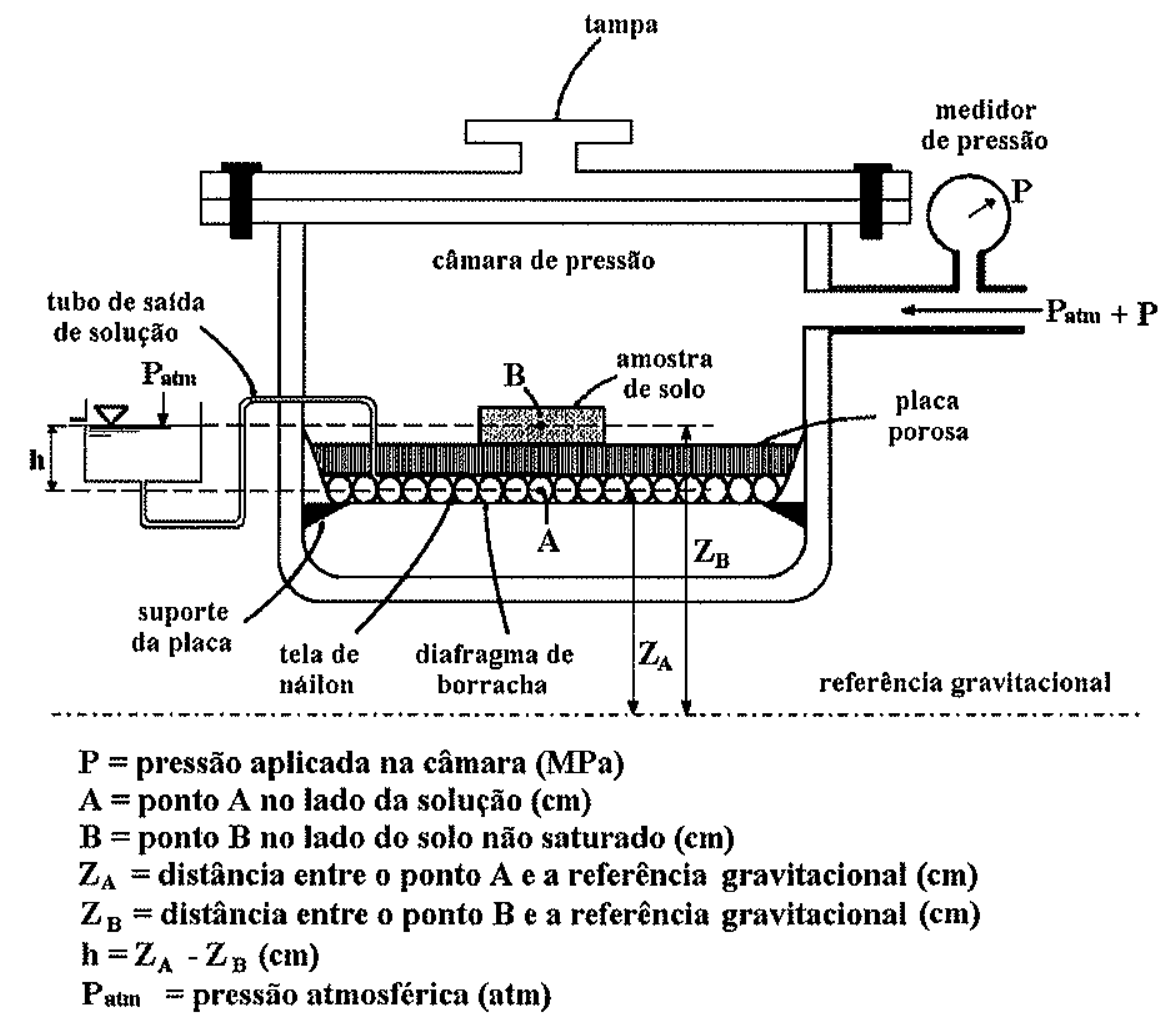

Figura 4.1 Câmara de pressão de Richards. Fonte: Libardi (1999). 
Para a determinação da curva de retenção da água no solo em estudo foram utilizados dados de umidade à base de volume obtidos por meio do Funil de Haines nas tensões de $0,0005,0,001,0,003,0,006$ e $0,01 \mathrm{MPa}$, e em câmara de pressão de Richards nas tensões de $0,01,0,03,0,08,0,5$ e 1,58 MPa.

Os dados foram inseridos no programa Curvaret versão 2.16 (1992) para ajuste da curva de retenção, segundo o modelo de van Genuchten (1980).

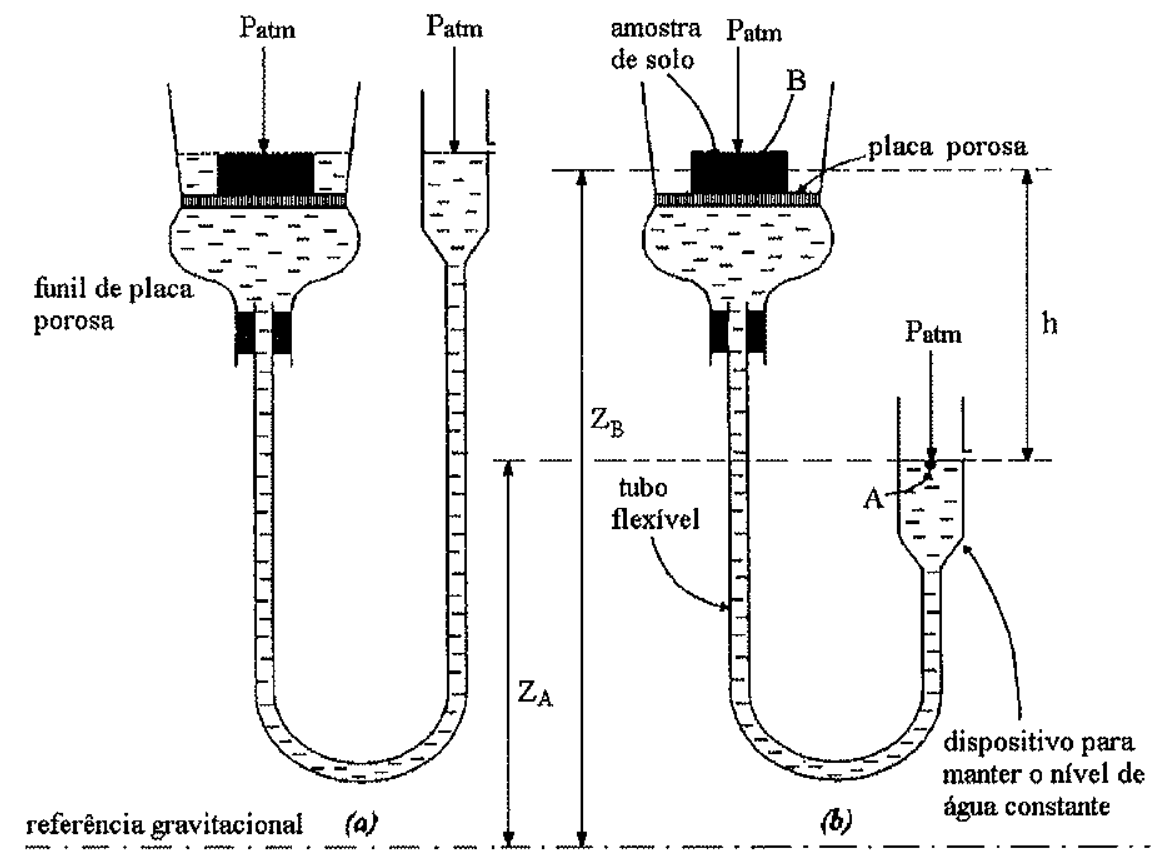

Patm = pressão atmosférica (atm)

$A=$ ponto correspondente ao mesmo nivel da solução no

dispositivo de manutenção do nível de solução

$B=$ ponto correspondente ao centro geométrico da amostra

$Z_{A}=$ distancia entre o ponto $A$ e a referência gravitacional $(\mathrm{cm})$

$\mathrm{Z}_{\mathrm{B}}=$ distância entre o ponto $\mathrm{B}$ e a referência gravitacional $(\mathrm{cm})$

$\mathbf{h}=\mathrm{Z}_{\mathrm{B}}-\mathrm{Z}_{\mathrm{A}}(\mathrm{cm})$

Figura 4.2 Procedimento da medida do potencial mátrico com o funil de placa porosa: (a) saturação do solo; (b) aplicação da tensão $h$. Fonte: Libardi (1999). 


\subsection{Tensiômetros}

Para a medição do potencial mátrico "in situ" utilizaram-se tensiômetros de aproximadamente $2 \mathrm{~cm}$ de diâmetro por $7 \mathrm{~cm}$ de comprimento, com manômetros de mercúrio cujas cápsulas porosas foram instaladas a cada $0,1 \mathrm{~m}$ de profundidade, entre 0,1 e 1,0 m. A instalação foi feita abrindo-se um orifício com um trado, colocando-se uma pasta de pó de sílica no fundo para que a cápsula tivesse um bom contato com o solo.

Para obter o potencial mátrico, a partir das leituras feitas em $\mathrm{cm}$ de mercúrio no tensiômetro (Figura 4.3), utilizou-se a seguinte equação:

$$
\phi_{m}=-12,6 H+h_{c}+z
$$

onde

$\phi_{m}=$ potencial mátrico ( $\mathrm{cm}$ de coluna de água)

$h_{c}=$ distância entre o nível de mercúrio na cuba à superfície do solo no momento da leitura $(\mathrm{cm})$

$\mathrm{z}=$ profundidade de instalação da cápsula $(\mathrm{cm})$

$H=$ leitura do tensiômetro feita a partir da superfície do mercúrio na cuba (cm de $\mathrm{Hg}$ )

Entretanto, para cada leitura de $H\left(H^{\prime}+H^{\prime \prime}\right)$ há um valor correspondente para $h_{c}$, uma vez que, conforme $H$ aumenta, $h_{c}$ diminui, e vice-versa. Isso ocorre devido ao fato de que o volume de mercúrio utilizado para se obter $H$ é retirado da cuba, diminuindo desse modo $h_{c}$. Alguns procedimentos foram relatados por Pauletto (1986) e Libardi (1995) para contornar este problema, os quais recomendam que, na instalação dos tensiômetros, quando se coloca o mercúrio na cuba, faça-se uma marca na cuba na posição da interface mercúrio-ar, obtendo-se o valor constante de $H^{*}$ (Figura $4.3($ a)), ou seja, a distância da superfície do solo até essa marca.

Após o acionamento do manômetro (Figura 4.3 (b)), tem-se que: 


$$
\underbrace{\frac{\pi D^{2}}{4}\left(H-H^{\prime \prime}\right)-\frac{\pi d^{2}}{4}\left(H-H^{\prime \prime}\right)}_{\begin{array}{c}
\text { volume de mercúrio } \\
\text { que é retirado da cuba }
\end{array}}=\underbrace{\frac{\pi d^{2}}{4} H^{\prime \prime}}_{\begin{array}{c}
\text { volume de mercúrio que } \\
\text { vai para o tubo de letura }
\end{array}}
$$

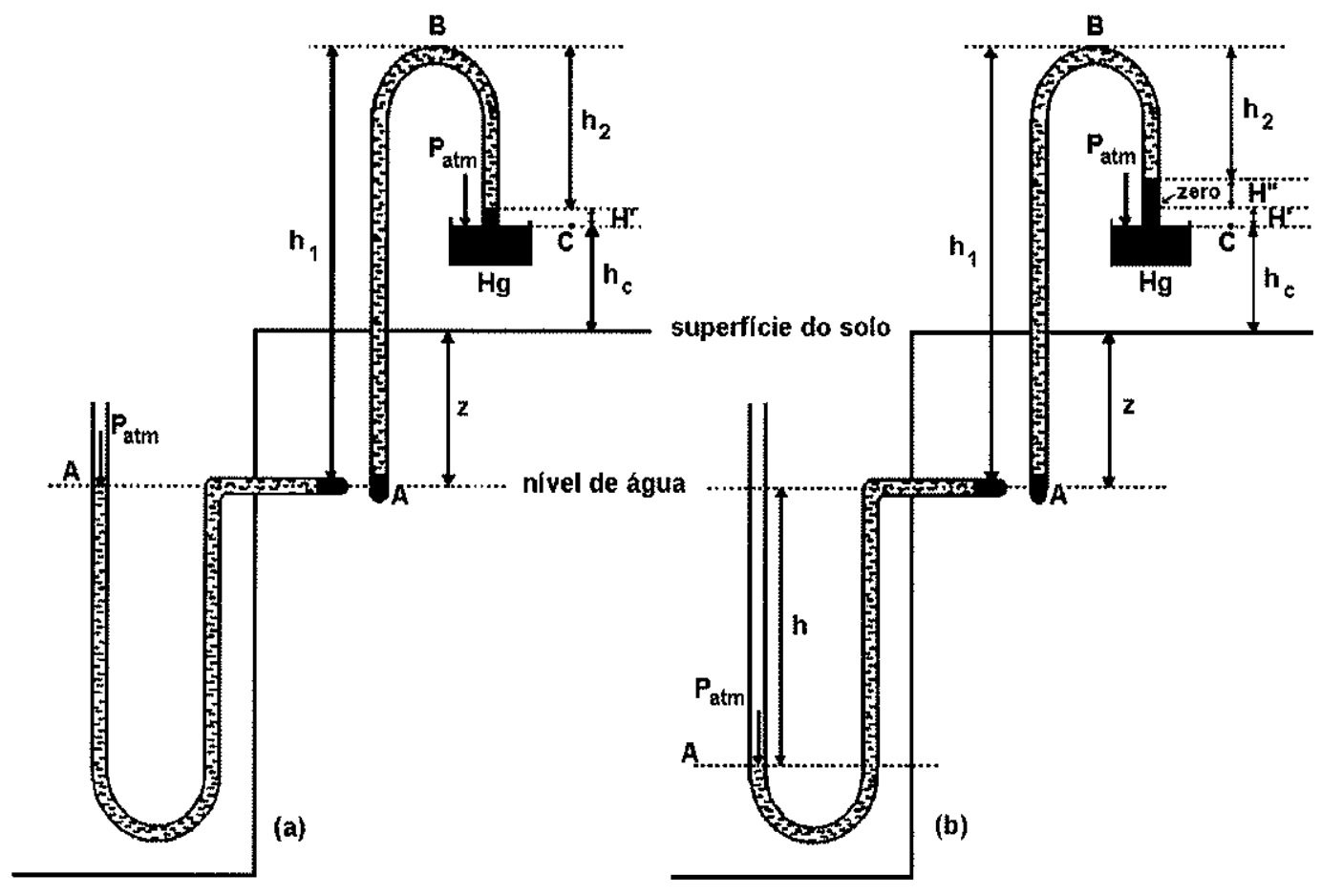

Figura 4.3 Tensiômetro com manômetro de mercúrio instalado no campo: (a) solo saturado $(h=0)$; (b) solo não saturado $(h>0)$.

Da equação 2, obtém-se a leitura do tensiômetro em $\mathrm{m}$ de $\mathrm{Hg}$ :

$$
H=H^{\prime \prime}+\left(\frac{d^{2}}{D^{2}-d^{2}}\right) H^{\prime \prime}
$$

onde

$H^{\prime \prime}$ = altura de mercúrio a partir da marca fixa feita na cuba com o tensiômetro desativado $(\mathrm{cm}$ de $\mathrm{Hg})$

$D=$ diâmetro da cuba $(\mathrm{cm})$

$d=$ diâmetro do tubo de leitura $(\mathrm{cm})$ 
Finalmente, obtém-se $h_{c}$ pela equação 4 , conhecendo-se os valores constantes de $H^{\prime}, D$ e d:

$$
h_{c}=H^{\prime}-\left(\frac{d^{2}}{D^{2}-d^{2}}\right) H^{\prime \prime}
$$

$h_{c}$ deve ser substituído na equação 1 para a obtenção do potencial mátrico.

Com os valores de potencial mátrico, calculou-se o potencial total pela aplicação da equação:

$$
\phi_{\mathrm{t}}=\phi_{\mathrm{m}}+\mathrm{z}
$$

onde

$\phi_{t}=$ potencial total ( $\mathrm{cm}$ água)

$\phi_{m}=$ potencial mátrico ( $\mathrm{cm}$ água)

$z=$ profundidade $(\mathrm{cm})$

\subsection{Sonda de nêutrons}

A medida da umidade do solo pela sonda de nêutrons é um método não destrutivo e permite obter a umidade à base de volume.

Seu princípio de funcionamento é o da termalização de nêutrons rápidos, ou seja, a sonda possui uma fonte radioativa (geralmente amerício-berílio) que emite nêutrons rápidos (10 keV a $20 \mathrm{MeV}$ ), os quais são termalizados, isto é, são desacelerados quando colidem com os átomos de hidrogênio presentes no solo, tornando-se lentos. Há um detector de nêutrons lentos (podem ser contadores proporcionais de $\mathrm{BF}_{3}$, de $3 \mathrm{He}$, ou cristal de cintilação) logo acima da fonte radioativa, que fazem a integração da contagem desses nêutrons em um tempo $t$, a qual é registrada em um contador à superfície do solo. 
Portanto, tem-se a relação direta entre a leitura do aparelho (cpm - contagens por minuto, ou cps - contagens por segundo) e a umidade do solo $\theta \quad\left(\mathrm{cm}^{3} / \mathrm{cm}^{3}\right)$ obtida pelo método gravimétrico. Obtendo-se um conjunto de dados de $\theta$ e cpm, pode-se proceder à calibração do equipamento para o solo a ser estudado. Entretanto, para a calibração trabalha-se com a contagem relativa $(C R)$, que é a razão entre cpm obtida no solo pela $\mathrm{cpm}$ obtida em um padrão, e não diretamente com a taxa de contagem obtida pelo aparelho no solo. A contagem obtida em um padrão pode ser realizada na própria blindagem de proteção da sonda, ou em um tubo de acesso instalado dentro de um tanque com água. Esta contagem no padrão deve ser constante por longos períodos de tempo, oscilando somente dentro dos limites dos desvios estatísticos, de acordo com as especificações de cada fabricante.

Finalmente obtém-se um gráfico de $C R$ versus $\theta$, e pela regressão linear temse as equações de calibração do equipamento para aquele tipo de solo.

A sonda de nêutrons utilizada no estudo foi a 503DR Hydroprobe da CPN Corporation, com fonte de ${ }^{241} \mathrm{Am} / \mathrm{Be}$ de intensidade radioativa de $50 \mathrm{mCi}$ e diâmetro de $2 "$ (Foto 4.1).

Os tubos de acesso da sonda utilizados eram de alumínio, e foram instalados até a profundidade de $1,5 \mathrm{~m}$. As extremidades foram fechadas para evitar a entrada de solo na sua instalação, a qual foi feita perfurando-se o solo com um trado de diâmetro um pouco menor que o diâmetro externo do tubo de alumínio, para que este fosse introduzido sem que houvesse a formação de bolsas de ar, permitindo um perfeito ajuste com o solo.

As curvas de calibração da sonda para o solo Terra Roxa Estruturada Latossólica foram elaboradas por Moraes et al. (1998) para a parcela experimental com dados coletados durante aproximadamente 28 dias, com medidas realizadas no ponto estudado e em mais outros onze pontos, dentro de uma área de $1000 \mathrm{~m}^{2}$. 


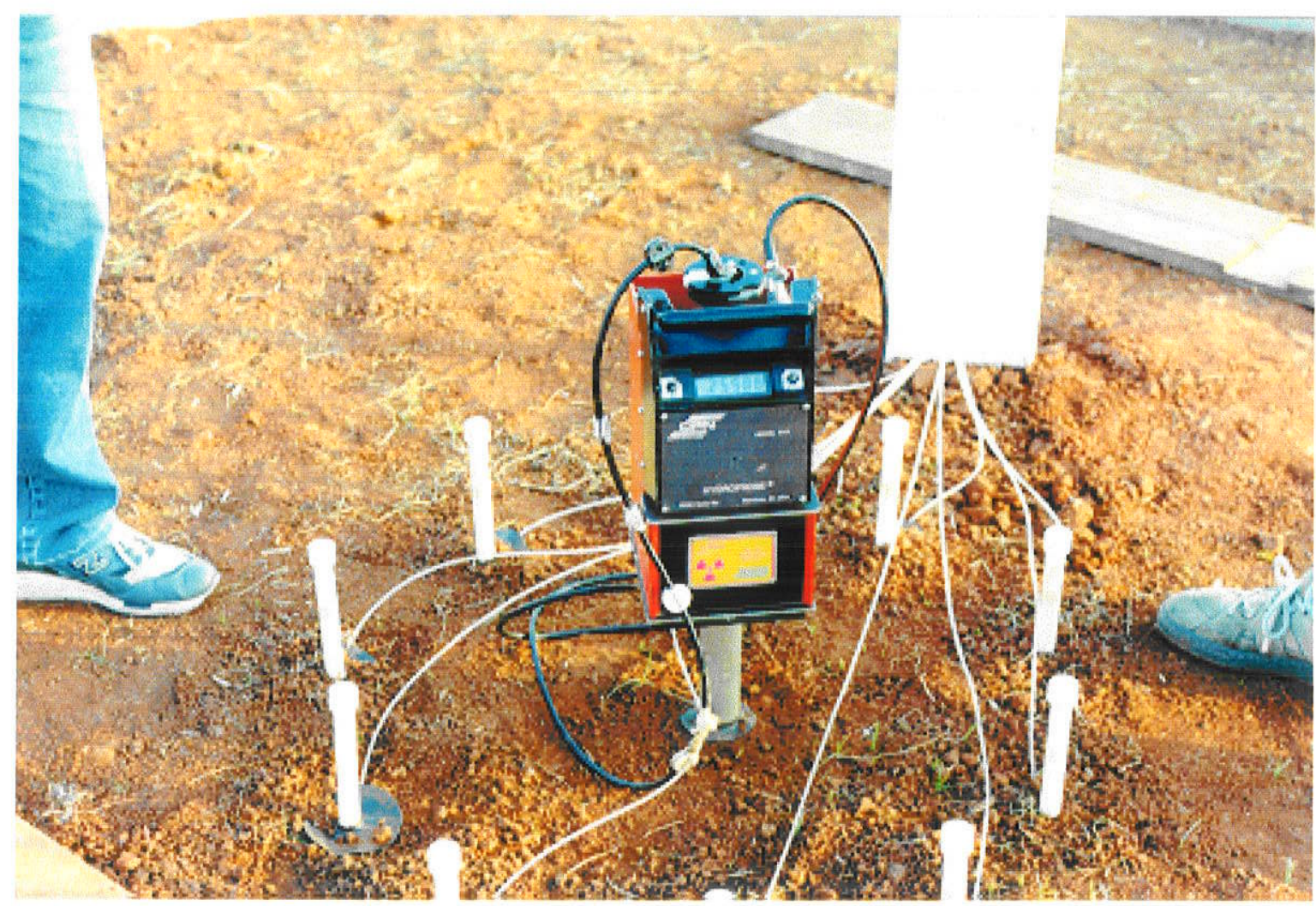

Figura 4.1 Detalhe da sonda de nêutrons efetuando medidas no campo. 
O tempo de integração de cada contagem foi de $30 \mathrm{~s}$ e, em cada profundidade foram feitas três contagens por observação, obtendo-se valores médios típicos da ordem de grandeza de $2,5.10^{4}$. Nos dias de coleta de dados a contagem no padrão era realizada com a sonda dentro da sua própria blindagem. A contagem relativa $(C R)$ foi obtida dividindo-se a média das três contagens pela contagem padrão, resultando em valores médios típicos de 1,35.104.

Em algumas datas procedeu-se à coleta de amostras de solo para a determinação da umidade volumétrica. Estas foram feitas simultaneamente com a leitura da sonda, próximas ao tubo de acesso instalado na parcela experimental, e nos outros onze pontos, dentro de uma área de $1000 \mathrm{~m}^{2}$.

A curva de calibração da sonda para cada profundidade da parcela experimental foi obtida por meio de regressão linear das leituras relativas e dos valores de umidade determinados nos doze pontos medidos.

\subsection{Método do perfil instantâneo}

Utilizou-se o método do perfil instantâneo (Watson, 1966) para a determinação da condutividade hidráulica do solo não saturado no campo. Os procedimentos feitos para a aplicação deste método são relatados a seguir e apresentados nas Fotos $4.2,4.3,4.4,4.5,4.6$ e 4.7.

Após a instalação dos tensiômetros e do tubo de acesso da sonda de nêutrons na parcela, delimitou-se uma área circular de 5,0 $\mathrm{m}$ de diâmetro com uma folha-de-flandre até a profundidade de aproximadamente $0,20 \mathrm{~m}$, permitindo a manutenção de uma lâmina de água de 0,10 a $0,15 \mathrm{~m}$ sobre a superfície do solo durante o processo de infiltração o qual foi interrompido quando se observou que a condição de quase saturação havia sido atingida, o que pôde ser verificado por meio dos tensiômetros, cujas leituras não variavam mais com o tempo. 


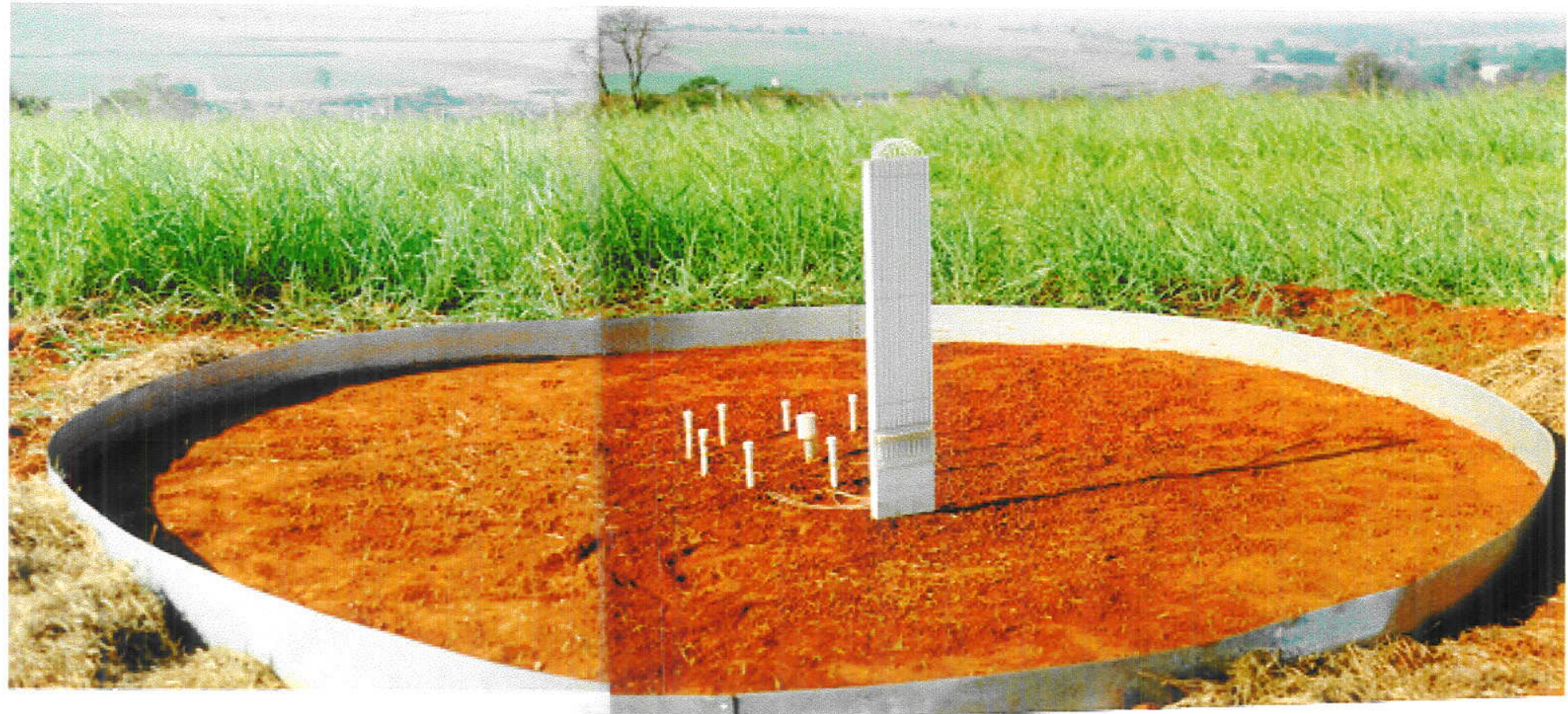

Foto 4.2 Parcela experimental pronta para ser inundada, com os dez tensiômetros e o tubo da sonda instalados em seu centro. 


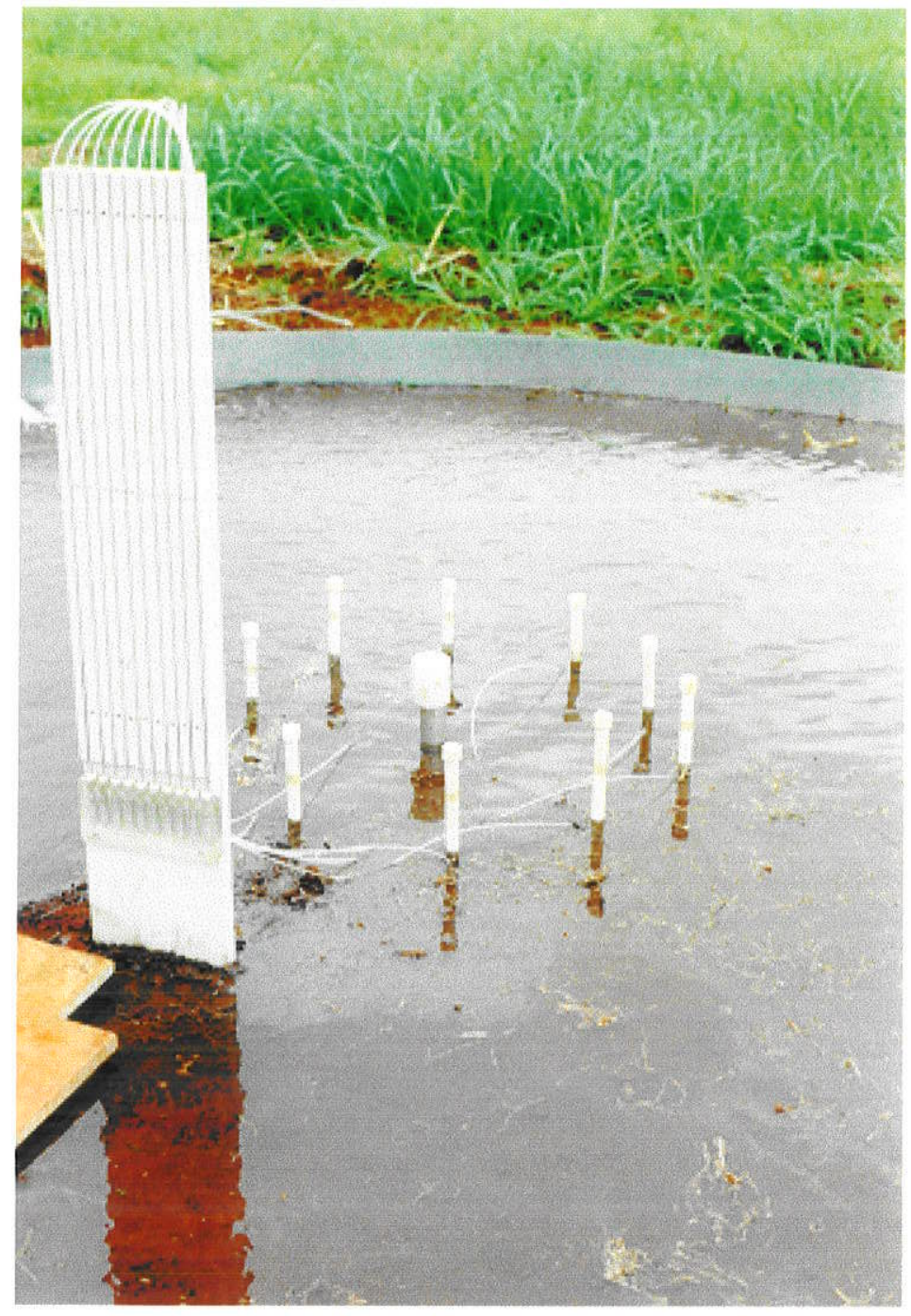

Foto 4.3 Parcela experimental inundada.

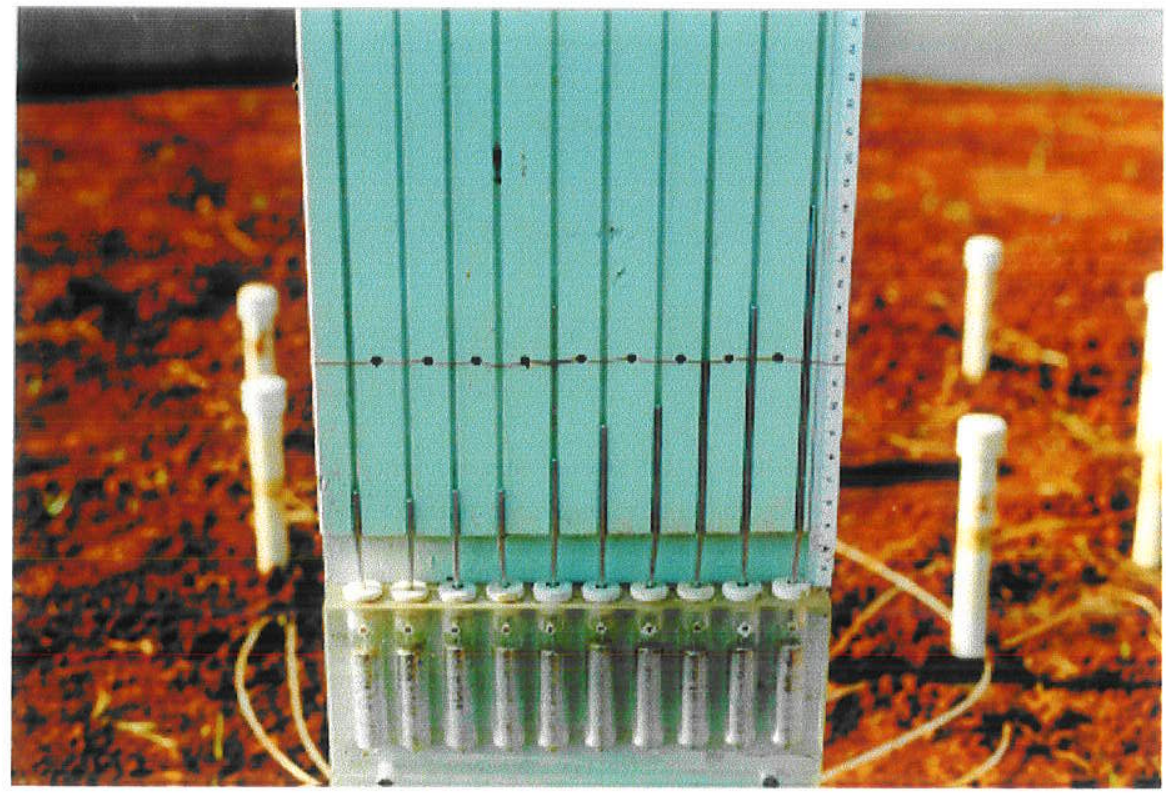

Foto 4.4 Detalhe dos manômetros de mercúrio dos tensiômetros instalados na parcela experimental. 


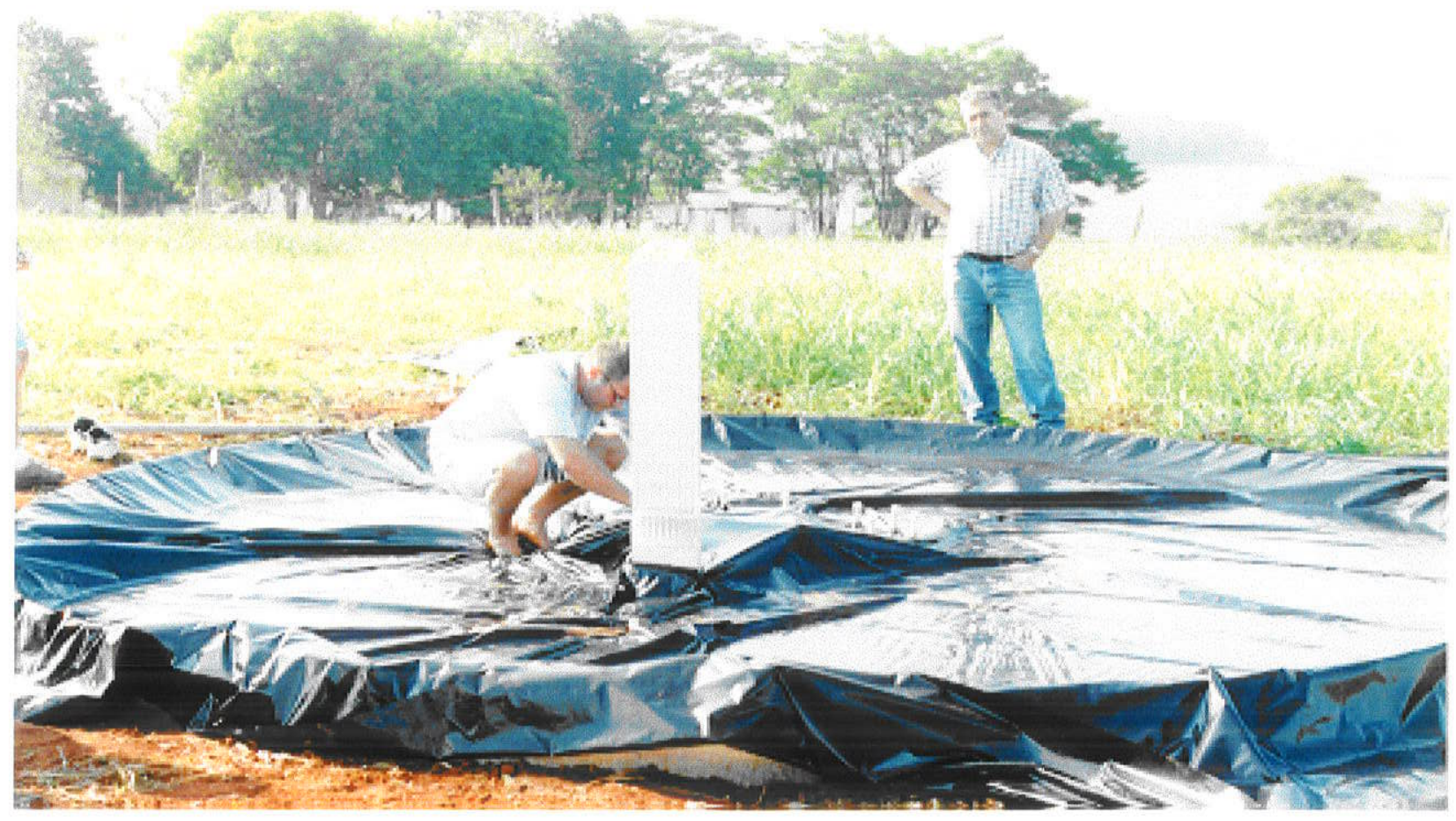

Foto 4.5 Colocação da lona sobre a superfície do solo da parcela experimental.

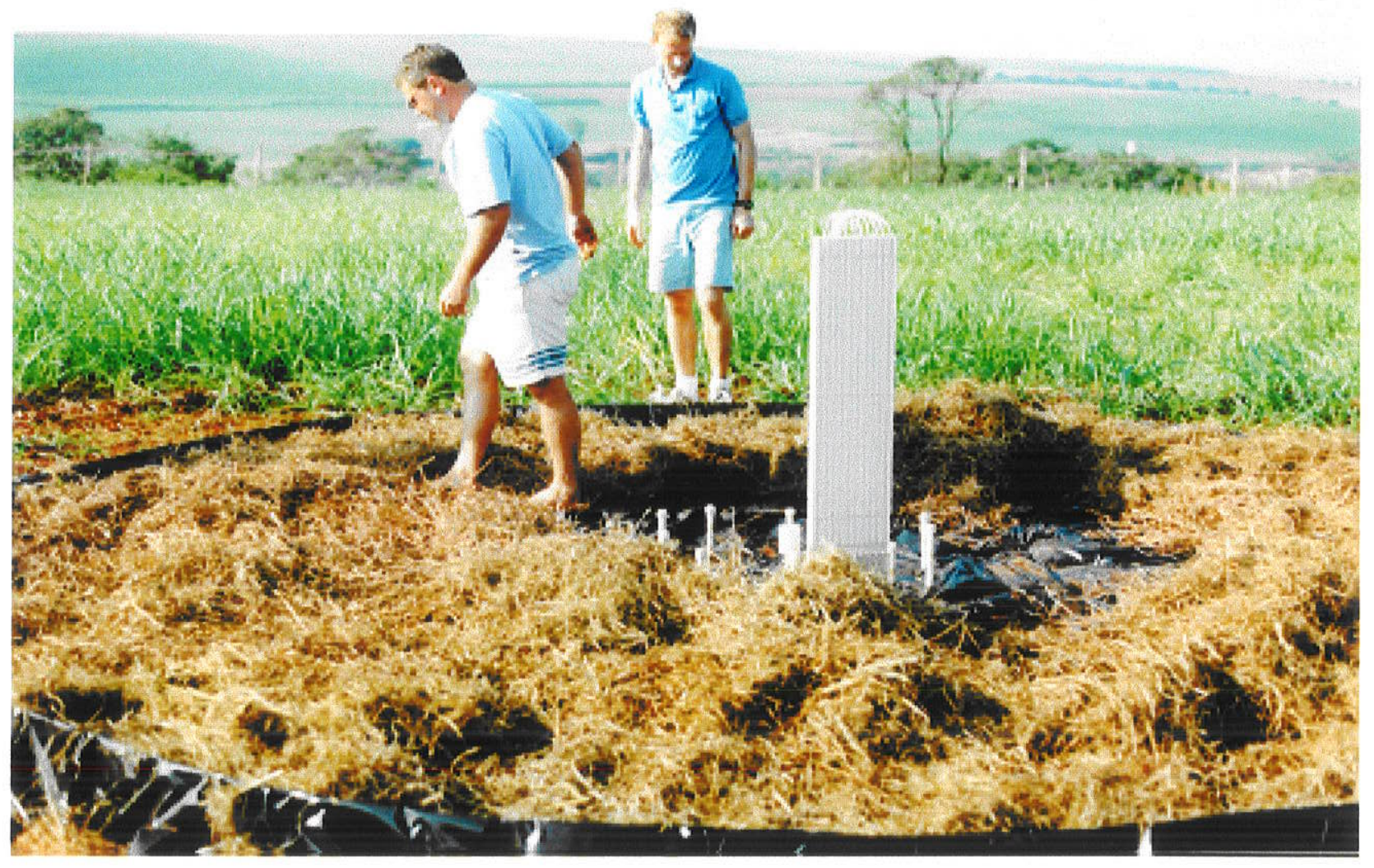

Foto 4.6 Colocação de capim sobre a primeira camada de lona na parcela experimental. 


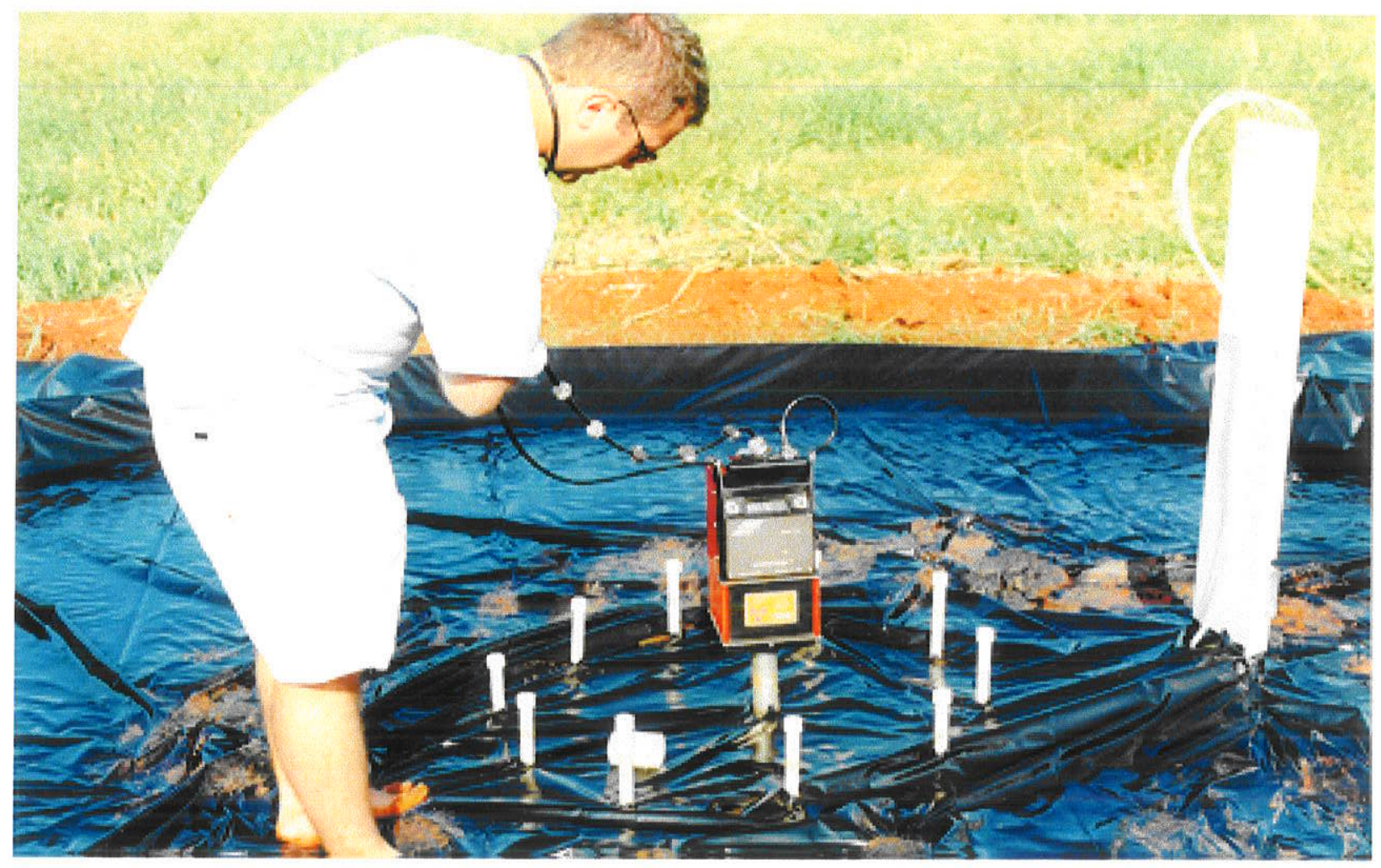

Foto 4.7 Início das medidas no tempo zero de redistribuição, feitas pela sonda de nêutrons e pelos tensiômetros. 
A superfície do solo foi então coberta com duas lonas plásticas para evitar a evaporação e a entrada de água. Entre as camadas de lona foi colocada uma camada de capim para minimizar um eventual aumento da temperatura na superfície do solo. A partir deste momento, inicia-se a redistribuição da água dentro do perfil do solo pelo processo de drenagem interna e, de acordo com o método, passam a ser monitorados a umidade do solo e o potencial mátrico, por meio de leituras dos tensiômetros e da sonda de nêutrons. O intervalo entre duas leituras variou de uma hora no início do experimento, a dois dias no fim do experimento. Os dados foram coletados durante um período de 50 dias ou 1200 horas, finalizando o experimento uma vez que no processo de redistribuição da água, as medidas de umidade e potencial mátrico não variavam mais com o tempo.

As leituras com a sonda de nêutrons foram efetuadas a cada $0,10 \mathrm{~m}$ de profundidade, a partir de $0,20 \mathrm{~m}$ até $1,10 \mathrm{~m}$, obtendo-se perfis de umidade para uma série de tempos de redistribuição.

Para a determinação da condutividade hidráulica utilizando-se o método do perfil instantâneo, procura-se obter uma solução para a equação de Richards na direção vertical:

$$
\frac{\partial \theta}{\partial t}=\frac{\partial}{\partial z}\left(K(\theta) \frac{\partial \phi_{t}}{\partial z}\right)
$$

onde

$\theta=$ umidade volumétrica $\left(\mathrm{cm}^{3} / \mathrm{cm}^{3}\right)$

$t=$ tempo $(\mathrm{h})$

$K=$ condutividade hidráulica $(\mathrm{cm} / \mathrm{h})$

$\phi_{\mathrm{t}}=$ potencial total da água ( $\mathrm{cm}$ água)

$z=$ coordenada vertical de posição $(\mathrm{cm})$

Após a saturação do perfil do solo e prevenção do fluxo de água através de sua superfície, as seguintes condições inicial e de contorno podem ser utilizadas durante o processo de redistribuição: 


$$
\begin{aligned}
& z=0 ; t>0 ; q=0 \\
& z=z ; t>0 ; q=q_{z}
\end{aligned}
$$

onde

$q=$ fluxo

$q_{z}=$ fluxo na profundidade $z$

Obtém-se, pela integração da equação de Richards com relação à profundidade $z$, entre os limites $z=0$ e $z=z$ e conforme as condições de contorno acima apresentadas:

$$
\int_{0}^{z} \frac{\partial \theta}{\partial t} d z=\left.K(\theta) \frac{\partial \phi_{t}}{\partial z}\right|_{z}=q_{z}
$$

ou, rearranjando

$$
\left.K(\theta)\right|_{z}=\frac{\int_{0}^{z} \frac{\partial \theta}{\partial t} d z}{\left.\frac{\partial \phi_{t}}{\partial z}\right|_{z}}=\frac{\frac{\partial h_{z}}{\partial t}}{\left.\frac{\partial \phi_{t}}{\partial z}\right|_{z}}
$$

onde

$h_{z}=$ armazenagem de água no solo $\left(\mathrm{cm}^{3} / \mathrm{cm}^{2}\right)$ entre a superfície $(z=0)$ e a profundidade $z$.

O valor de $K(\theta)$ é obtido, portanto, pela relação entre a variação de armazenagem $h_{z}$ com o tempo $t$ e o gradiente de $\phi_{t}$ ao longo de $z$, determinados através de medidas simultâneas de umidade e de potencial total ao longo do perfil de solo durante a redistribuição da água.

A armazenagem de água no solo é calculada multiplicando-se a umidade média do perfil pela profundidade considerada. A equação utilizada é:

$$
h_{z}=\bar{\theta} \cdot z
$$


onde

$\theta=$ umidade média do perfil até a profundidade $z\left(\mathrm{~cm}^{3} / \mathrm{cm}^{3}\right)$

$z=$ profundidade considerada $(\mathrm{cm})$

O gradiente de potencial total é calculado utilizando-se a equação:

$$
\frac{\partial \phi_{t}}{\partial z}=\frac{\phi_{t z_{1}}-\phi_{t z_{2}}}{\Delta z}
$$

onde

$\phi_{t z 1}=$ potencial total no ponto superior ao ponto a ser determinado (cm água)

$\phi_{t z 2}=$ potencial total no ponto inferior ao ponto a ser determinado ( $\mathrm{cm}$ água)

$\Delta z=$ diferença entre $z_{1}$ e $z_{2}(\mathrm{~cm})$

A condutividade hidráulica varia com a umidade $e$, normalmente, há uma relação exponencial com a umidade, isto é:

$$
K(\theta)=K_{0} \cdot e^{\gamma\left(\theta-\theta_{0}\right)}
$$

onde

$K_{0}=$ valor de $K$ no tempo zero de redistribuição $(\mathrm{cm} / \mathrm{dia})$

$\theta_{0}=$ valor de $\theta$ no tempo zero de redistribuição $\left(\mathrm{cm}^{3} / \mathrm{cm}^{3}\right)$

$\gamma=$ constante adimensional

A condutividade hidráulica relativa $(K r)$ é dada por $K(\theta) / K_{0}$.

Portanto, a partir da equação (10):

$$
K r=e^{\gamma\left(\theta-\theta_{0}\right)}
$$




\subsection{Modelo de van Genuchten}

Os métodos teóricos têm como finalidade estimar a condutividade hidráulica, e os que se baseiam na curva de retenção necessitam equações que a ajustem adequadamente.

O modelo de van Genuchten (1980) apresenta a equação abaixo para este ajuste:

$$
\theta=\theta_{r}+\frac{\theta_{s}-\theta_{r}}{\left[1+\left|\alpha \phi_{m}\right|^{n}\right]^{m}}
$$

onde

$\theta_{r}=$ umidade volumétrica residual

$\theta_{s}=$ umidade volumétrica de saturação

$\phi_{m}=$ potencial mátrico

$\alpha, n=$ constantes empíricas relacionadas com o solo

$m=1-1 / n$

Para a estimativa da condutividade hidráulica, van Genuchten combinou a equação acima com o modelo de Mualem (1976), obtendo:

$$
K(\theta)=K_{0} \omega^{\ell}\left[1-\left(1-\omega^{\frac{1}{m}}\right)^{m}\right]^{2}
$$

sendo

$$
\omega=\frac{\theta-\theta_{r}}{\theta_{s}-\theta_{r}}
$$

onde

$\omega=$ saturação efetiva 
$K_{0}=$ condutividade hidráulica do solo saturado

$\ell=$ parâmetro empírico estimado em 0,5 por Mualem (1976)

A condutividade relativa pelo modelo de van Genuchten (1980) é, portanto, dada por

$$
\frac{K(\theta)}{K_{0}}=K r=\omega^{\ell}\left[1-\left(1-\omega^{\frac{1}{m}}\right)^{m}\right]^{2}
$$




\section{RESULTADOS E DISCUSSÃO}

\subsection{Curva de retenção}

Foram obtidas três curvas de retenção da água no solo para cada um dos horizontes $\mathrm{Ap}(10$ e $20 \mathrm{~cm}), \mathrm{Bt}_{1}(30,40,50,60$ e $70 \mathrm{~cm}) \mathrm{e} \mathrm{Bt}_{2}(80,90$ e $100 \mathrm{~cm}) \mathrm{da}$ Terra Roxa Estruturada Latossólica, representadas na Tabela 5.1, pelo ajuste da equação de van Genuchten (Equação 12).

As curvas de retenção representativas para esse solo (Figuras 5.1, 5.2 e 5.3) apresentaram um bom ajuste dos dados experimentais à equação de van Genuchten. Isso pode ser confirmado pelos valores dos coeficientes de correlação obtidos, os quais encontram-se entre 0,98 e 0,99 .

TABELA 5.1 Equações representativas das curvas de retenção da água no solo para as profundidades amostradas.

\begin{tabular}{ccc}
\hline $\begin{array}{c}\text { Profundidade } \\
(\mathrm{cm})\end{array}$ & Equação & Correlação \\
\hline 10 e 20 & $\theta=0,478 /\left(1+\left(0,0178 \phi_{\mathrm{m}}\right)^{2,0897}\right)^{0,2688}$ & 0,989 \\
$30,40,50,60$ e 70 & $\theta=0,481 /\left(1+\left(0,0484 \phi_{m}\right)^{3,7151}\right)^{0,1448}$ & 0,982 \\
80,90 e 100 & $\theta=0,559 /\left(1+\left(0,0393 \phi_{m}\right)^{2,4476}\right)^{0,3240}$ & 0,996 \\
\hline
\end{tabular}

Pode-se verificar pelas equações representativas da curva de retenção, que o valor de $\mathrm{m}$ é maior para o horizonte $\mathrm{Bt}$ (profundidades de $30 \mathrm{a} 70 \mathrm{~cm}$ ) do que para os horizontes $\mathrm{Ap}$ e $\mathrm{Bt}_{2}$, o que deve estar relacionado com o tipo de solo estudado. 


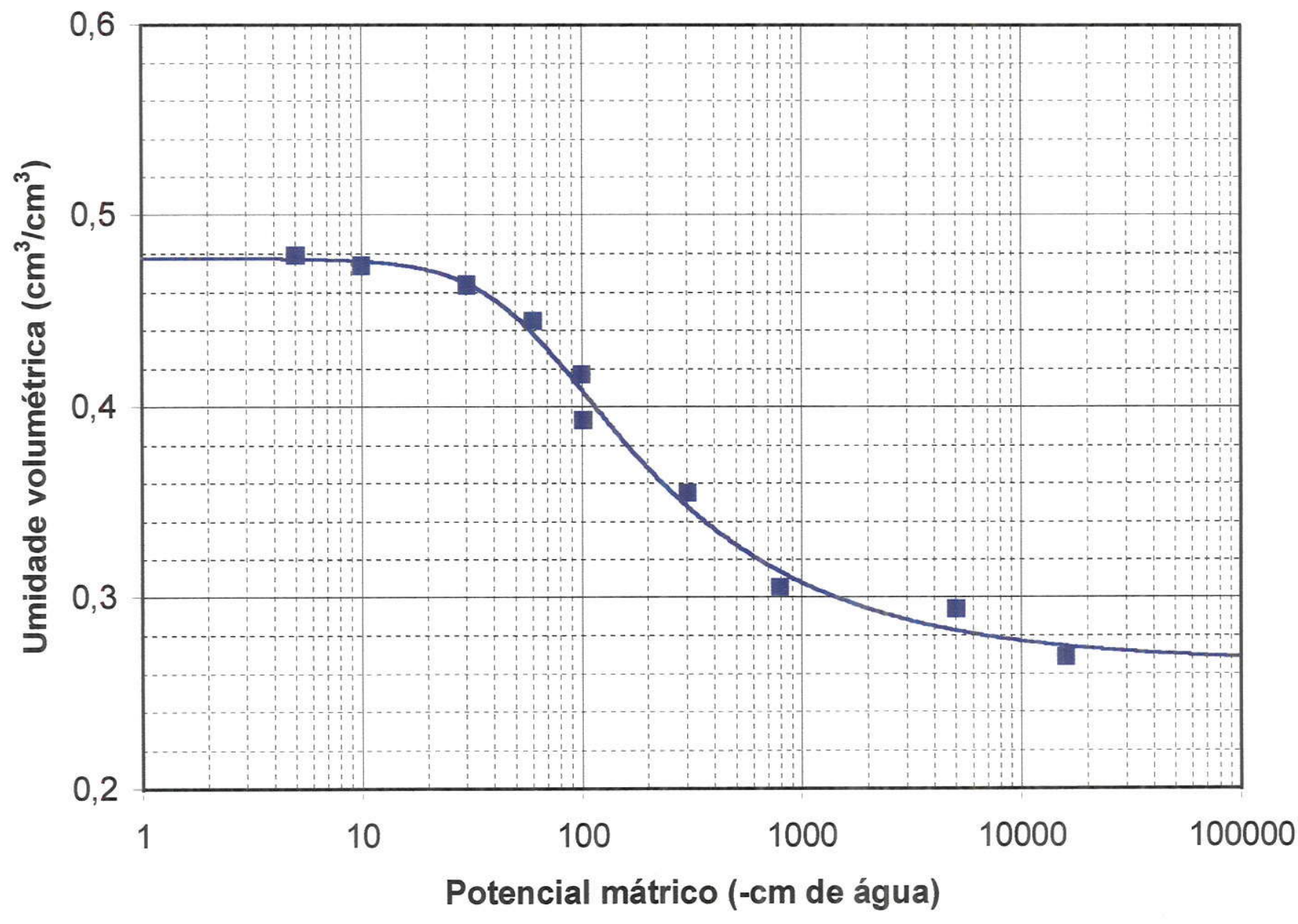

Figura 5.1 Curva de retenção do solo Terra Roxa Estruturada Latossólica, para as profundidades de 10 e 20 $\mathrm{cm}$, representativa do horizonte pedológico Ap. 


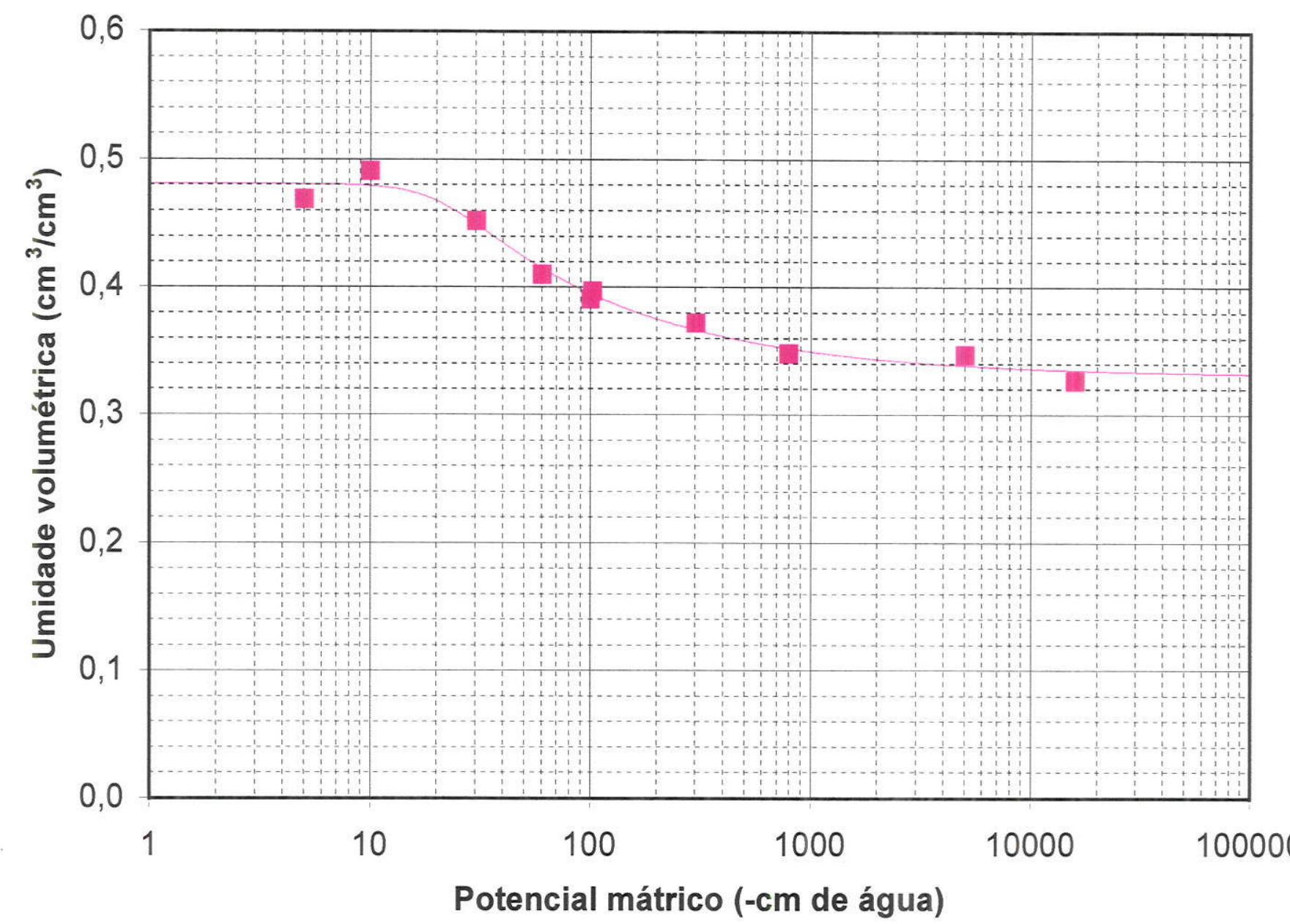

Figura 5.2 Curva de retenção do solo Terra Roxa Estruturada Latossólica, para as profundidades de 30 a 70 $\mathrm{cm}$, representativa do horizonte pedológico $\mathrm{Bt}_{1}$. 


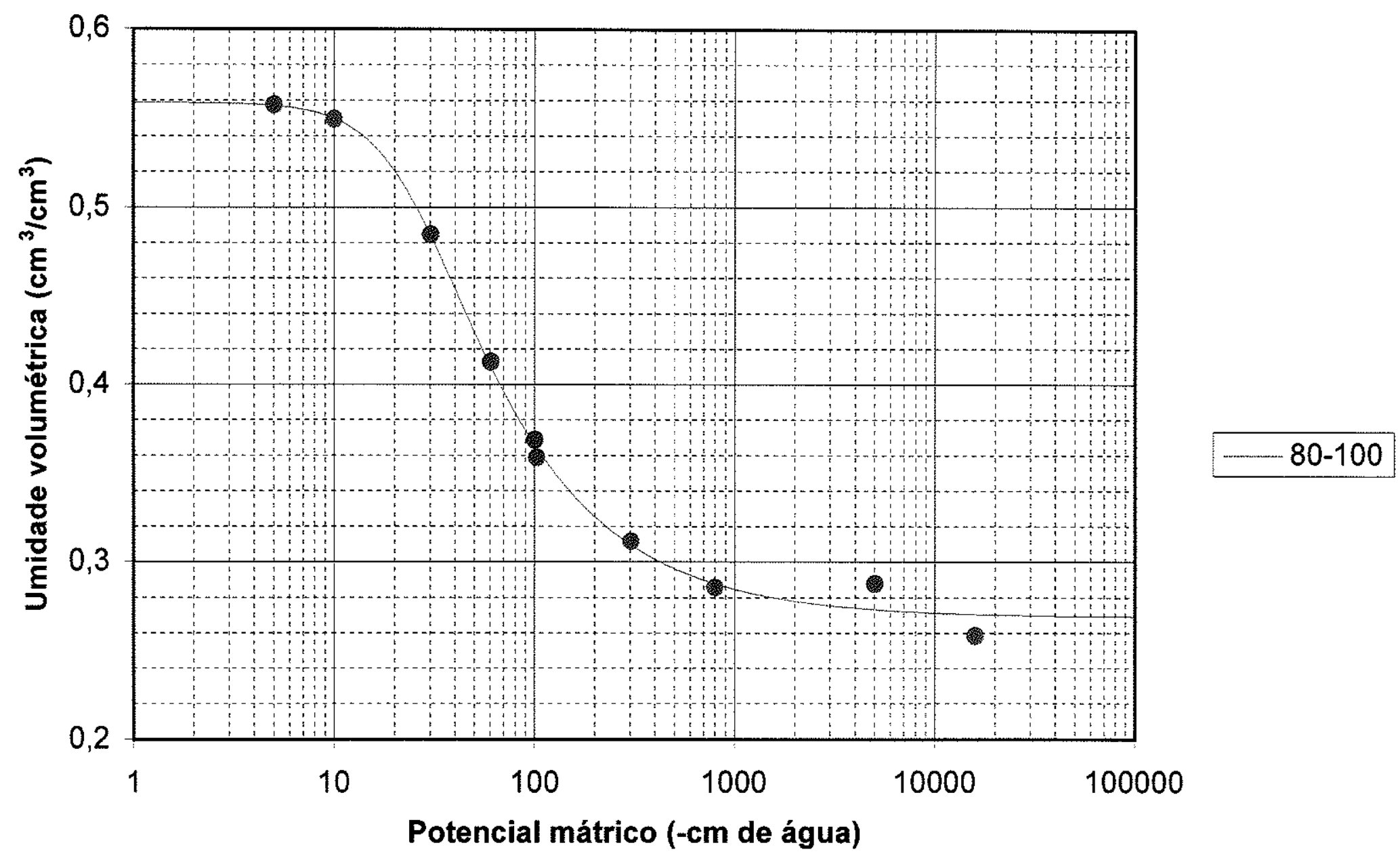

Figura 5.3 Curva de retenção da Terra Roxa Estruturada Latossólica, para as profundidades de 80 a $100 \mathrm{~cm}$, representativa do horizonte pedológico $\mathrm{Bt}_{2}$. 


\subsubsection{Tensiômetros}

Nas Tabelas 5.2 e 5.3 são apresentados os valores de potencial mátrico e de potencial total, respectivamente, obtidos para cada profundidade e para cada tempo de redistribuição. Esses valores foram obtidos aplicando-se a metodologia descrita no item 4.2 .

Os dados de umidade estimados por meio das equações de ajuste das curvas de retenção (Tabela 5.1) são mostrados na Tabela 5.4, para cada profundidade ao longo do tempo de drenagem interna do perfil.

Pela Tabela 5.4, pode-se observar que a umidade variou muito pouco desde as primeiras camadas do solo até a profundidade de $70 \mathrm{~cm}$, sendo que essa variação foi de $0,012,0,005,0,020,0,019,0,018,0,035$ e $0,046 \mathrm{~cm}^{3} / \mathrm{cm}^{3}$ para as profundidades de $10,20,30,40,50,60$ e $70 \mathrm{~cm}$, respectivamente. A variação de umidade para as últimas camadas estudadas, 80,90 e $100 \mathrm{~cm}$, fol de $0,131,0,158$ e 0,174 , respectivamente.

Essa pequena variação da umidade até a profundidade de $70 \mathrm{~cm}$ deve estar relacionada com as características do horizonte $\mathrm{Bt}_{1}(20$ a $70 \mathrm{~cm})$, um horizonte bastante argiloso com forte cerosidade, o que não ocorre com o horizonte $\mathrm{Bt}_{2}$ que já começa a adquirir características do horizonte $\mathrm{Bw}$. O horizonte Ap encontrava-se muito compactado por ocasião do experimento, o que também colaborou muito para sua pequena variação de umidade com o tempo de redistribuição além, é claro, da influência do $\mathrm{Bt}_{1}$.

Com os dados da Tabela 5.4 foram construídos os gráficos de umidade pelo tempo para cada profundidade (Figuras 5.4, 5.5, 5.6, 5.7 e 5.8). Pode-se observar claramente pelos gráficos que a umidade entre os tempos 0 e 24 horas nas profundidades de 10 a $60 \mathrm{~cm}$ variou muito pouco, apresentando um intervalo maior a partir de $70 \mathrm{~cm}$ até $100 \mathrm{~cm}$ de profundidade. Devido a essa característica apresentada pelo solo, foram processados para a determinação de $K(\theta)$ somente os 
TABELA 5.2- Valores de potencial mátrico $\left(-\phi_{\mathrm{m}} ; \mathrm{cm}\right.$ água) obtidos ao longo do tempo de drenagem interna do perfil.

\begin{tabular}{ccccccccccc}
\hline Tempo & \multicolumn{10}{c}{ Profundidade $(\mathrm{cm})$} \\
\cline { 2 - 11 } & 10 & 20 & 30 & 40 & 50 & 60 & 70 & 80 & 90 & 100 \\
\hline 24,2 & 14,7 & 6,1 & 11,1 & 14,8 & 0,7 & 9,8 & 21,7 & 32,2 & 45,5 & 61,5 \\
48,2 & 17,4 & 10,2 & 12,5 & 17,5 & 7,5 & 13,9 & 23,1 & 39,1 & 56,4 & 75,2 \\
54,6 & 21,5 & 10,2 & 12,5 & 18,9 & 10,3 & 19,4 & 27,2 & 43,2 & 64,6 & 79,3 \\
99,3 & 22,9 & 12,9 & 15,2 & 23,0 & 14,4 & 22,2 & 29,9 & 47,3 & 68,7 & 88,8 \\
124,8 & 21,5 & 11,5 & 16,6 & 18,9 & 10,3 & 22,2 & 31,3 & 48,7 & 68,7 & 91,6 \\
144,7 & 22,9 & 12,9 & 18,0 & 20,3 & 14,4 & 24,9 & 31,3 & 51,4 & 75,6 & 90,2 \\
168,8 & 25,6 & 15,6 & 19,3 & 21,6 & 15,7 & 26,3 & 35,4 & 54,1 & 75,6 & 92,9 \\
216,5 & 27,0 & 15,6 & 20,7 & 23,0 & 17,1 & 29,0 & 38,1 & 58,2 & 82,4 & 99,8 \\
239,8 & 31,1 & 18,4 & 22,1 & 24,4 & 21,2 & 30,4 & 39,5 & 59,6 & 86,5 & 106,6 \\
265,9 & 27,0 & 17,0 & 19,3 & 21,6 & 15,7 & 30,4 & 39,5 & 61,0 & 85,2 & 105,2 \\
288,2 & 32,5 & 18,4 & 23,4 & 23,0 & 19,8 & 31,7 & 39,5 & 62,3 & 90,6 & 112,1 \\
312,2 & 29,8 & 18,4 & 24,8 & 23,0 & 22,6 & 33,1 & 42,2 & 65,1 & 92,0 & 116,2 \\
359,9 & 32,5 & 19,8 & 24,8 & 25,7 & 22,6 & 33,1 & 43,6 & 66,4 & 97,5 & 124,4 \\
\hline
\end{tabular}


TABELA 5.3 Valores de potencial total $\left(-\phi_{t} ; \mathrm{cm}\right.$ água) obtidos ao longo do tempo durante a drenagem interna do perfil.

\begin{tabular}{ccccccccccc}
\hline Tempo & \multicolumn{10}{c}{ Profundidade (cm) } \\
\cline { 2 - 11 } (h) & 10 & 20 & 30 & 40 & 50 & 60 & 70 & 80 & 90 & 100 \\
\hline 24,2 & 24,7 & 26,1 & 41,1 & 54,8 & 50,7 & 69,8 & 91,7 & 112,2 & 135,5 & 161,5 \\
48,2 & 27,4 & 30,2 & 42,5 & 57,5 & 57,5 & 73,9 & 93,1 & 119,1 & 146,4 & 175,2 \\
54,6 & 31,5 & 30,2 & 42,5 & 58,9 & 60,3 & 79,4 & 97,2 & 123,2 & 154,6 & 179,3 \\
99,3 & 32,9 & 32,9 & 45,2 & 63,0 & 64,4 & 82,2 & 99,9 & 127,3 & 158,7 & 188,8 \\
124,8 & 31,5 & 31,5 & 46,6 & 58,9 & 60,3 & 82,2 & 101,3 & 128,7 & 158,7 & 191,6 \\
144,7 & 32,9 & 32,9 & 48,0 & 60,3 & 64,4 & 84,9 & 101,3 & 131,4 & 165,6 & 190,2 \\
168,8 & 35,6 & 35,6 & 49,3 & 61,6 & 65,7 & 86,3 & 105,4 & 134,1 & 165,6 & 192,9 \\
216,5 & 37,0 & 35,6 & 50,7 & 63,0 & 67,1 & 89,0 & 108,1 & 138,2 & 172,4 & 199,8 \\
239,8 & 41,1 & 38,4 & 52,1 & 64,4 & 71,2 & 90,4 & 109,5 & 139,6 & 176,5 & 206,6 \\
265,9 & 37,0 & 37,0 & 49,3 & 61,6 & 65,7 & 90,4 & 109,5 & 141,0 & 175,2 & 205,2 \\
288,2 & 42,5 & 38,4 & 53,4 & 63,0 & 69,8 & 91,7 & 109,5 & 142,3 & 180,6 & 212,1 \\
312,2 & 39,8 & 38,4 & 54,8 & 63,0 & 72,6 & 93,1 & 112,2 & 145,1 & 182,0 & 216,2 \\
359,9 & 42,5 & 39,8 & 54,8 & 65,7 & 72,6 & 93,1 & 113,6 & 146,4 & 187,5 & 224,4 \\
\hline
\end{tabular}


TABELA 5.4 Umidade $\left(\mathrm{cm}^{3} / \mathrm{cm}^{3}\right)$ estimada pela curva de retenção da água no solo.

\begin{tabular}{ccccccccccc}
\hline Tempo & \multicolumn{10}{c}{ Profundidade (cm) } \\
\cline { 2 - 10 } (h) & 10 & 20 & 30 & 40 & 50 & 60 & 70 & 80 & 90 & 100 \\
\hline 6,0 & - & - & - & - & - & - & 0,476 & 0,532 & 0,526 & 0,525 \\
12,0 & - & - & - & - & - & - & 0,473 & 0,510 & 0,500 & 0,475 \\
24,2 & 0,475 & 0,477 & 0,479 & 0,476 & 0,481 & 0,480 & 0,465 & 0,477 & 0,440 & 0,408 \\
48,2 & 0,473 & 0,476 & 0,478 & 0,472 & 0,480 & 0,477 & 0,462 & 0,456 & 0,417 & 0,389 \\
54,6 & 0,471 & 0,476 & 0,478 & 0,470 & 0,479 & 0,469 & 0,455 & 0,445 & 0,403 & 0,385 \\
99,3 & 0,470 & 0,475 & 0,475 & 0,462 & 0,476 & 0,464 & 0,450 & 0,435 & 0,397 & 0,375 \\
124,8 & 0,471 & 0,476 & 0,473 & 0,470 & 0,479 & 0,464 & 0,448 & 0,432 & 0,397 & 0,373 \\
144,7 & 0,470 & 0,475 & 0,471 & 0,467 & 0,476 & 0,459 & 0,448 & 0,426 & 0,389 & 0,374 \\
168,8 & 0,468 & 0,474 & 0,469 & 0,465 & 0,474 & 0,456 & 0,441 & 0,421 & 0,389 & 0,371 \\
216,5 & 0,467 & 0,474 & 0,467 & 0,462 & 0,473 & 0,452 & 0,437 & 0,414 & 0,381 & 0,366 \\
239,8 & 0,464 & 0,473 & 0,464 & 0,460 & 0,466 & 0,449 & 0,436 & 0,411 & 0,377 & 0,361 \\
265,9 & 0,467 & 0,474 & 0,469 & 0,465 & 0,474 & 0,449 & 0,436 & 0,409 & 0,378 & 0,362 \\
288,2 & 0,463 & 0,473 & 0,462 & 0,462 & 0,468 & 0,447 & 0,436 & 0,407 & 0,373 & 0,358 \\
312,2 & 0,465 & 0,473 & 0,459 & 0,462 & 0,463 & 0,445 & 0,432 & 0,403 & 0,372 & 0,355 \\
359,9 & 0,463 & 0,472 & 0,459 & 0,457 & 0,463 & 0,445 & 0,430 & 0,401 & 0,368 & 0,351 \\
\hline
\end{tabular}



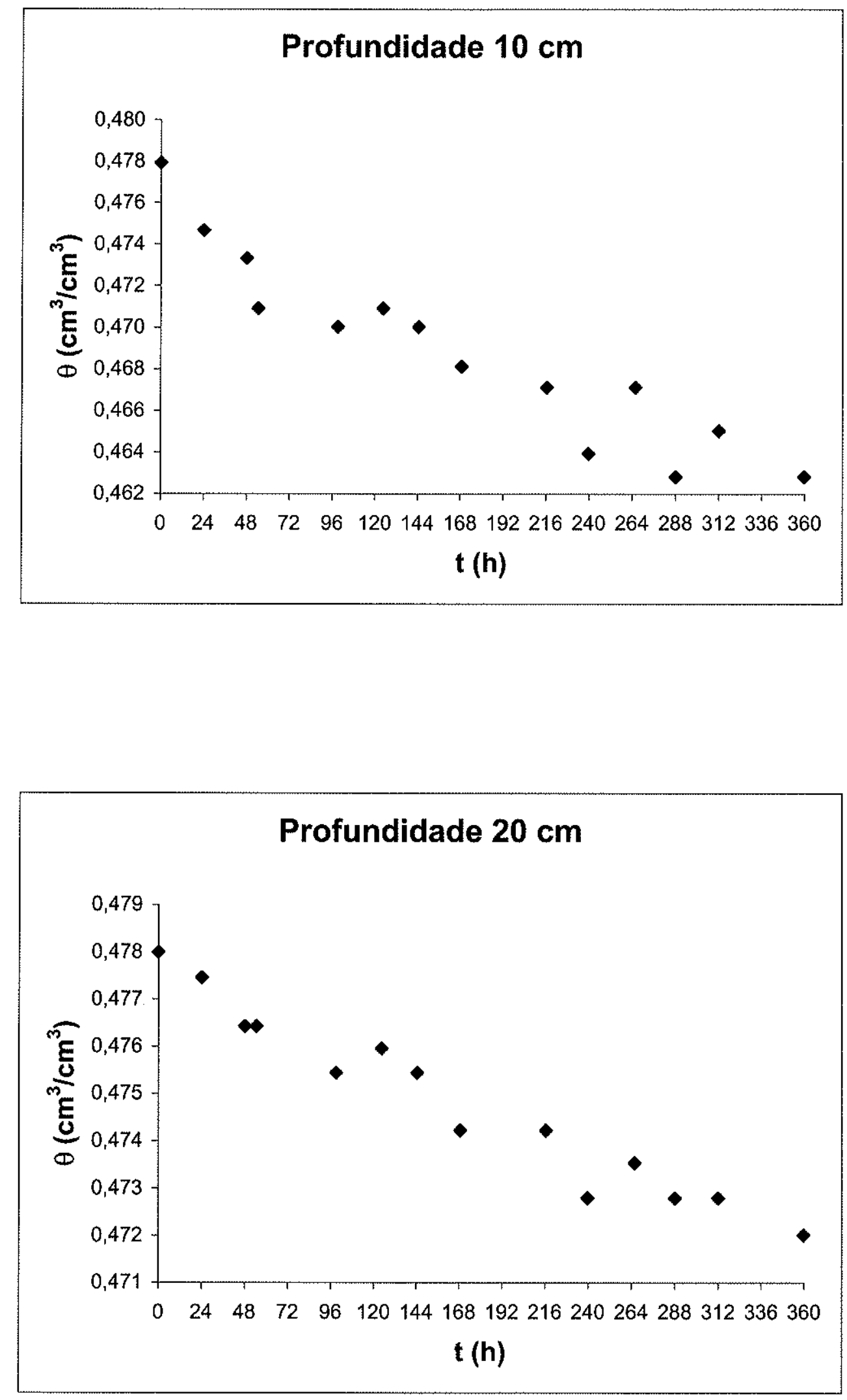

Figura 5.4 Gráficos de umidade $(\theta)$ pelo tempo $(t)$ de redistribuição em horas, para as profundidades de 10 e $20 \mathrm{~cm}$, com dados obtidos pela curva de retenção. 

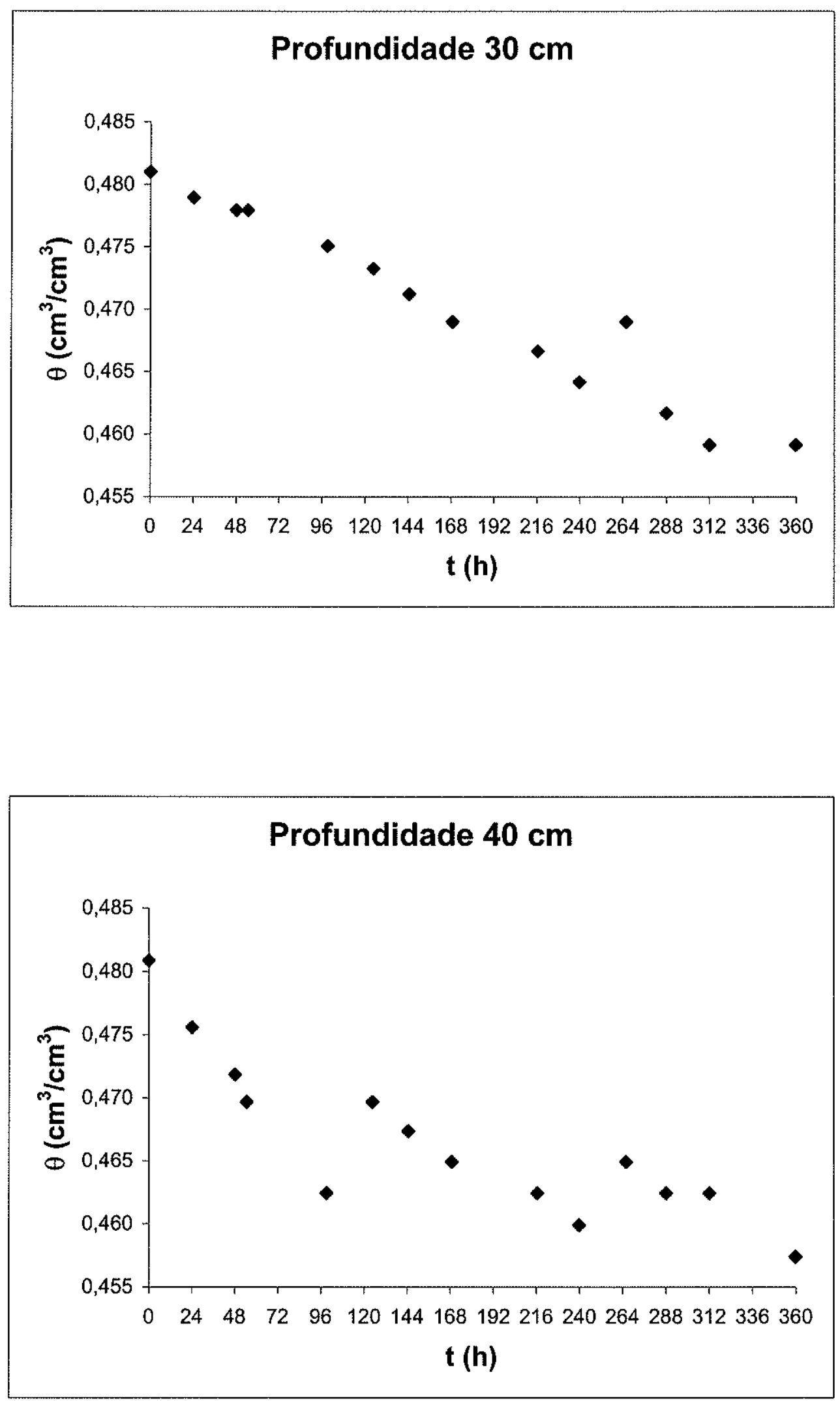

Figura 5.5 Gráficos de umidade $(\theta)$ pelo tempo $(t)$ de redistribuição em horas, para as profundidades de 30 e $40 \mathrm{~cm}$, com dados obtidos pela curva de retenção. 

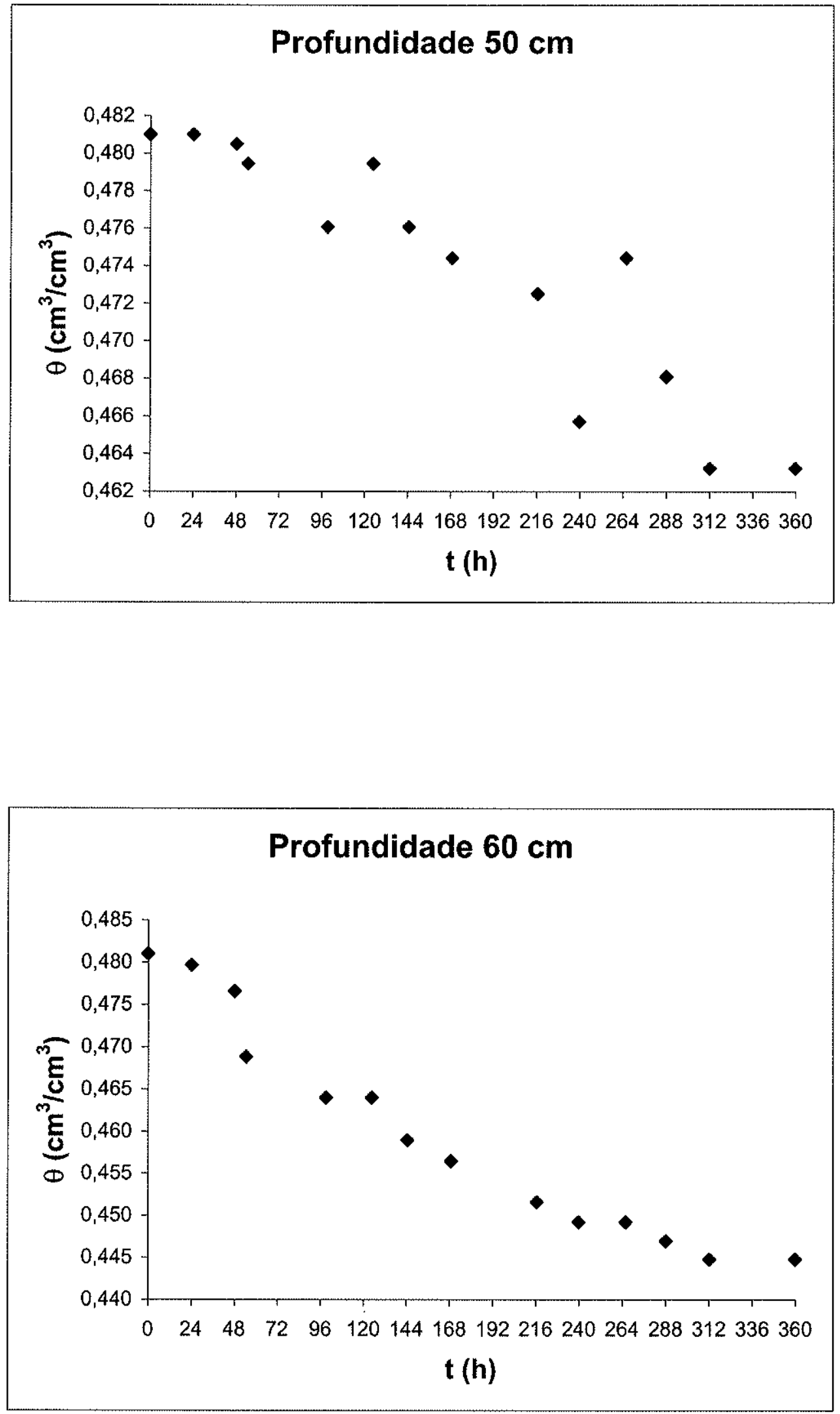

Figura 5.6 Gráficos de umidade $(\theta)$ pelo tempo $(t)$ de redistribuição em horas, para as profundidades de 50 e $60 \mathrm{~cm}$, com dados obtidos pela curva de retenção. 

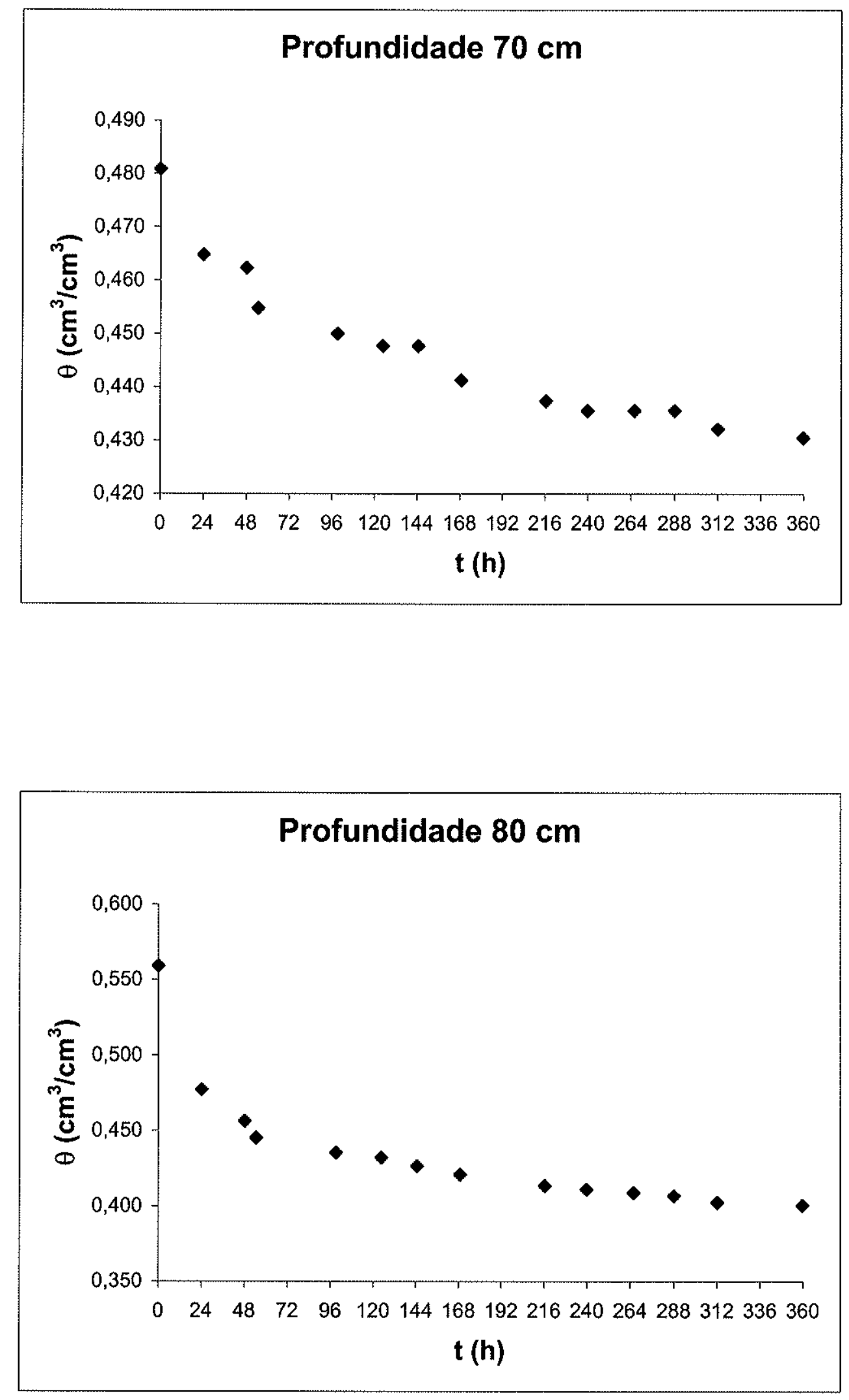

Figura 5.7 Gráficos de umidade $(\theta)$ pelo tempo $(t)$ de redistribuição em horas, para as profundidades de 70 e $80 \mathrm{~cm}$, com dados obtidos pela curva de retenção. 

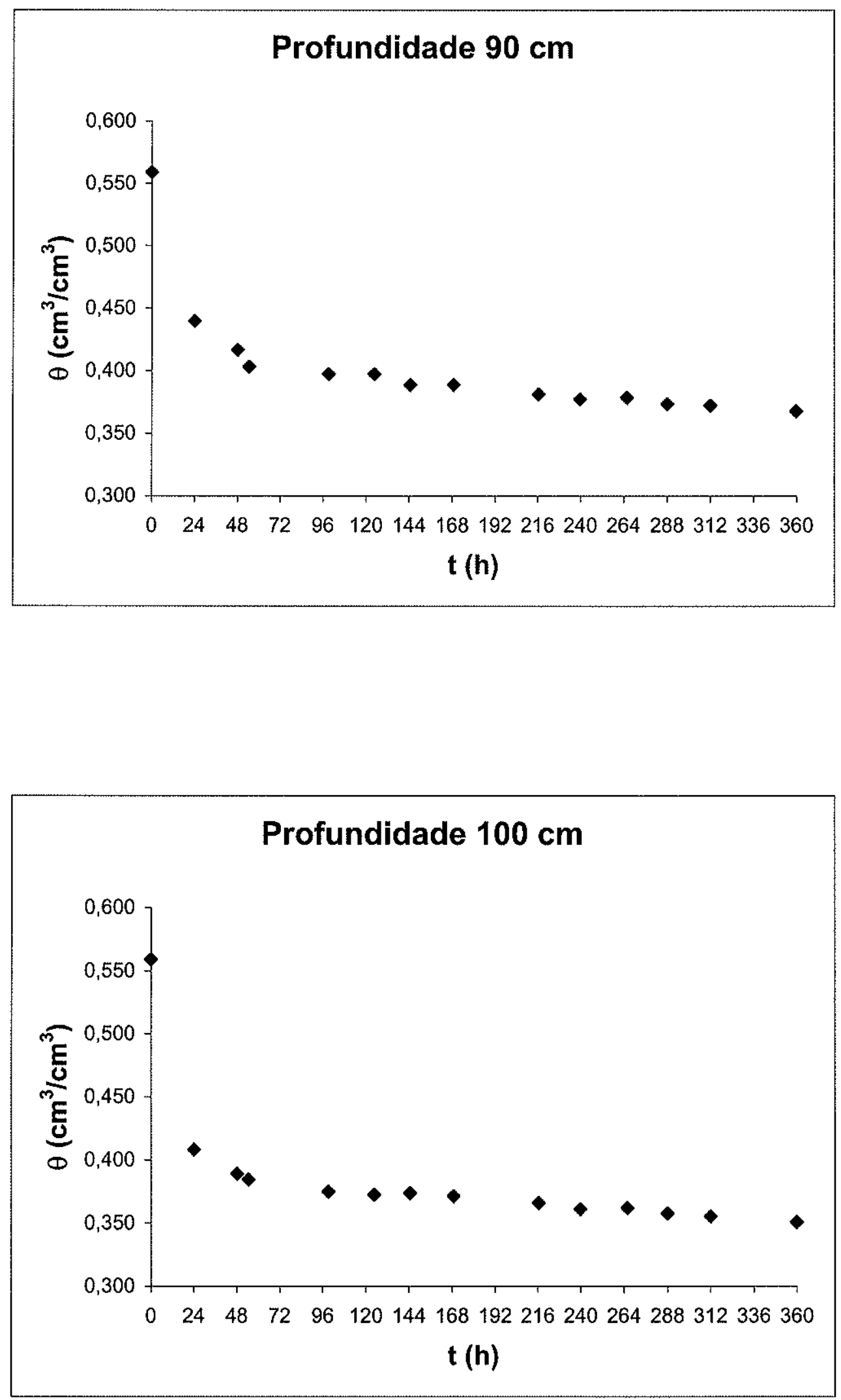

Figura 5.8 Gráficos de umidade $(\theta)$ pelo tempo $(t)$ de redistribuição em horas, para as profundidades de 90 e $100 \mathrm{~cm}$, com dados obtidos pela curva de retenção. 
dados de umidade a partir de 24 horas do início da leitura dos tensiômetros, para as profundidades de 10 a $60 \mathrm{~cm}$. Para as demais profundidades, $70,80,90$ e $100 \mathrm{~cm}$, estimou-se a umidade para os tempos 6 e 12 horas, a partir do gráfico de umidade pelo tempo em horas, com a finalidade de diminuir o intervalo entre o tempo 0 e 24 horas.

Pelos gráficos de umidade $\theta$ versus In t (Figuras 5.9, 5.10, 5.11, 5.12 e 5.13), pode-se observar a tendência da umidade em diminuir com o tempo de redistribuição, e a maior dispersão dos valores de umidade em relação à reta obtida por regressão para esses valores, apresentando coeficientes de correlação (Tabela 5.5) mais baixos (entre 0,89 a 0,70 ) nas primeiras camadas do solo (de 10 a $50 \mathrm{~cm}$ ) em relação às camadas mais profundas (de 60 a $90 \mathrm{~cm}$ ), com coeficientes entre 0,93 e 0,99 . Entre as profundidades de 10 a $50 \mathrm{~cm}$, o menor coeficiente de correlação foi obtido para a profundidade de $50 \mathrm{~cm}$, o que coincide com o horizonte que mais expressa o $\mathrm{Bt}$ do solo estudado, apresentando muita dispersão dos valores de umidade.

\subsection{Sonda de nêutrons}

As contagens relativas da sonda foram transformadas em umidade (Tabela 5.6) por meio das curvas de calibração obtidas para cada profundidade de solo estudada $(20,30,40,50,60,70,80,90,100 \mathrm{~cm})$, segundo Moraes et al. (1998), as quais são mostradas na Tabela 5.7 com seus respectivos coeficientes de correlação. Os valores de $r^{2}$ apresentaram-se melhores nas profundidades de 20,30 e $40 \mathrm{~cm}(0,74,0,76$ e 0,70 , respectivamente), enquanto nas demais profundidades os coeficientes foram mais baixos (entre 0,39 e 0,58 ) sendo que a exceção foi para $90 \mathrm{~cm}$, onde $\mathrm{r}^{2}$ apresentou valor de 0,69.

Pode-se observar pela Tabela 5.6 que a sonda de nêutrons mostrou-se pouco sensível às variações de umidade, chegando a apresentar o mesmo valor de umidade no início e no final da drenagem, e durante o tempo de redistribuição, não 

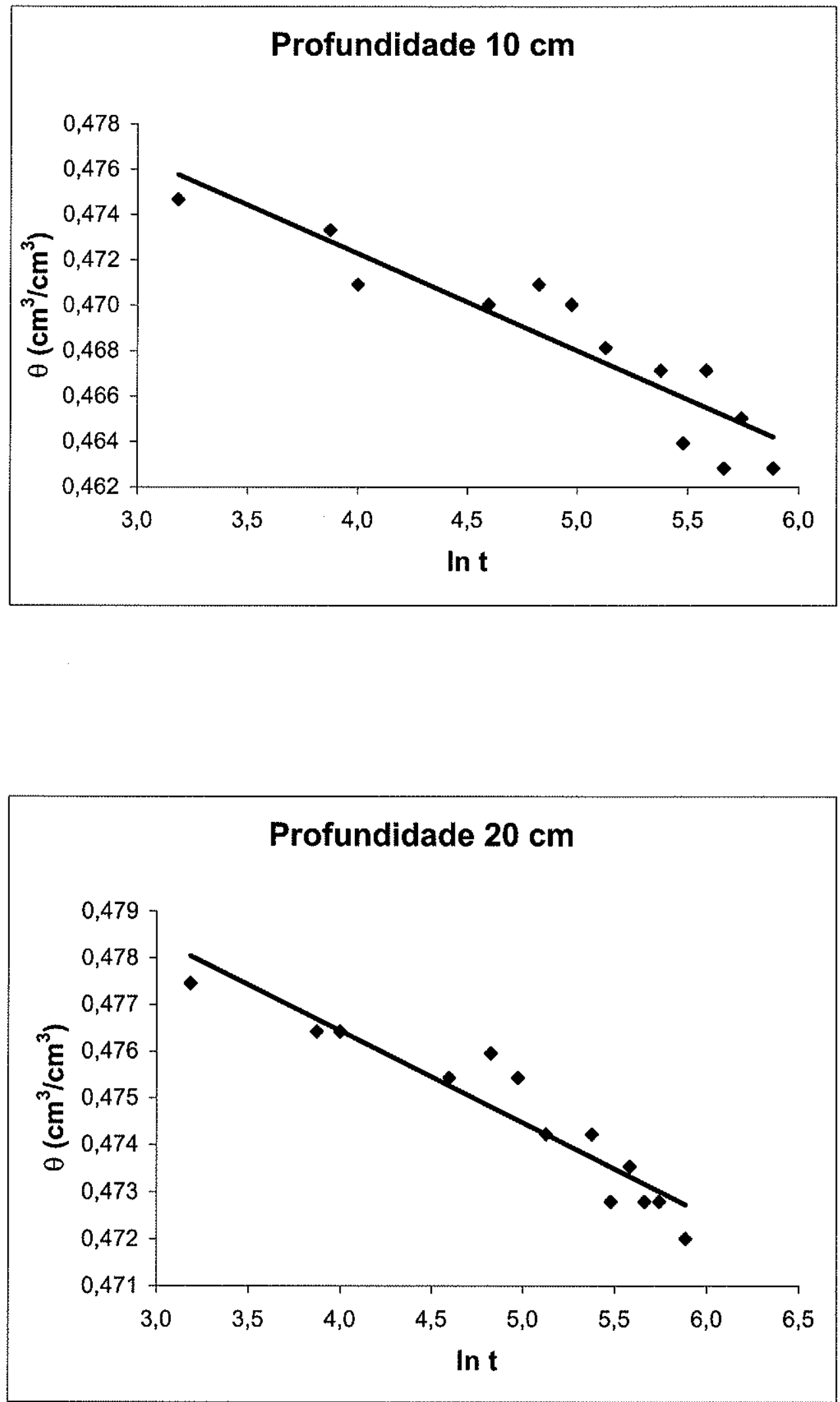

Figura 5.9 Gráficos de umidade ( $\theta$ ) por $I n t$, para as profundidades de 10 e $20 \mathrm{~cm}$, com dados obtidos pela curva de retenção. 

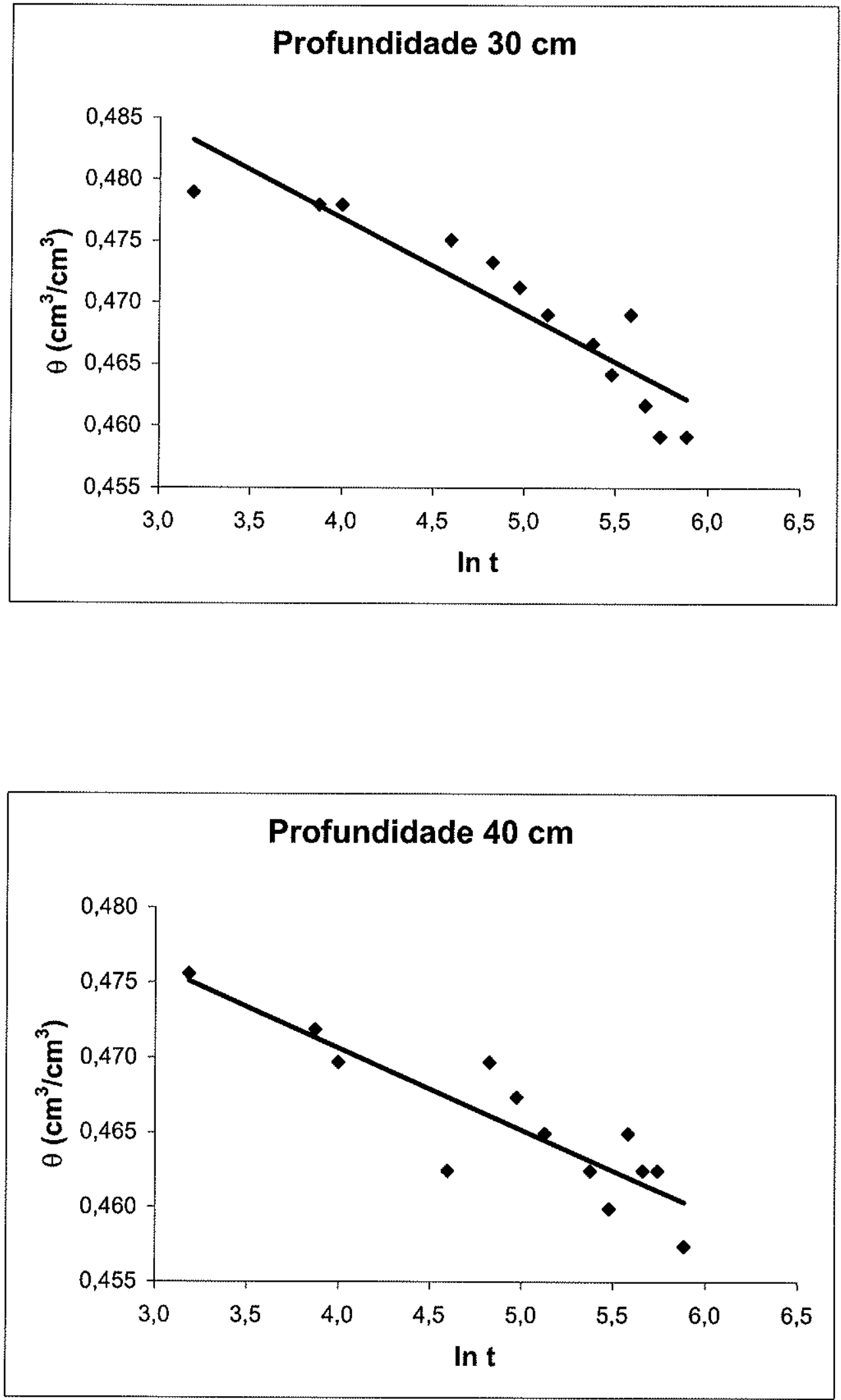

Figura 5.10 Gráficos de umidade ( $\theta$ ) por In $t$, para as profundidades de 30 e $40 \mathrm{~cm}$, com dados obtidos pela curva de retenção. 

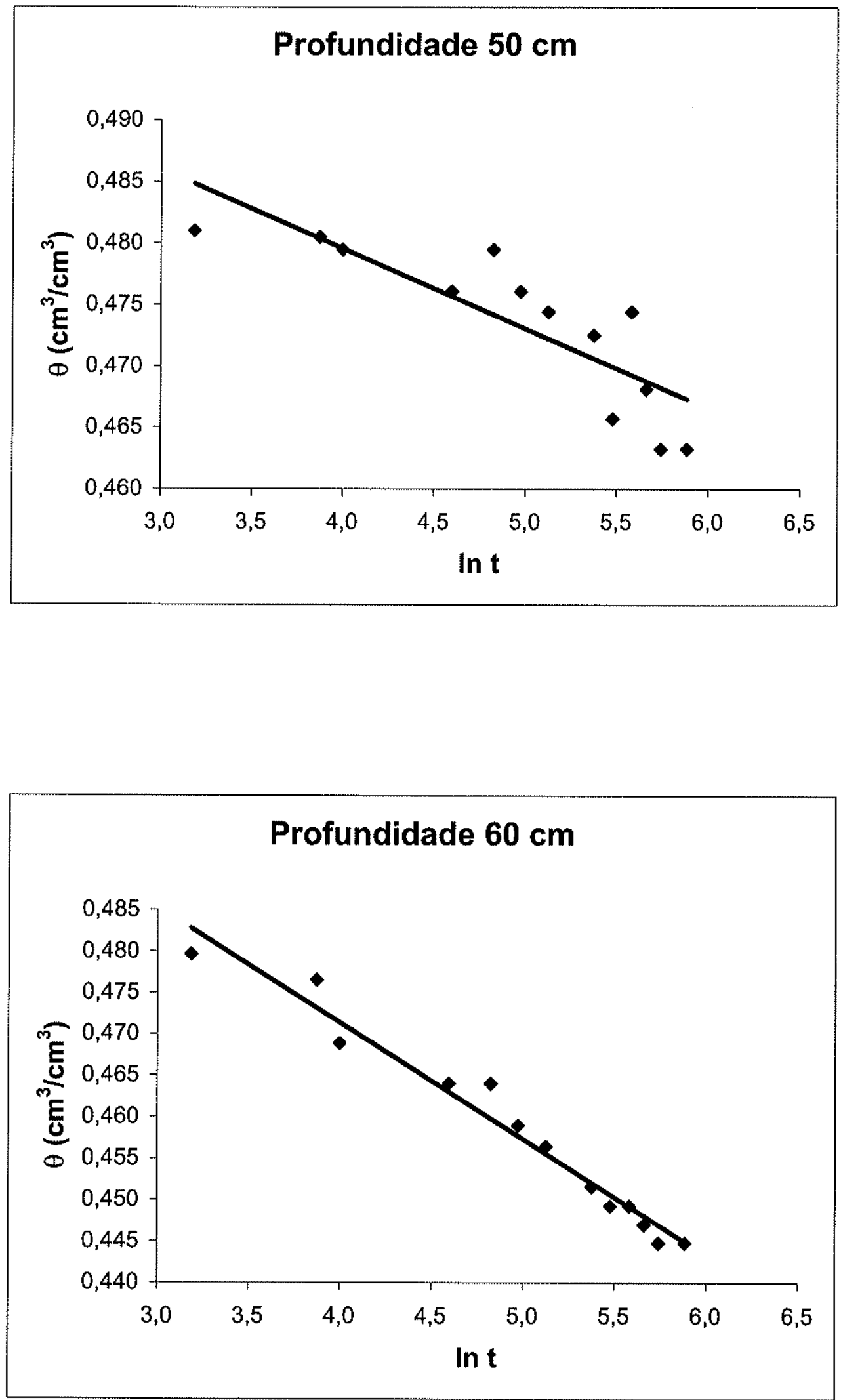

Figura 5.11 Gráficos de umidade ( $\theta$ ) por in $t$, para as profundidades de 50 e $60 \mathrm{~cm}$, com dados obtidos pela curva de retenção. 

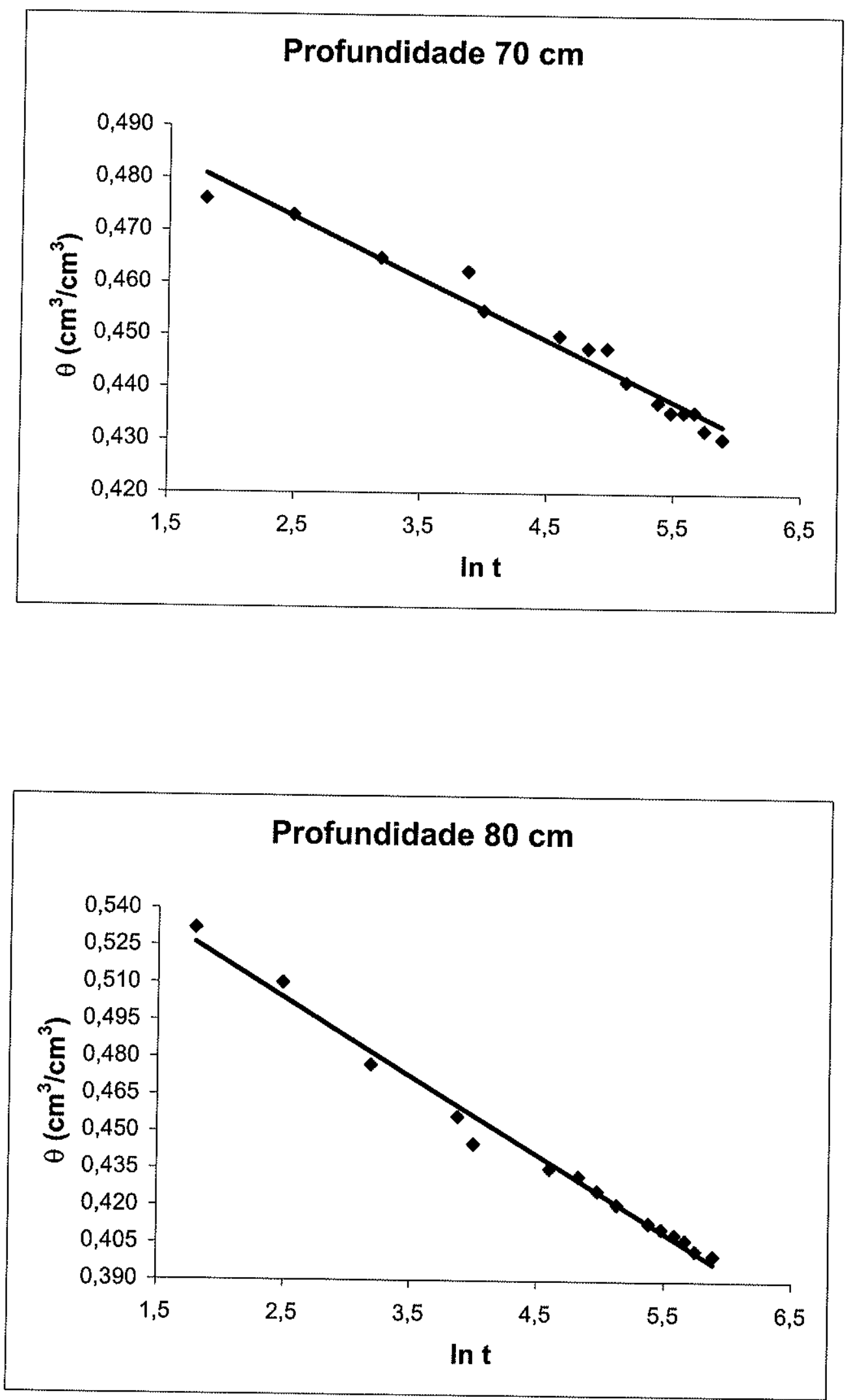

Figura 5.12 Gráficos de umidade $(\theta)$ por $\ln t$, para as profundidades de 70 e $80 \mathrm{~cm}$, com dados obtidos pela curva de retenção. 

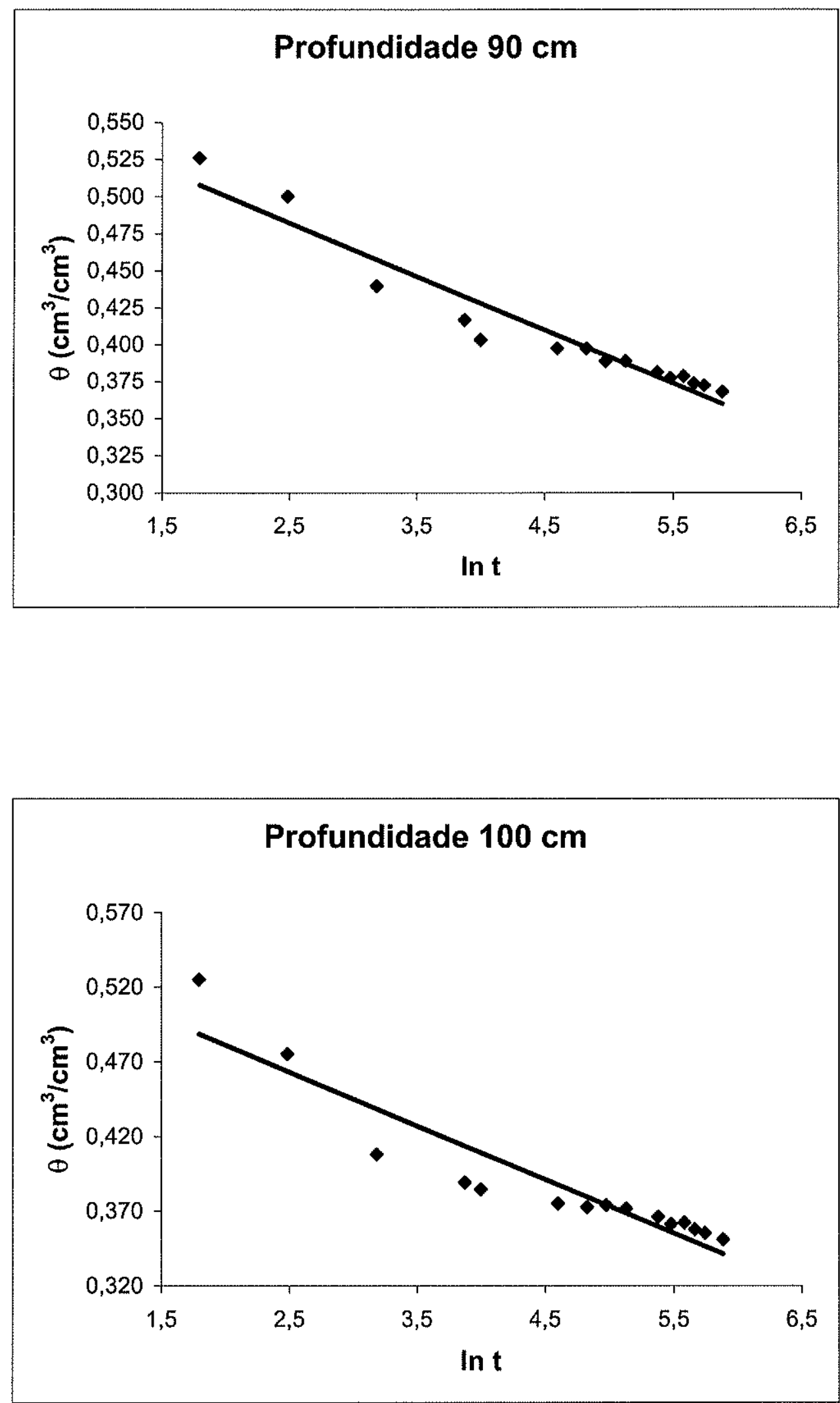

Figura 5.13 Gráficos de umidade $(\theta)$ por In $t$, para as profundidades de 90 e $100 \mathrm{~cm}$, com dados obtidos pela curva de retenção. 
TABELA 5.5 Equações lineares obtidas por regressão da umidade $\theta$ versus in $t$, para valores obtidos pela curva de retenção.

\begin{tabular}{ccc}
\hline $\begin{array}{c}\text { Profundidade } \\
(\mathrm{cm})\end{array}$ & $\begin{array}{c}\text { Equação } \\
\text { Linear }\end{array}$ & $\begin{array}{c}\text { Coeficiente de } \\
\text { correlação }\left(\mathrm{r}^{2}\right)\end{array}$ \\
\hline 10 & $\theta=-0,004282 \ln \mathrm{t}+0,4894$ & 0,85 \\
20 & $\theta=-0,001968 \ln \mathrm{t}+0,4843$ & 0,89 \\
30 & $\theta=-0,007796 \ln \mathrm{t}+0,508$ & 0,84 \\
40 & $\theta=-0,0015464 \mathrm{n} \mathrm{t}+0,4925$ & 0,78 \\
50 & $\theta=-0,006497 \ln \mathrm{t}+0,5055$ & 0,70 \\
60 & $\theta=-0,01402 \ln \mathrm{t}+0,5274$ & 0,97 \\
70 & $\theta=-0,0117 \ln \mathrm{t}+0,5017$ & 0,97 \\
80 & $\theta=-0,0315 \ln \mathrm{t}+0,5825$ & 0,99 \\
90 & $\theta=-0,0362 \ln \mathrm{t}+0,5725$ & 0,93 \\
100 & $\theta=-0,036 \ln \mathrm{t}+0,553$ & 0,87 \\
\hline
\end{tabular}


TABELA 5.6 Umidade $\left(\mathrm{cm}^{3} / \mathrm{cm}^{3}\right)$ estimada pela sonda de nêutrons.

\begin{tabular}{cccccccccc}
\hline \multirow{2}{*}{ Lnt } & \multicolumn{10}{c}{ Profundidade $(\mathrm{cm})$} \\
\cline { 2 - 9 } & 20 & 30 & 40 & 50 & 60 & 70 & 80 & 90 & 100 \\
\hline 0,7 & 0,404 & 0,379 & 0,408 & 0,408 & 0,413 & 0,423 & 0,379 & 0,373 & 0,372 \\
1,4 & 0,393 & 0,377 & 0,398 & 0,405 & 0,409 & 0,420 & 0,369 & 0,362 & 0,360 \\
1,8 & 0,390 & 0,378 & 0,400 & 0,404 & 0,408 & 0,415 & 0,368 & 0,365 & 0,358 \\
2,1 & 0,396 & 0,383 & 0,405 & 0,408 & 0,411 & 0,419 & 0,373 & 0,359 & 0,359 \\
3,2 & 0,387 & 0,382 & 0,400 & 0,407 & 0,407 & 0,418 & 0,366 & 0,357 & 0,349 \\
3,9 & 0,386 & 0,379 & 0,395 & 0,404 & 0,403 & 0,408 & 0,356 & 0,351 & 0,342 \\
4,0 & 0,396 & 0,381 & 0,401 & 0,408 & 0,408 & 0,414 & 0,363 & 0,355 & 0,348 \\
4,6 & 0,385 & 0,375 & 0,391 & 0,400 & 0,401 & 0,408 & 0,353 & 0,344 & 0,335 \\
4,8 & 0,390 & 0,378 & 0,398 & 0,402 & 0,401 & 0,407 & 0,353 & 0,344 & 0,338 \\
5,0 & 0,387 & 0,367 & 0,392 & 0,396 & 0,399 & 0,404 & 0,350 & 0,340 & 0,333 \\
5,1 & 0,393 & 0,378 & 0,398 & 0,404 & 0,404 & 0,407 & 0,354 & 0,344 & 0,338 \\
5,5 & 0,394 & 0,377 & 0,399 & 0,403 & 0,404 & 0,407 & 0,355 & 0,344 & 0,336 \\
5,5 & 0,391 & 0,380 & 0,400 & 0,405 & 0,404 & 0,407 & 0,355 & 0,344 & 0,333 \\
5,6 & 0,386 & 0,370 & 0,395 & 0,405 & 0,402 & 0,401 & 0,350 & 0,340 & 0,331 \\
5,7 & 0,389 & 0,372 & 0,389 & 0,401 & 0,399 & 0,401 & 0,351 & 0,337 & 0,330 \\
5,7 & 0,385 & 0,369 & 0,390 & 0,398 & 0,396 & 0,399 & 0,345 & 0,333 & 0,330 \\
5,9 & 0,389 & 0,379 & 0,391 & 0,402 & 0,402 & 0,403 & 0,350 & 0,339 & 0,332 \\
\hline
\end{tabular}


TABELA 5.7 Equações de calibração da sonda para o solo estudado, para cada profundidade.

\begin{tabular}{ccc}
\hline Profundidade $(\mathrm{cm})$ & $\begin{array}{c}\text { Equação } \\
\text { de calibração }\end{array}$ & $\begin{array}{c}\text { Coeficiente de correlação } \\
\left(\mathrm{r}^{2}\right)\end{array}$ \\
\hline 20 & $\theta=-0,00576+0,2344 \mathrm{CR}$ & 0,75 \\
30 & $\theta=-0,11109+0,2662 \mathrm{CR}$ & 0,76 \\
40 & $\theta=-0,03276+0,2266 \mathrm{CR}$ & 0,70 \\
50 & $\theta=-0,13800+0,1371 \mathrm{CR}$ & 0,44 \\
60 & $\theta=-0,16311+0,1255 \mathrm{CR}$ & 0,39 \\
70 & $\theta=-0,09008+0,1705 \mathrm{CR}$ & 0,56 \\
80 & $\theta=-0,06988+0,1584 \mathrm{CR}$ & 0,60 \\
90 & $\theta=-0,08694+0,1538 \mathrm{CR}$ & 0,69 \\
100 & $\theta=-0,09373+0,1507 \mathrm{CR}$ & 0,58 \\
\hline
\end{tabular}


apresentou a tendência de diminuir com o tempo, apresentando valores maiores e menores. Entretanto, as variações foram pequenas, chegando no máximo a 0,042 $\mathrm{cm}^{3} / \mathrm{cm}^{3}$ na profundidade de $100 \mathrm{~cm}$.

Foram plotados os valores de umidade $\theta$ por In $t$ (Figuras 5.14, 5.15, 5.16, 5.17 e 5.18), cujas equações de regressão e coeficientes de correlação são mostrados na Tabela 5.8. Pode-se observar que os coeficientes de correlação para as profundidades de $20,30,40$ e $50 \mathrm{~cm}$ são baixos, estando entre 0,21 e 0,50 . Isso decorre do fato da umidade medida pela sonda variar pouco nessas camadas, apresentando coeficientes mais altos a partir da profundidade de $60 \mathrm{~cm}$ (entre 0,73 e 0,96 ).

Comparando-se os gráficos de umidade $\theta$ por in $t$ obtidos por dados da curva de retenção (Figuras 5.9, 5.10, 5.11, 5.12 e 5.13) e pela sonda de nêutrons (Figuras $5.14,5.15,5.16,5.17$ e 5.18 ), pode-se observar a maior correlação dos valores de umidade, e a menor sensibilidade da sonda de nêutrons em medir a variação de umidade ao longo do tempo de drenagem do perfil do solo estudado. Entretanto, pode-se observar também a mesma tendência do aumento de correlação com a profundidade, confirmando o comportamento deste solo em apresentar pouca variação de umidade nas primeiras camadas, devido a influência do horizonte Bt.

\subsection{Método do perfil instantâneo}

Para a determinação da condutividade hidráulica em função da umidade pelo método do perfil instantâneo, foi utilizada a Equação 7 baseada na teoria abordada no item 4.4, utilizando-se dois procedimentos diferentes para a determinação da umidade: a curva de retenção e a sonda de nêutrons. 

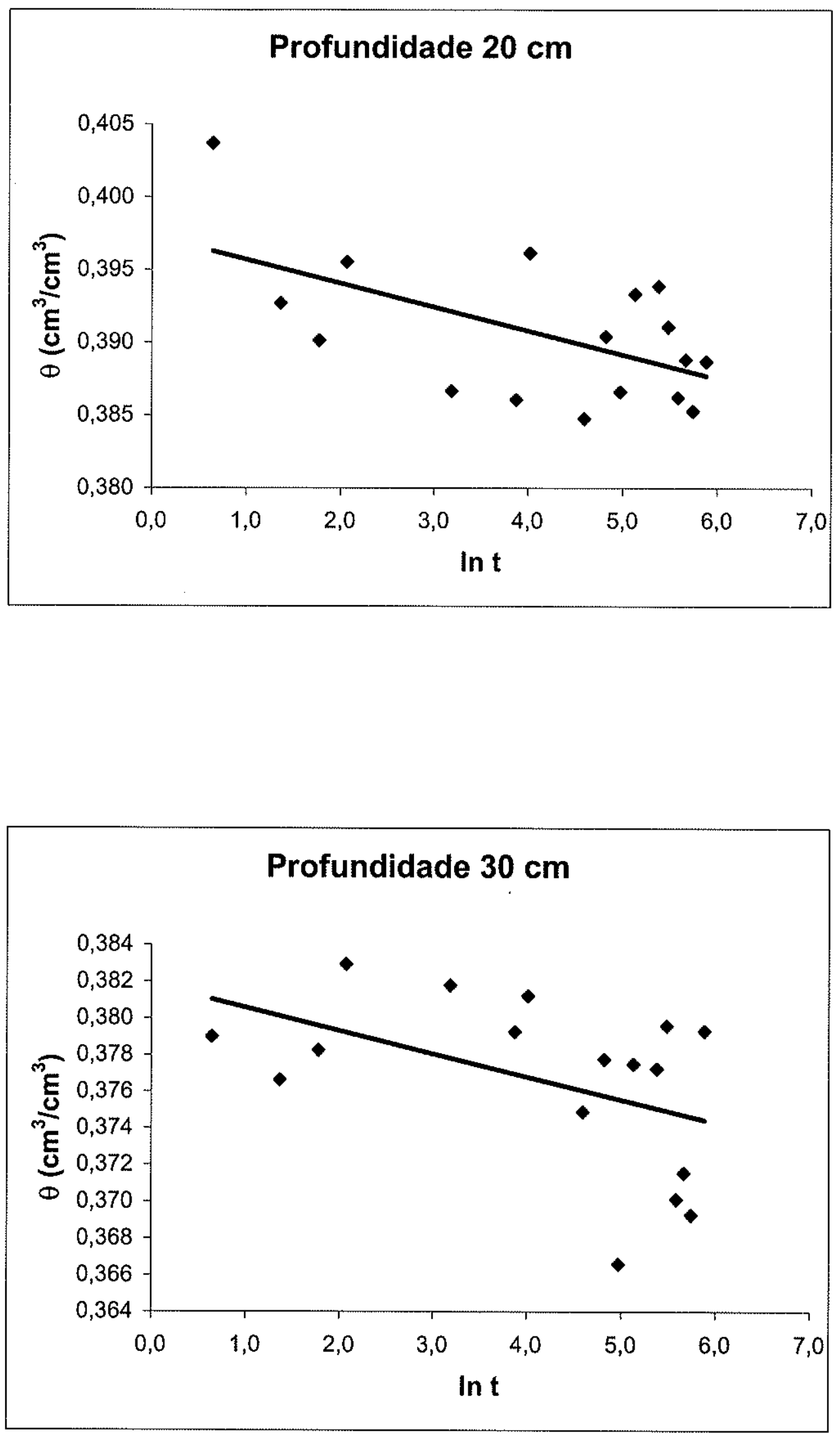

Figura 5.14 Gráficos de umidade $(\theta$ ) por $\ln t$, para as profundidades de 20 e $30 \mathrm{~cm}$, com dados obtidos pela sonda de nêutrons. 

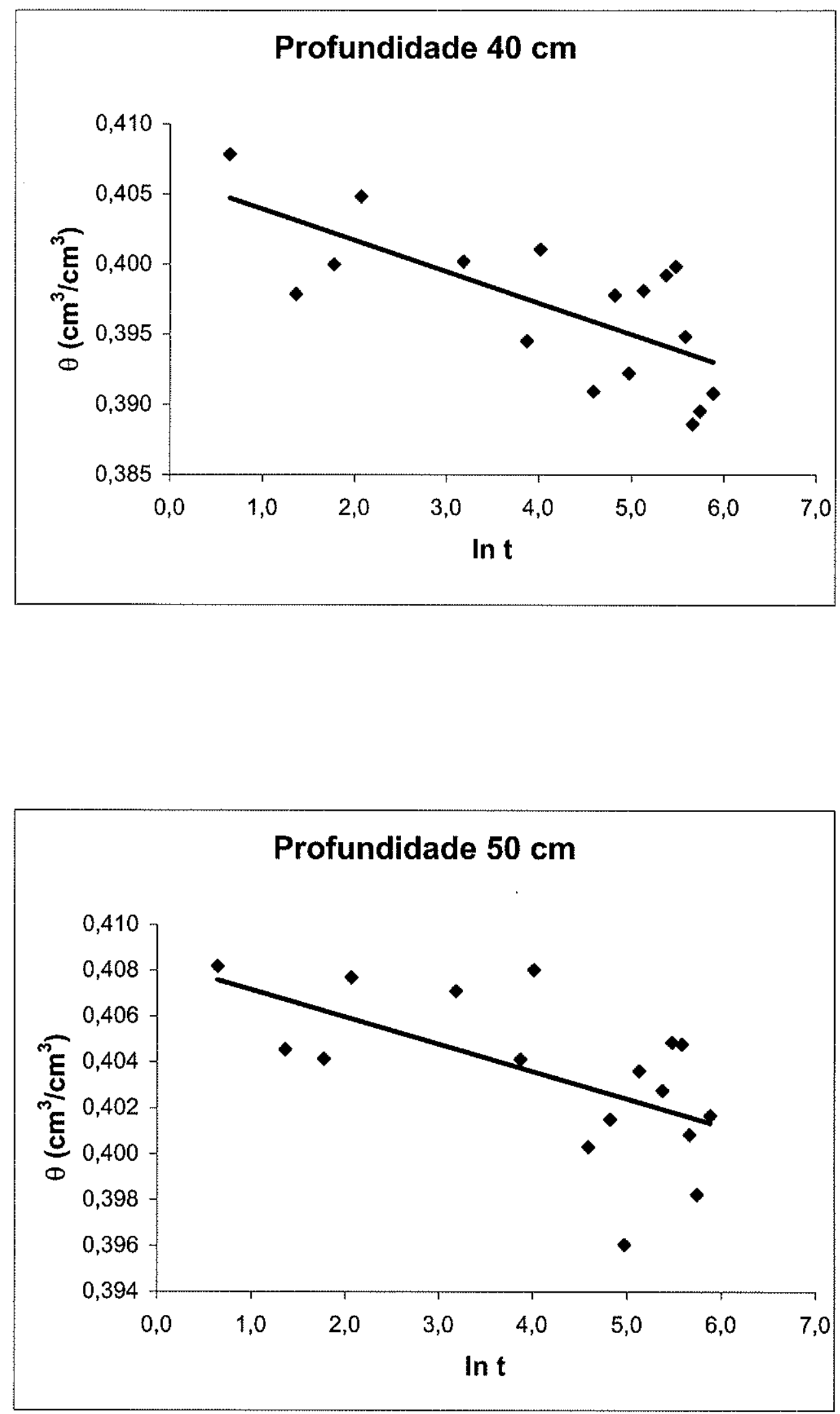

Figura 5.15 Gráficos de umidade $(\theta$ ) por $\ln t$, para as profundidades de 40 e $50 \mathrm{~cm}$, com dados obtidos pela sonda de nêutrons. 

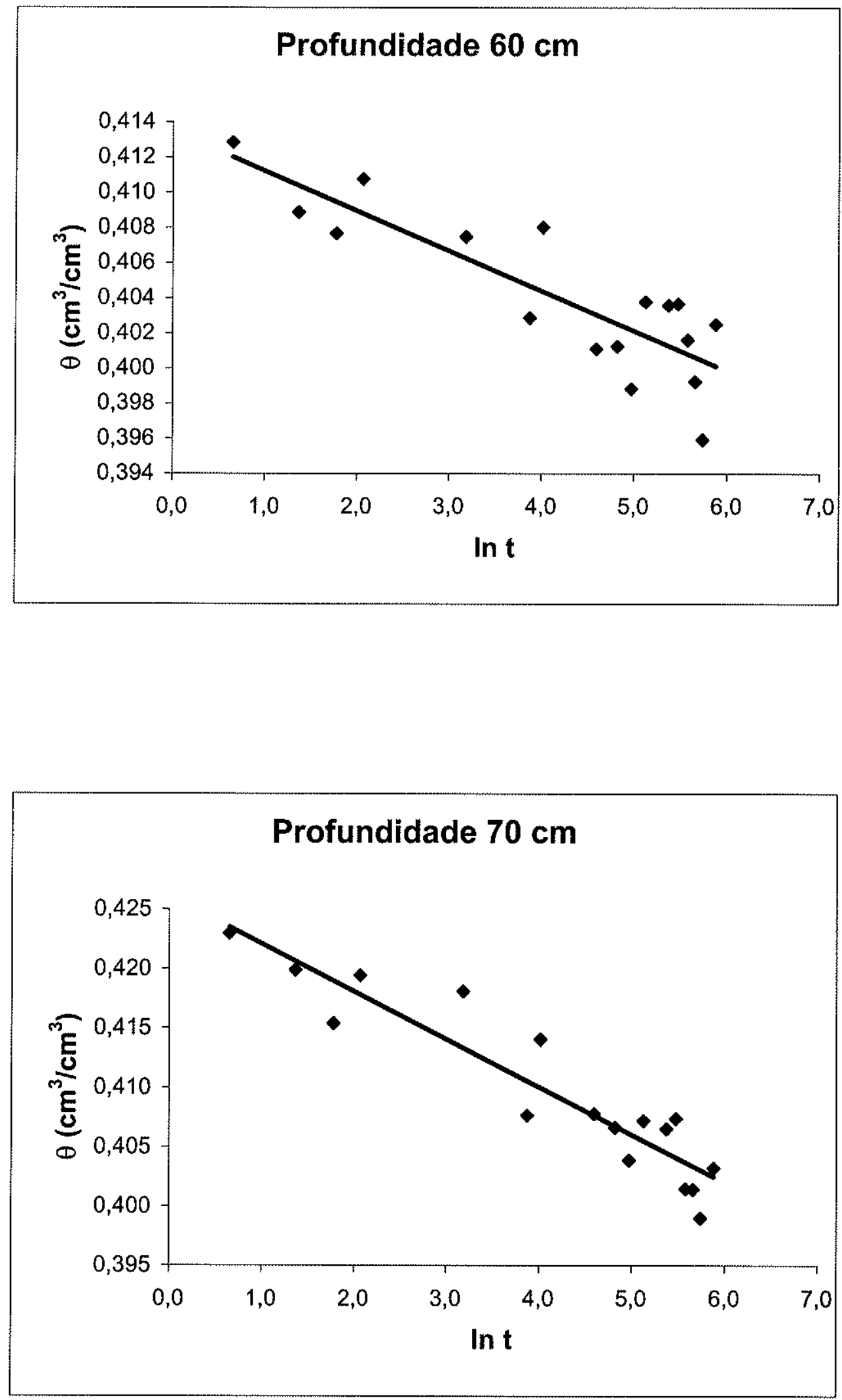

Figura 5.16 Gráficos de umidade $(\theta)$ por In $t$, para as profundidades de 60 e $70 \mathrm{~cm}$, com dados obtidos pela sonda de nêutrons. 

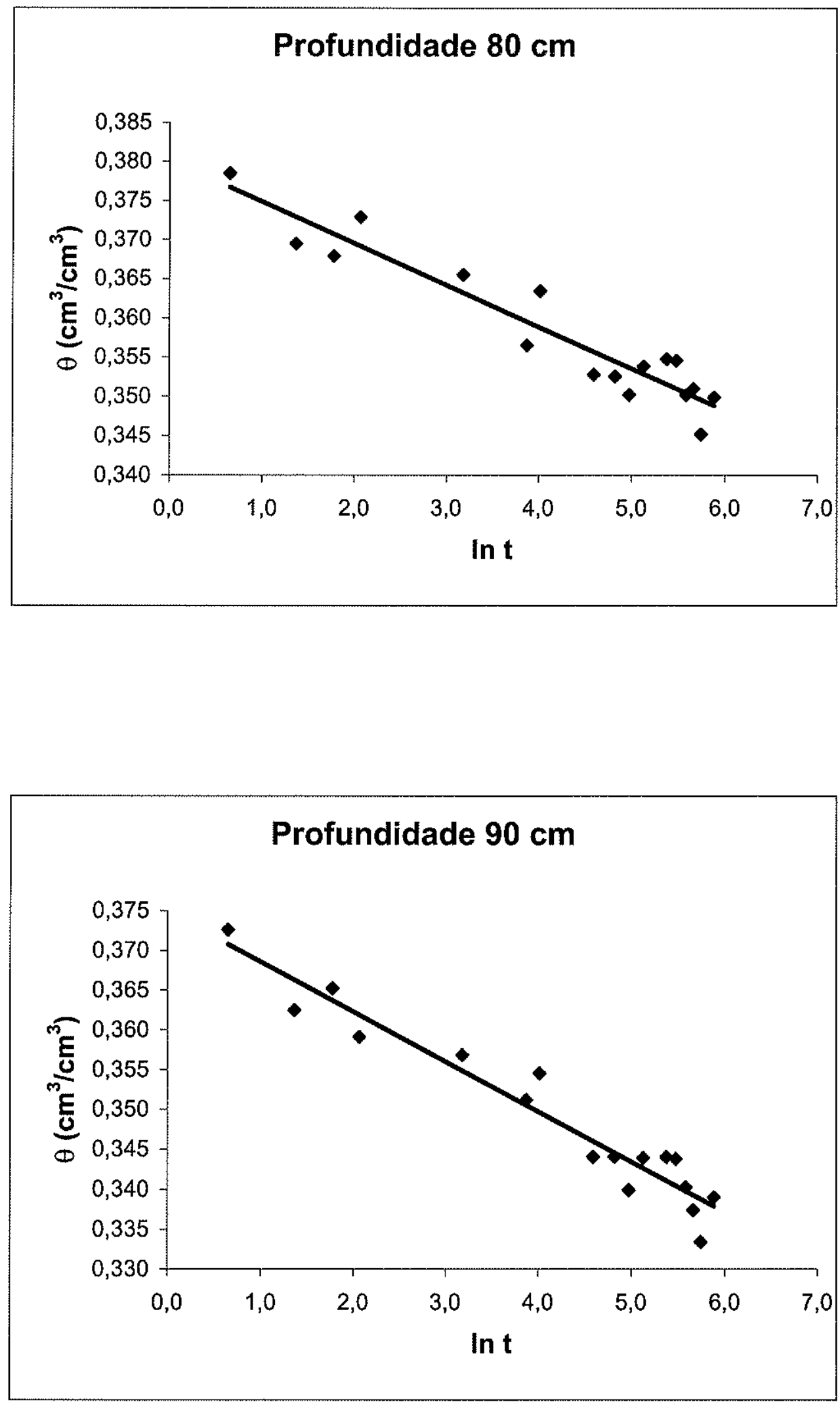

Figura 5.17 Gráficos de umidade $(\theta)$ por In $t$, para as profundidades de 80 e $90 \mathrm{~cm}$, com dados obtidos pela sonda de nêutrons. 


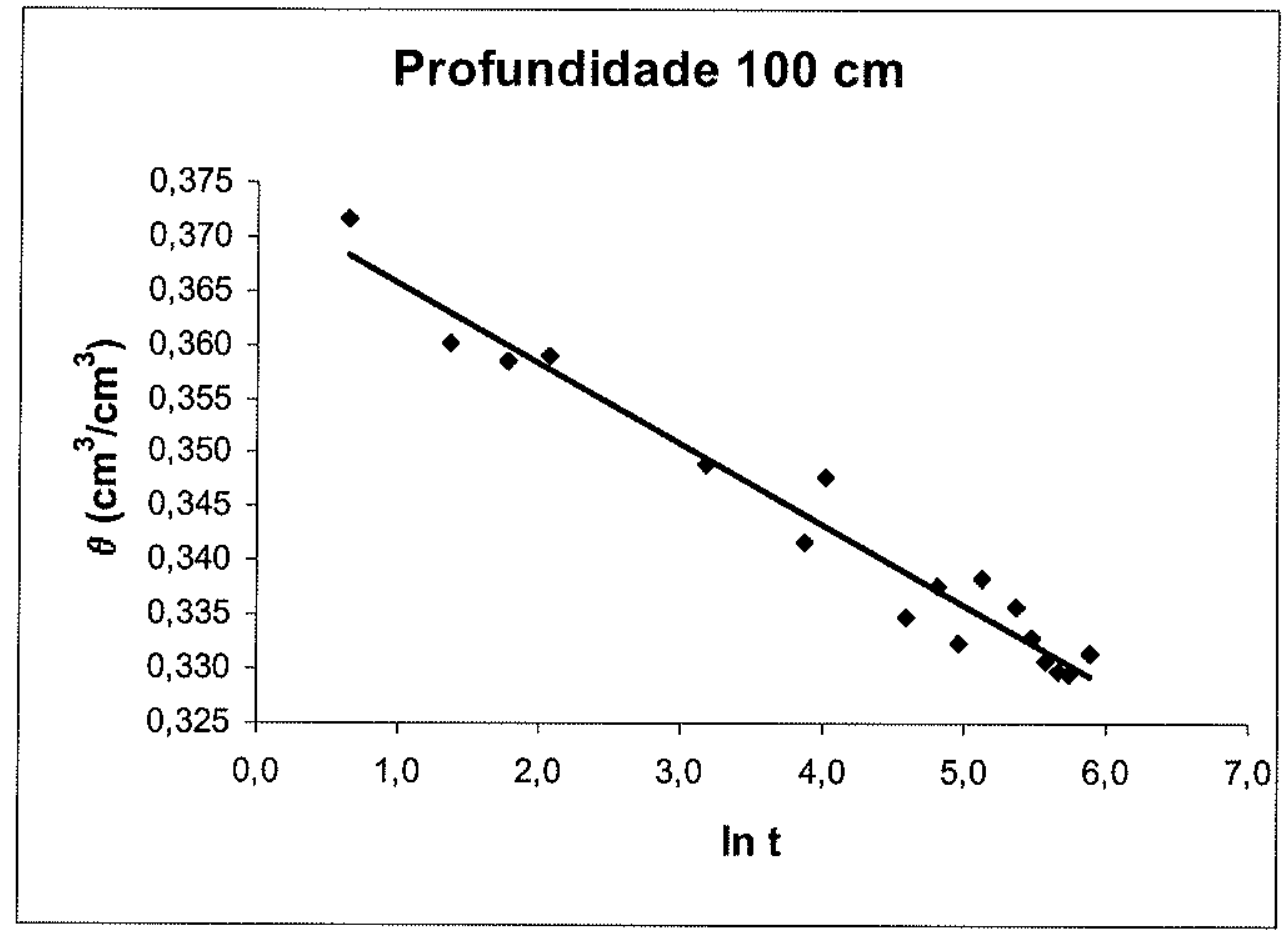

Figura 5.18 Gráfico de umidade $(\theta)$ por in $t$, para a profundidade de $100 \mathrm{~cm}$, com dados obtidos pela sonda de nêutrons. 
TABELA 5.8 Equações lineares obtidas por regressão da armazenagem $\left(h_{z}\right)$ versus $\ln t$, com dados obtidos pela sonda de nêutrons.

\begin{tabular}{ccc}
\hline Profundidade $(\mathrm{cm})$ & $\begin{array}{c}\text { Equação } \\
\text { linear }\end{array}$ & $\begin{array}{c}\text { Coeficiente de correlação } \\
\left(\mathrm{r}^{2}\right)\end{array}$ \\
\hline 20 & $\theta=-0,0016 \ln \mathrm{t}+0,3973$ & 0,32 \\
30 & $\theta=-0,0013 \ln \mathrm{t}+0,3818$ & 0,21 \\
40 & $\theta=-0,0022 \ln \mathrm{t}+0,4062$ & 0,50 \\
50 & $\theta=-0,0012 \ln \mathrm{t}+0,4084$ & 0,35 \\
60 & $\theta=-0,0023 \ln \mathrm{t}+0,4135$ & 0,73 \\
70 & $\theta=-0,004 \ln \mathrm{t}+0,4261$ & 0,87 \\
80 & $\theta=-0,0053 \ln \mathrm{t}+0,3802$ & 0,90 \\
90 & $\theta=-0,0063 \ln \mathrm{t}+0,3749$ & 0,93 \\
100 & $\theta=-0,0074 \ln \mathrm{t}+0,3731$ & 0,96 \\
\hline
\end{tabular}




\subsubsection{Curva de retenção}

A armazenagem de água no solo $\left(h_{z}\right)$ foi calculada pela aplicação da equação 8, e os valores obtidos encontram-se na Tabela 5.9. Os gráficos de $h_{z}$ versus in $t$ encontram-se nas Figuras $5.19,5.20,5.21,5.22$ e 5.23. Observa-se nesses gráficos a armazenagem diminuindo com o tempo, e nota-se que a regressão linear obtida apresenta bons valores de correlação (entre 0,84 e 0,88 ) nas profundidades de 10 a $50 \mathrm{~cm}$, que melhoram a partir da profundidade de $60 \mathrm{~cm}$, ajustando-se melhor à reta e passando para valores entre 0,90 e 0,98 . Os valores referentes a 6 e 12 horas foram considerados apenas para as profundidades de $70,80,90$ e $100 \mathrm{~cm}$.

O fluxo da água no solo foi calculado a partir da tangente da curva obtida pela regressão linear do gráfico de $h_{z}$ versus $\ln t$, para cada profundidade. Os valores de fluxo são apresentados na Tabela 5.10; as equações ajustadas e os valores de coeficiente de correlação estão mostrados na Tabela 5.11 .

O gradiente de potencial total da água no solo foi calculado utilizando-se a equação 9 , obtendo-se os valores contidos na Tabela 5.12. Os valores referentes aos tempos 6 e 12 horas, para as profundidades de 70,80 e $90 \mathrm{~cm}$ foram calculados pela equação de regressão de grad $\phi_{t}$ versus $t$ (Figuras 5.24, 5.25, $5.26 \mathrm{e}$ 5.27). As equações e seus coeficientes de correlação apresentam-se na Tabela 5.13.

A condutividade hidráulica pode então ser calculada para cada profundidade e para cada tempo de redistribuição, aplicando-se a equação 7.

Os valores de $K(\theta)$ podem ser observados na Tabela 5.14. As retas ajustadas apresentaram melhor coeficiente de correlação a partir de $60 \mathrm{~cm}$ de profundidade (entre 0,91 e 0,98 ), sendo que a profundidade de $50 \mathrm{~cm}$ (maior expressão do horizonte $\mathrm{Bt}$ ) foi a que apresentou o menor coeficiente de correlação 
TABELA 5.9 Armazenagem de água $\left(\mathrm{cm}^{3} / \mathrm{cm}^{2}\right)$ calculada com dados obtidos pela curva de retenção, para cada profundidade ao longo do tempo de drenagem interna do perfil.

\begin{tabular}{ccccccccccc}
\hline Tempo & \multicolumn{10}{c}{ Profundidade (cm) } \\
\cline { 2 - 11 } & 10 & 20 & 30 & 40 & 50 & 60 & 70 & 80 & 90 & 100 \\
\hline 6,0 & - & - & - & - & - & - & 33,52 & 38,84 & 44,10 & 49,35 \\
12,0 & - & - & - & - & - & - & 33,46 & 38,56 & 43,56 & 48,31 \\
24,2 & 4,75 & 9,52 & 14,31 & 19,07 & 23,88 & 28,67 & 33,32 & 38,09 & 42,49 & 46,57 \\
48,2 & 4,73 & 9,50 & 14,28 & 19,00 & 23,80 & 28,57 & 33,19 & 37,75 & 41,92 & 45,81 \\
54,6 & 4,71 & 9,47 & 14,25 & 18,95 & 23,74 & 28,43 & 32,98 & 37,43 & 41,46 & 45,31 \\
99,3 & 4,70 & 9,45 & 14,21 & 18,83 & 23,59 & 28,23 & 32,73 & 37,08 & 41,06 & 44,81 \\
124,8 & 4,71 & 9,47 & 14,20 & 18,90 & 23,69 & 28,33 & 32,81 & 37,13 & 41,11 & 44,83 \\
147,4 & 4,70 & 9,45 & 14,17 & 18,84 & 23,60 & 28,19 & 32,67 & 36,93 & 40,82 & 44,56 \\
168,8 & 4,68 & 9,42 & 14,11 & 18,76 & 23,51 & 28,07 & 32,48 & 36,69 & 40,58 & 44,29 \\
216,5 & 4,67 & 9,41 & 14,08 & 18,70 & 23,43 & 27,94 & 32,32 & 36,45 & 40,27 & 43,93 \\
239,8 & 4,64 & 9,37 & 14,01 & 18,61 & 23,27 & 27,76 & 32,11 & 36,22 & 40,00 & 43,61 \\
265,9 & 4,67 & 9,41 & 14,10 & 18,75 & 23,49 & 27,98 & 32,34 & 36,43 & 40,21 & 43,83 \\
288,2 & 4,63 & 9,36 & 13,97 & 18,60 & 23,28 & 27,75 & 32,10 & 39,17 & 39,90 & 43,48 \\
312,2 & 4,65 & 9,38 & 13,97 & 18,59 & 23,23 & 27,67 & 31,99 & 36,02 & 39,74 & 43,30 \\
359,9 & 4,63 & 9,35 & 13,94 & 18,51 & 23,15 & 27,59 & 31,90 & 35,90 & 39,58 & 43,09 \\
\hline
\end{tabular}



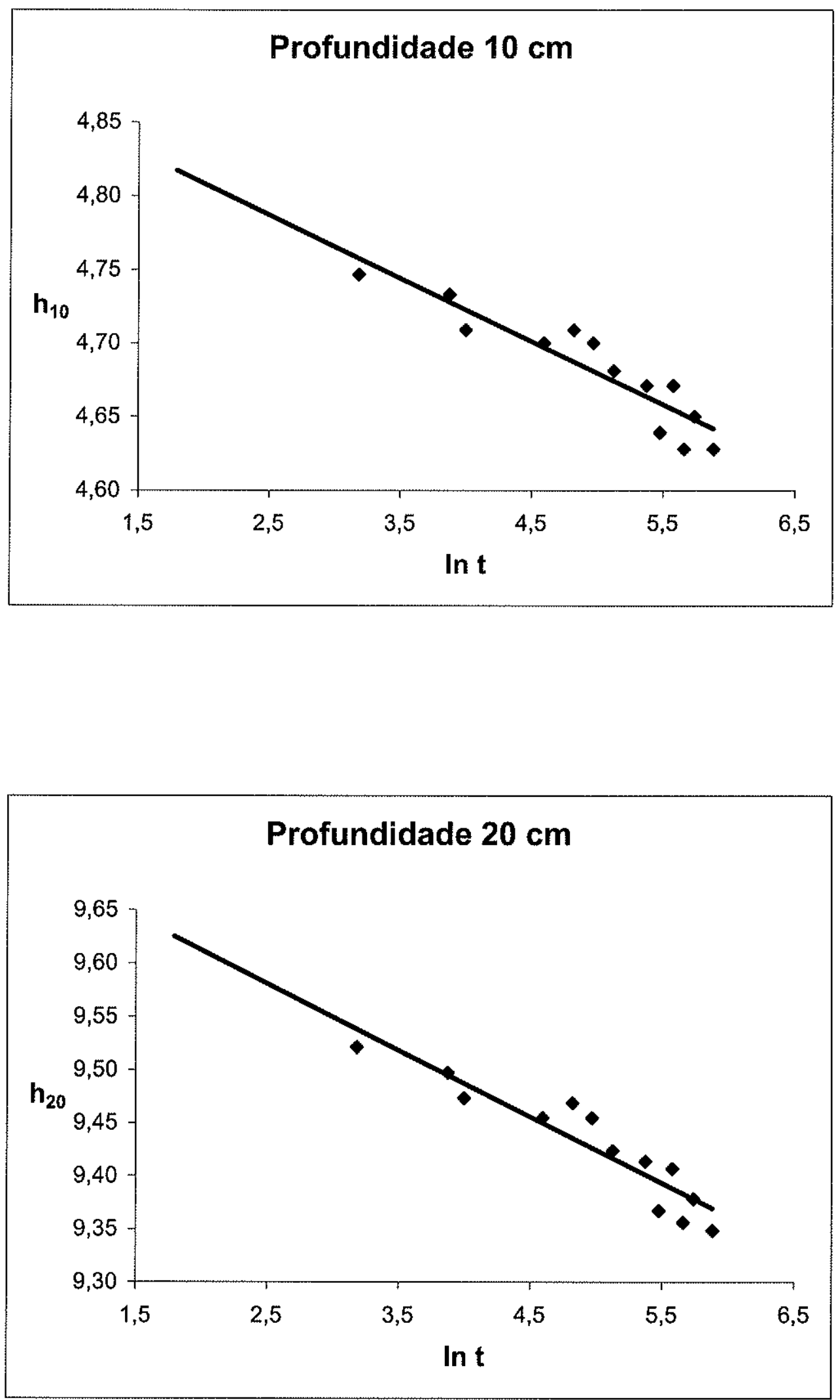

Figura 5.19 Gráficos de armazenagem $\left(h_{z}\right)$ por In $t$, para as profundidades de 10 e 20 $\mathrm{cm}$, com dados obtidos pela curva de retenção. 

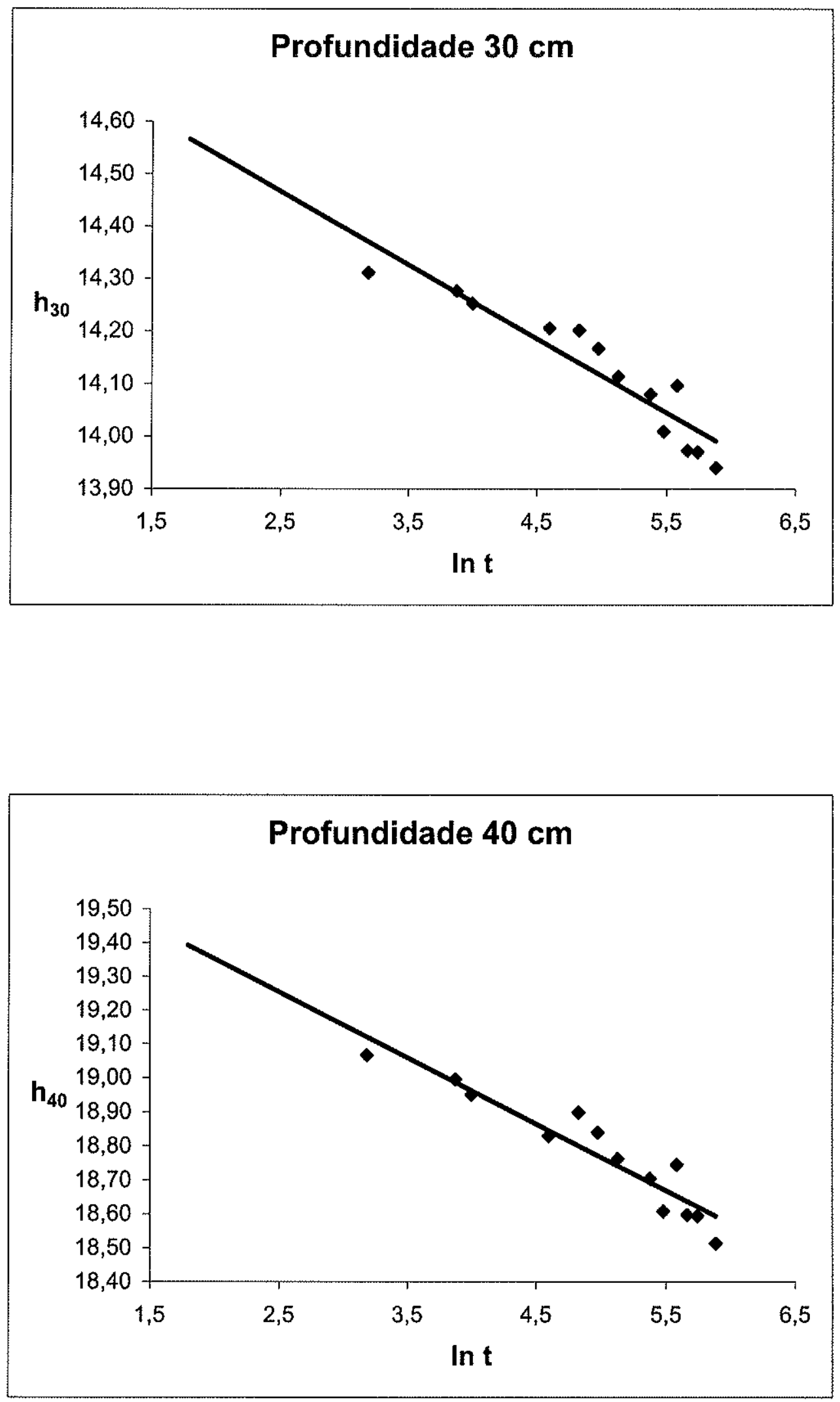

Figura 5.20 Gráficos de armazenagem $\left(h_{z}\right)$ por $\ln t$, para as profundidades de 30 e 40 $\mathrm{cm}$, com dados obtidos pela curva de retenção. 

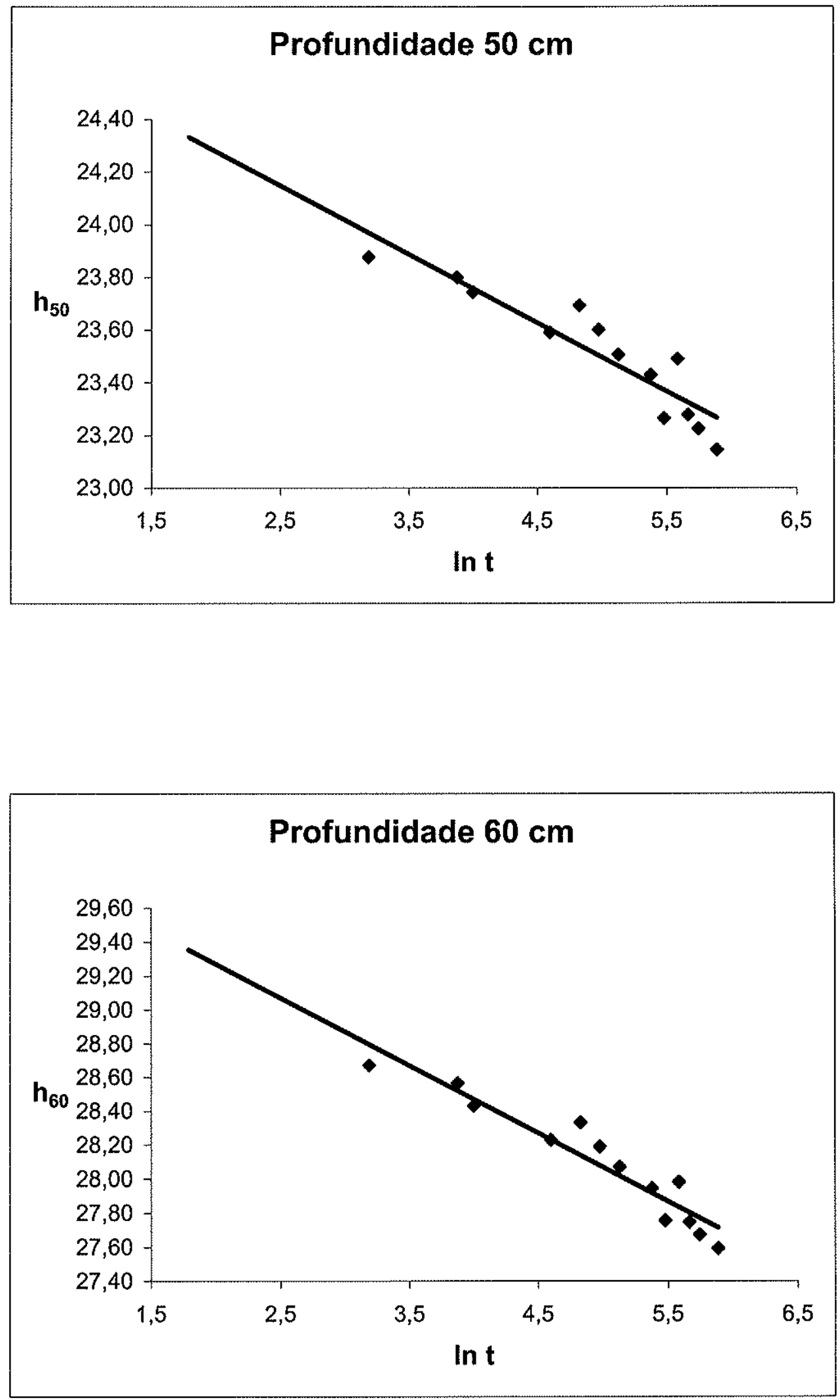

Figura 5.21 Gráficos de armazenagem $\left(h_{z}\right)$ por $\ln t$, para as profundidades de 50 e 60 $\mathrm{cm}$, com dados obtidos pela curva de retenção. 

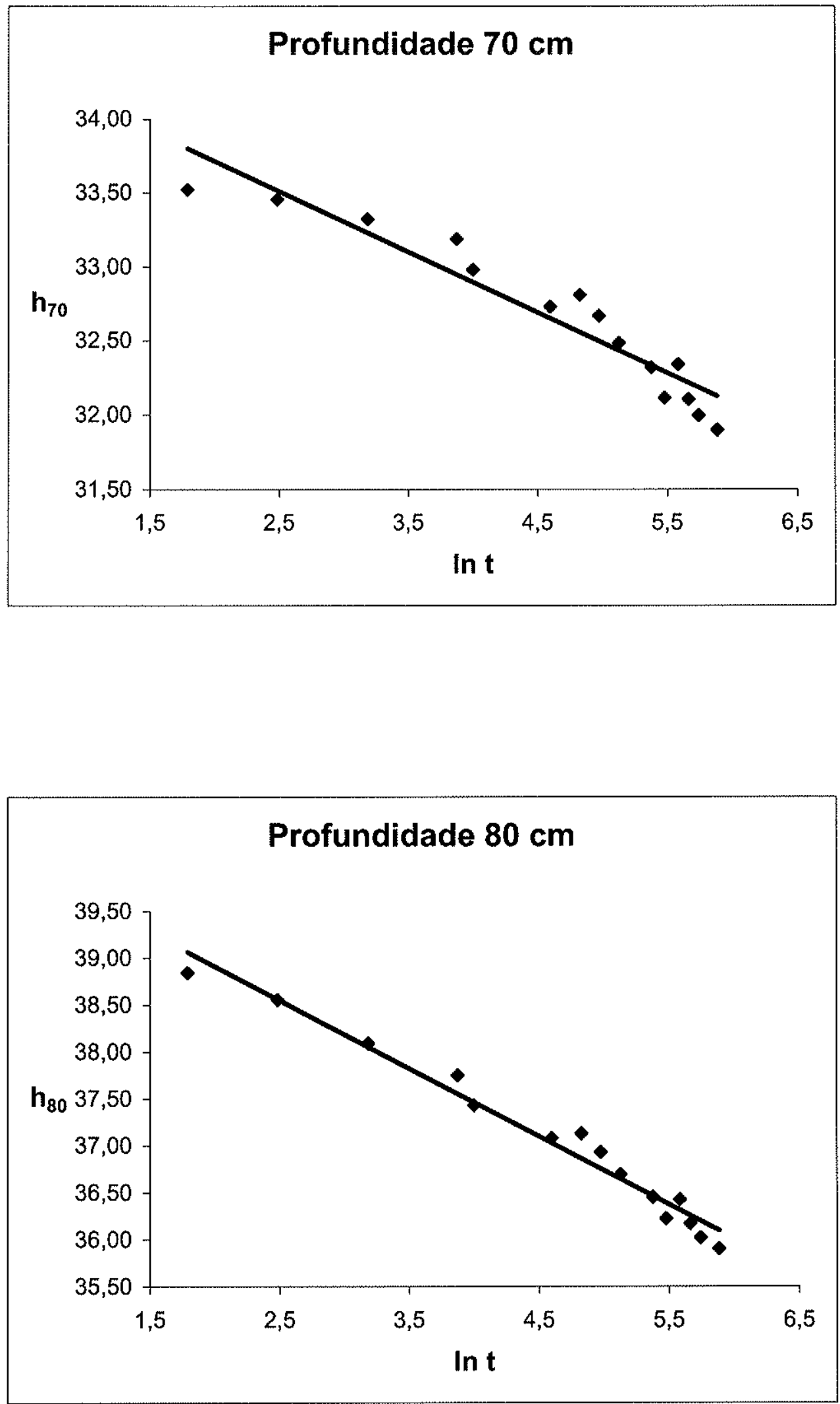

Figura 5.22 Gráficos de armazenagem $\left(h_{z}\right)$ por $\ln t$, para as profundidades de 70 e 80 $\mathrm{cm}$, com dados obtidos pela curva de retenção. 

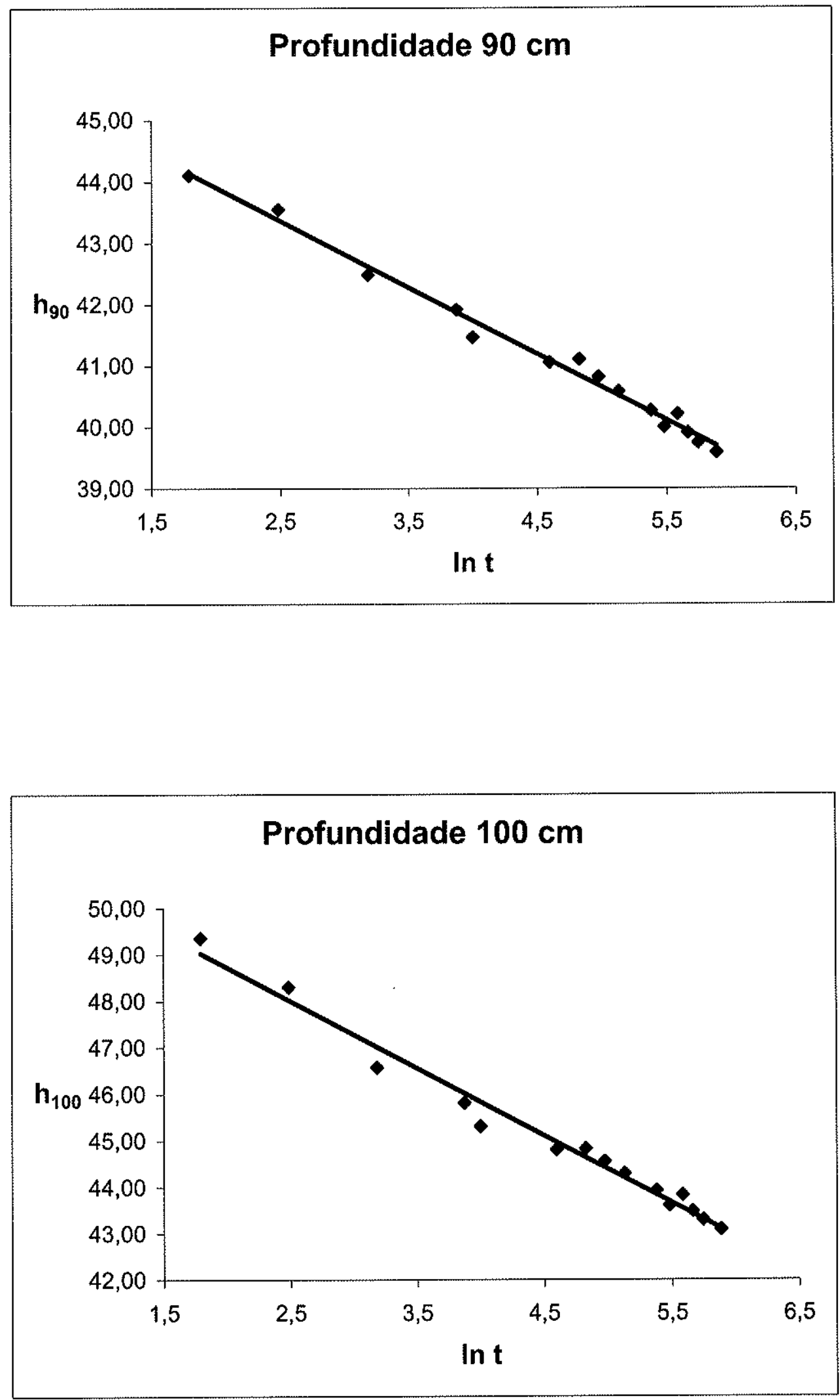

Figura 5.23 Gráficos de armazenagem $\left(h_{z}\right)$ por $\ln t$, para as profundidades de $90 \mathrm{e}$ $100 \mathrm{~cm}$, com dados obtidos pela curva de retenção. 
TABELA 5.10 Fluxos calculados $(\mathrm{cm} / \mathrm{h})$ com dados obtidos pela curva de retenção, para cada profundidade ao longo do tempo de drenagem interna do perfil.

\begin{tabular}{|c|c|c|c|c|c|c|c|c|}
\hline \multirow{2}{*}{$\begin{array}{c}\text { Tempo } \\
\text { (h) }\end{array}$} & \multicolumn{8}{|c|}{ Profundidade $(\mathrm{cm})$} \\
\hline & 20 & 30 & 40 & 50 & 60 & 70 & 80 & 90 \\
\hline 6,0 & - & - & - & - & - & $6,83.10^{-2}$ & $1,21.10^{-1}$ & $1,81.10^{-1}$ \\
\hline 12,0 & - & - & - & - & - & $3,41.10^{-2}$ & $6,04.10^{-2}$ & $9,05.10^{-2}$ \\
\hline 24,2 & $2,59.10^{-3}$ & $5,81 \cdot 10^{-3}$ & $8,07.10^{-3}$ & $1,08.10^{-2}$ & $1,66.10^{-2}$ & $1,69.10^{-2}$ & $3,00.10^{-2}$ & $4,49.10^{-2}$ \\
\hline 48,2 & $1,30.10^{-3}$ & $2,92.10^{-3}$ & $4,05.10^{-3}$ & $5,40.10^{-3}$ & $8,31.10^{-3}$ & $8,50.10^{-3}$ & $1,50.10^{-2}$ & $2,25.10^{-2}$ \\
\hline 54,6 & $1,15.10^{-3}$ & $2,57.10^{-3}$ & $3,57.10^{-3}$ & $4,77.10^{-3}$ & $7,33.10^{-3}$ & $7,50.10^{-3}$ & $1,33.10^{-2}$ & $1,99.10^{-2}$ \\
\hline 99,3 & $6,30.10^{-4}$ & $1,42.10^{-3}$ & $1,97.10^{-3}$ & $2,62.10^{-3}$ & $4,03.10^{-3}$ & $4,13.10^{-3}$ & $7,30.10^{-3}$ & $1,09.10^{-2}$ \\
\hline 124,8 & $5,01.10^{-4}$ & $1,13.10^{-3}$ & $1,56.10^{-3}$ & $2,08.10^{-3}$ & $3,21.10^{-3}$ & $3,28.10^{-3}$ & $5,81.10^{-3}$ & $8,70.10^{-3}$ \\
\hline 144,7 & $4,32.10^{-4}$ & $9,71.10^{-4}$ & $1,35.10^{-3}$ & $1,80.10^{-3}$ & $2,77.10^{-3}$ & $2,83.10^{-3}$ & $5,01.10^{-3}$ & $7,50.10^{-3}$ \\
\hline 168,8 & $3,70.10^{-4}$ & $8,32.10^{-4}$ & $1,16.10^{-3}$ & $1,54.10^{-3}$ & $2,37.10^{-3}$ & $2,43.10^{-3}$ & $4,29.10^{-3}$ & $6,43.10^{-3}$ \\
\hline 216,5 & $2,89.10^{-4}$ & $6,49.10^{-4}$ & $9,01.10^{-4}$ & $1,20.10^{-3}$ & $1,85.10^{-3}$ & $1,89.10^{-3}$ & $3,35.10^{-3}$ & $5,01.10^{-3}$ \\
\hline 239,8 & $2,61.10^{-4}$ & $5,86.10^{-4}$ & $8,14.10^{-4}$ & $1,08.10^{-3}$ & $1,67.10^{-3}$ & $1,71.10^{-3}$ & $3,02.10^{-3}$ & $4,53.10^{-3}$ \\
\hline 265,9 & $2,35.10^{-4}$ & $5,28.10^{-4}$ & $7,34.10^{-4}$ & $9,78.10^{-4}$ & $1,51.10^{-3}$ & $1,54.10^{-3}$ & $2,72.10^{-3}$ & $4,08 \cdot 10^{-3}$ \\
\hline 288,2 & $2,17.10^{-4}$ & $4,88.10^{-4}$ & $6,77.10^{-4}$ & $9,03.10^{-4}$ & $1,39.10^{-3}$ & $1,42.10^{-3}$ & $2,51.10^{-3}$ & $3,77.10^{-3}$ \\
\hline 312,2 & $2,00.10^{-4}$ & $4,50.10^{-4}$ & $6,25.10^{-4}$ & $8,33.10^{-4}$ & $1,28.10^{-3}$ & $1,31.10^{-3}$ & $2,32 \cdot 10^{-3}$ & $3,48.10^{-3}$ \\
\hline 359,9 & $1,74.10^{-4}$ & $3,90.10^{-4}$ & $5,42.10^{-4}$ & $7,23.10^{-4}$ & $1,11.10^{-3}$ & $1,14.10^{-3}$ & $2,01.10^{-3}$ & $3,02.10^{-3}$ \\
\hline
\end{tabular}


TABELA 5.11 Equações lineares obtidas por regressão de $h_{z}$ versus $\ln t$.

\begin{tabular}{ccc}
\hline Profundidade $(\mathrm{cm})$ & $\begin{array}{c}\text { Equação } \\
\text { linear }\end{array}$ & $\begin{array}{c}\text { Coeficiente de } \\
\text { correlação }\left(\mathrm{r}^{2}\right)\end{array}$ \\
\hline 10 & $\mathrm{~h}_{10}=-0,0428 \ln \mathrm{t}+4,894$ & 0,85 \\
20 & $h_{20}=-0,0625 \ln \mathrm{t}+9,7371$ & 0,87 \\
30 & $h_{30}=-0,1405 \ln \mathrm{t}+14,817$ & 0,87 \\
40 & $h_{40}=-0,1951 \ln \mathrm{t}+19,742$ & 0,89 \\
50 & $h_{50}=-0,2601 \ln \mathrm{t}+24,798$ & 0,85 \\
60 & $h_{60}=-0,4003 \ln t+30,072$ & 0,91 \\
70 & $h_{70}=-0,4095 \ln t+34,534$ & 0,90 \\
80 & $h_{80}=-0,7242 \ln t+40,359$ & 0,97 \\
90 & $h_{80}=-1,0857 \ln t+46,084$ & 0,99 \\
100 & $h_{100}=-1,4454 \ln t+51,614$ & 0,98 \\
\hline
\end{tabular}


TABELA 5.12 Valores de gradiente de potencial total $(\mathrm{cm} / \mathrm{cm})$.

\begin{tabular}{ccccccccc}
\hline Tempo & \multicolumn{7}{c}{ Profundidade (cm) } \\
\cline { 2 - 9 }$(\mathrm{h})$ & 20 & 30 & 40 & 50 & 60 & 70 & 80 & 90 \\
\hline 6,0 & - & - & - & - & - & 2,13 & 2,38 & 2,67 \\
12,0 & - & - & - & - & - & 2,14 & 2,41 & 2,68 \\
24,2 & 0,82 & 1,44 & 0,48 & 0,75 & 2,05 & 2,12 & 2,19 & 2,46 \\
48,2 & 0,75 & 1,37 & 0,75 & 0,82 & 1,78 & 2,26 & 2,67 & 2,80 \\
54,6 & 0,55 & 1,44 & 0,89 & 1,03 & 1,85 & 2,19 & 2,87 & 2,80 \\
99,3 & 0,62 & 1,50 & 0,96 & 0,96 & 1,78 & 2,26 & 2,94 & 3,08 \\
124,8 & 0,75 & 1,37 & 0,68 & 1,16 & 2,05 & 2,33 & 2,87 & 3,15 \\
144,7 & 0,75 & 1,37 & 0,82 & 1,23 & 1,85 & 2,33 & 3,21 & 2,94 \\
168,8 & 0,68 & 1,30 & 0,82 & 1,23 & 1,98 & 2,39 & 3,01 & 2,94 \\
216,5 & 0,68 & 1,37 & 0,82 & 1,30 & 2,05 & 2,46 & 3,21 & 3,08 \\
239,8 & 0,55 & 1,30 & 0,96 & 1,30 & 1,91 & 2,46 & 3,35 & 3,35 \\
265,9 & 0,62 & 1,23 & 0,82 & 1,44 & 2,19 & 2,53 & 3,28 & 3,21 \\
288,2 & 0,55 & 1,23 & 0,82 & 1,44 & 1,98 & 2,53 & 3,56 & 3,49 \\
312,2 & 0,75 & 1,23 & 0,89 & 1,50 & 1,98 & 2,60 & 3,49 & 3,56 \\
359,9 & 0,62 & 1,30 & 0,89 & 1,37 & 2,05 & 2,67 & 3,69 & 3,90 \\
\hline
\end{tabular}



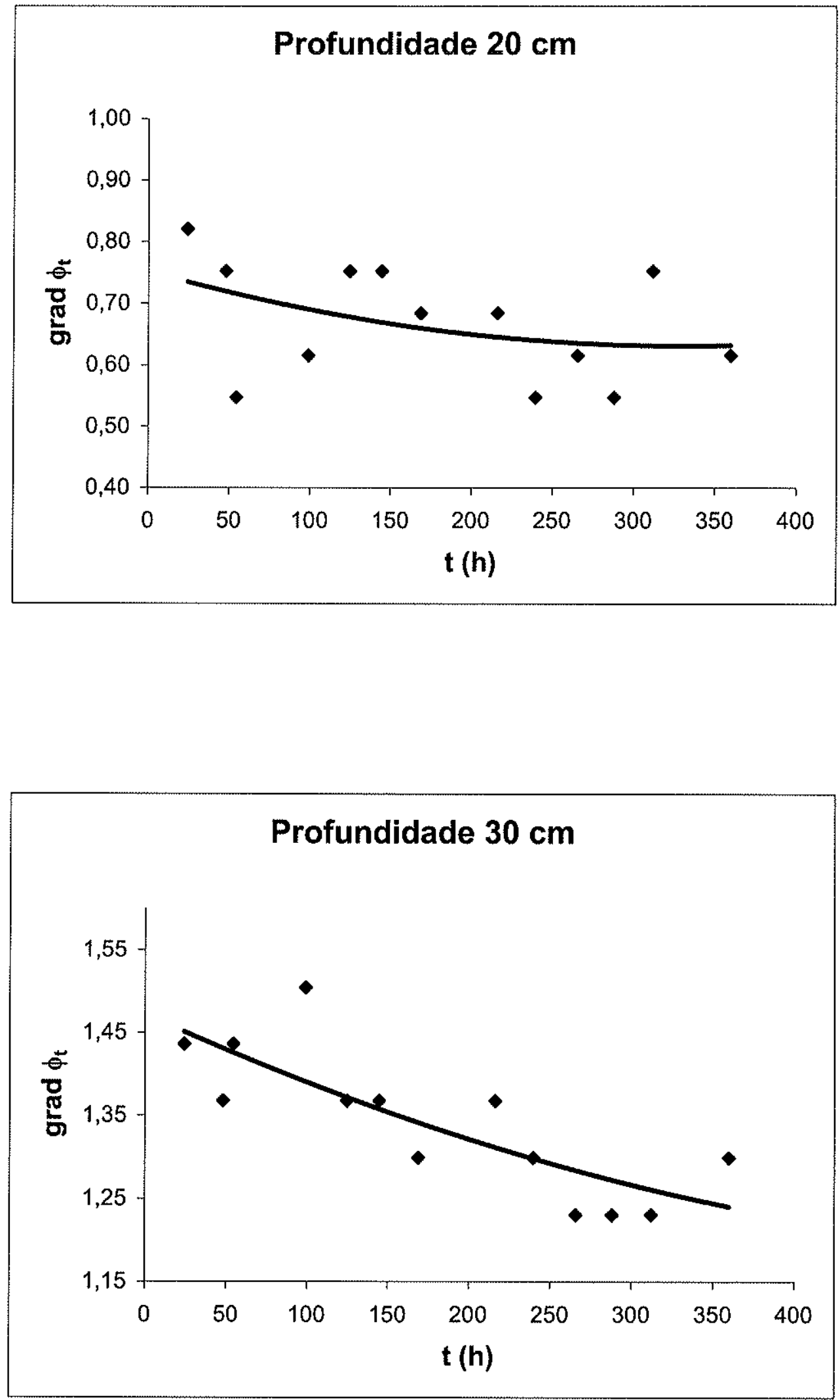

Figura 5.24 Gráficos de gradiente de potencial total (grad $\phi_{t}$ ) pelo tempo de redistribuição $(t)$, para as profundidades de 20 e $30 \mathrm{~cm}$, com dados obtidos pela curva de retenção. 

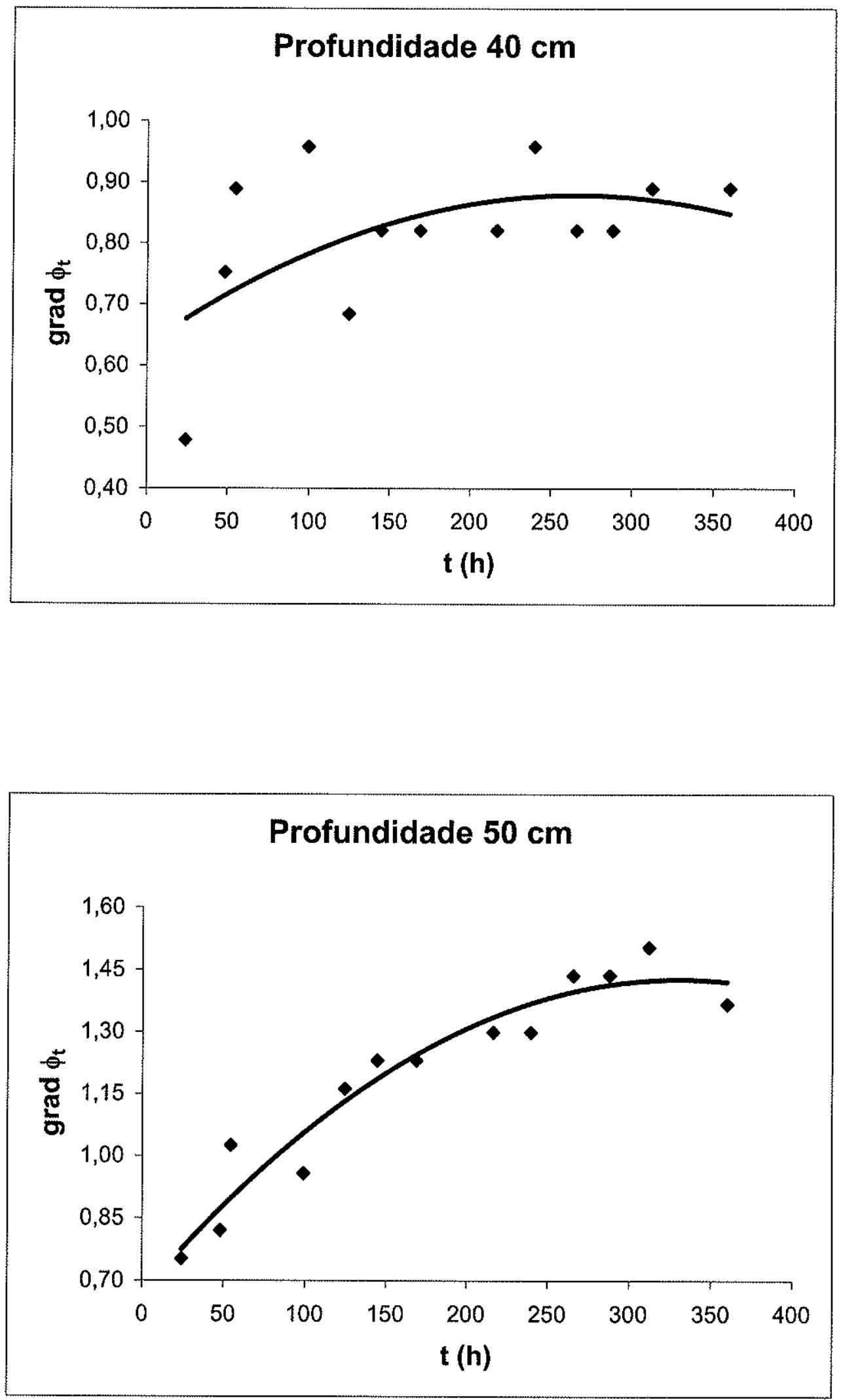

Figura 5.25 Gráficos de gradiente de potencial total (grad $\phi_{t}$ ) pelo tempo de redistribuição $(t)$, para as profundidades de 40 e $50 \mathrm{~cm}$, com dados obtidos pela curva de retenção. 

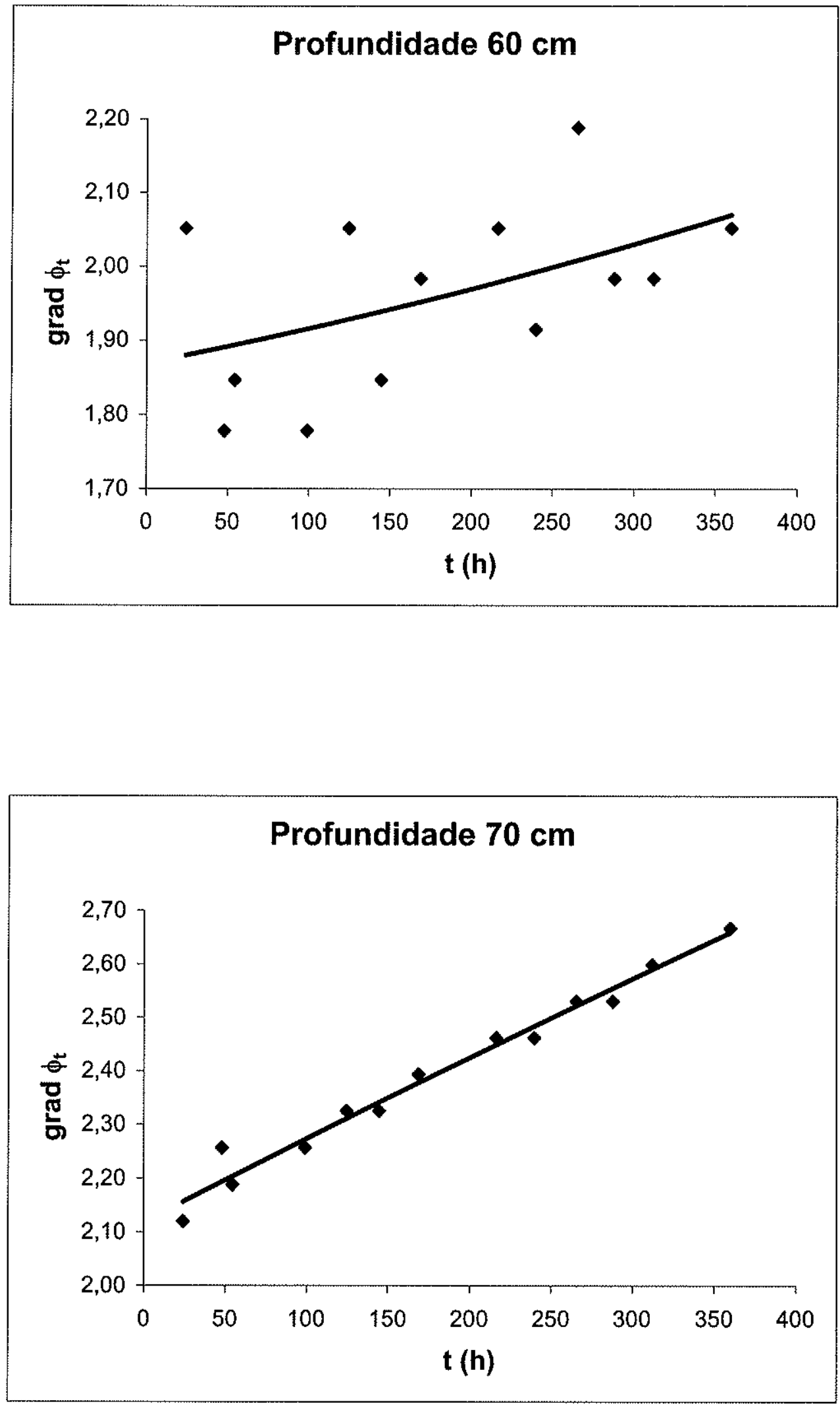

Figura 5.26 Gráficos de gradiente de potencial total (grad $\phi_{t}$ ) pelo tempo de redistribuição $(t)$, para as profundidades de 60 e $70 \mathrm{~cm}$, com dados obtidos pela curva de retenção. 

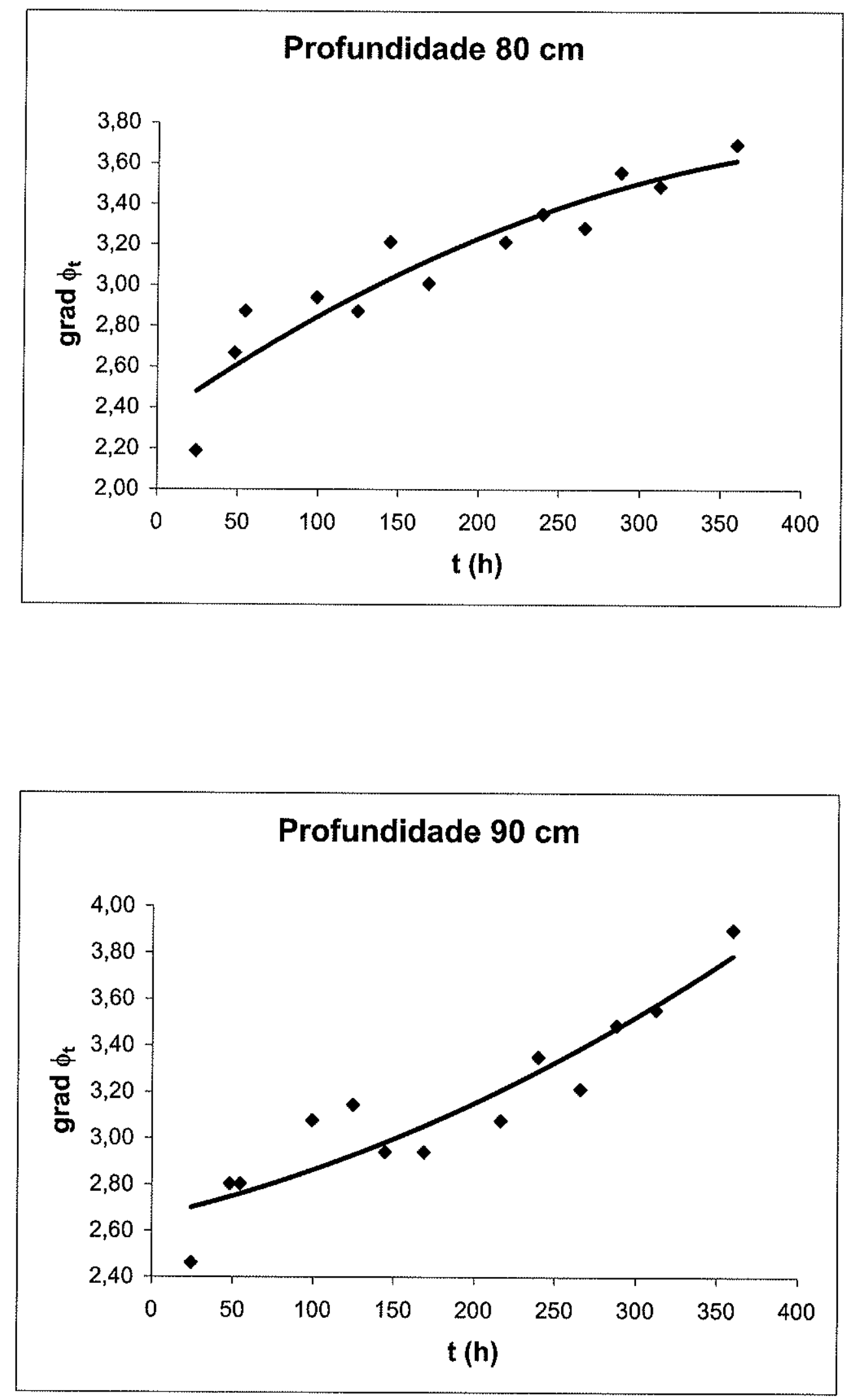

Figura 5.27 Gráficos de gradiente de potencial total ( $g r a d \phi_{t}$ ) pelo tempo de redistribuição $(t)$, para as profundidades de 80 e $90 \mathrm{~cm}$, com dados obtidos pela curva de retenção. 
TABELA 5.13 Equações polinomiais obtidas por regressão do gradiente de potencial total $\left(\operatorname{grad} \phi_{t}\right)$ versus tempo $(t)$

\begin{tabular}{ccc}
\hline Profundidade $(\mathrm{cm})$ & $\begin{array}{c}\text { Equação } \\
\text { polinomial }\end{array}$ & $\begin{array}{c}\text { Coeficiente de } \\
\text { correlação }\left(r^{2}\right)\end{array}$ \\
\hline 20 & $\operatorname{grad} \phi_{\mathrm{t}}=1.10^{-6} \mathrm{t}^{2}-0,0007 \mathrm{t}+0,7519$ & 0,15 \\
30 & $\operatorname{grad} \phi_{\mathrm{t}}=7.10^{-7} \mathrm{t}^{2}-0,0009 t+1,4721$ & 0,65 \\
40 & $\operatorname{grad} \phi_{\mathrm{t}}=-3.10^{-6} \mathrm{t}^{2}+0,0018 \mathrm{t}+0,6333$ & 0,31 \\
50 & $\operatorname{grad} \phi_{\mathrm{t}}=-7.10^{-6} \mathrm{t}^{2}+0,0046 \mathrm{t}+0,6677$ & 0,93 \\
60 & $\operatorname{grad} \phi_{\mathrm{t}}=3.10^{-7} \mathrm{t}^{2}+0,0004 \mathrm{t}+1,869$ & 0,25 \\
70 & $\operatorname{grad} \phi_{\mathrm{t}}=-2.10^{-7} \mathrm{t}^{2}+0,0016 \mathrm{t}+2,1191$ & 0,98 \\
80 & $\operatorname{grad} \phi_{\mathrm{t}}=-6.10^{-6} \mathrm{t}^{2}+0,0055 \mathrm{t}+2,348$ & 0,88 \\
90 & $\operatorname{grad} \phi_{\mathrm{t}}=4.10^{-6} \mathrm{t}^{2}+0,0016 \mathrm{t}+2,659$ & 0,86
\end{tabular}


TABELA 5.14 Condutividade hidráulica $(\mathrm{cm} / \mathrm{h})$ calculada com dados obtidos pela curva de retenção, para cada profundidade ao longo do tempo de drenagem interna do perfil.

\begin{tabular}{|c|c|c|c|c|c|c|c|c|}
\hline \multirow{2}{*}{$\begin{array}{c}\text { Tempo } \\
\text { (h) }\end{array}$} & \multicolumn{8}{|c|}{ Profundidade $(\mathrm{cm})$} \\
\hline & 20 & 30 & 40 & 50 & 60 & 70 & 80 & 90 \\
\hline 6 , & 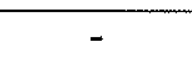 & 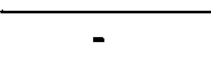 & $\begin{array}{l}- \\
-\end{array}$ & 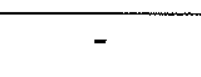 & - & $3,21.10^{-2}$ & $5,07.10^{-2}$ & $6,78.10^{-2}$ \\
\hline 12,0 & - & - & - & - & - & $1,60.10^{-2}$ & $2,50.10^{-2}$ & $3,38.10^{-2}$ \\
\hline 24,2 & $3,15.10^{-3}$ & $4,05.10^{-3}$ & $1,69.10^{-2}$ & $1,43.10^{-2}$ & $8,07.10^{-3}$ & $7,99.10^{-3}$ & $1,37.10^{-2}$ & $1,82.10^{-2}$ \\
\hline 48,2 & $1,72.10^{-3}$ & $2,13.10^{-3}$ & $5,38 \cdot 10^{-3}$ & $6,58.10^{-3}$ & $4,67.10^{-3}$ & $3,77.10^{-3}$ & $5,64.10^{-3}$ & $8,04.10^{-3}$ \\
\hline 54,6 & $2,09.10^{-3}$ & $1,79.10^{-3}$ & $4,02 \cdot 10^{-3}$ & $4,65.10^{-3}$ & $3,97.10^{-3}$ & $3,43.10^{-3}$ & $4,62.10^{-3}$ & $7,09.10^{-3}$ \\
\hline 99,3 & $1,02.10^{-3}$ & $9,41.10^{-4}$ & $2,05.10^{-3}$ & $2,74.10^{-3}$ & $2,27.10^{-3}$ & $1,83.10^{-3}$ & $2,48.10^{-3}$ & $3,55.10^{-3}$ \\
\hline 124,8 & $6,66.10^{-4}$ & $8,23.10^{-4}$ & $2,29.10^{-3}$ & $1,79.10^{-3}$ & $1,56.10^{-3}$ & $1,41.10^{-3}$ & $2,02.10^{-3}$ & $2,77.10^{-3}$ \\
\hline 144,7 & $5,74.10^{-4}$ & $7,10.10^{-4}$ & $1,64.10^{-3}$ & $1,46.10^{-3}$ & $1,50.10^{-3}$ & $1,22.10^{-3}$ & $1,56.10^{-3}$ & $2,55.10^{-3}$ \\
\hline 168,8 & & & & & & $1,01.10^{-3}$ & $1,43.10^{-3}$ & $2,19.10^{-3}$ \\
\hline 216,5 & $4,22.10^{-4}$ & $6,74.10^{-4}$ & $1,10.10^{-3}$ & $9,25.10^{-4}$ & $9,01.10^{-4}$ & $7,68.10^{-4}$ & $1,04.10^{-3}$ & $1,63.10^{-3}$ \\
\hline 239,8 & $4,77.10^{-4}$ & $4,51.10^{-4}$ & $8,50.10^{-4}$ & $8,35.10^{-4}$ & $8,72.10^{-4}$ & $6,94 \cdot 10^{-4}$ & $9,01.10^{-4}$ & $1,35.10^{-3}$ \\
\hline 265,9 & $3,82.10^{-4}$ & $4,29.10^{-4}$ & $8,94.10^{-4}$ & $6,81.10^{-4}$ & $6,88.10^{-4}$ & $6,09.10^{-4}$ & $8,30.10^{-4}$ & $1,27.10^{-3}$ \\
\hline 288,2 & $3,96.10^{-4}$ & $3,96.10^{-4}$ & $8,25.10^{-4}$ & $6,29.10^{-4}$ & $7,00.10^{-4}$ & $5,62.10^{-4}$ & $7,07.10^{-4}$ & $1,08.10^{-3}$ \\
\hline 312 & $2,66.10^{-4}$ & $3,66.10^{-4}$ & $7,03.10^{-4}$ & $5,54.10^{-4}$ & $6,47.10^{-4}$ & $5,05.10^{-4}$ & $6,65.10^{-4}$ & $9,78.10^{-4}$ \\
\hline 359,9 & $2,82 \cdot 10^{-4}$ & $3,00.10^{-4}$ & $6,10.10^{-4}$ & $5,28.10^{-4}$ & $5,42 \cdot 10^{-4}$ & $4,27.10^{-4}$ & $5,45 \cdot 10^{-4}$ & $7,74.10^{-4}$ \\
\hline
\end{tabular}


$(0,69)$. Os gráficos e as equações com os coeficientes de correlação encontram-se respectivamente nas Figuras 5.28, 5.29, 5.30 e 5.31, e na Tabela 5.15.

Após a determinação de $K(\theta)$, calculou-se a condutividade hidráulica "saturada" $\left(K_{0}\right)$ através da aplicação da equação potencial ajustada para a reta, em cada profundidade, que estão listadas na Tabela 5.15. Os valores de $K_{0}$ foram obtidos, considerando-se o $\theta$ da equação 10 como $\theta_{0}$, ou seja, o valor de umidade no tempo considerado o início da redistribuição, no caso 24 horas, para as profundidades de 0,20 a $0,60 \mathrm{~m}$, e de 6 horas para as camadas mais profundas $(0,60$ a $1,0 \mathrm{~m})$. Esses valores encontram-se na Tabela 5.16 .

Com os valores de $K_{0}$ pode-se calcular a condutividade hidráulica relativa $(K r)$, dividindo-se a condutividade hidráulica obtida experimentalmente pela curva de retenção por $K_{0}$. Foram obtidos os valores mostrados na Tabela 5.17.

\subsubsection{Sonda de nêutrons}

A condutividade hidráulica foi determinada pelo mesmo procedimento utilizado para a curva de retenção, entretanto utilizou-se dados de umidade fornecidos pela sonda de nêutrons.

Nos gráficos de $h_{z}$ versus In $t$ (Figuras 5.32, 5.33, 5.34, 5.35 e 5.36) obteve-se coeficientes de correlação melhores (Tabela 5.18) em relação aos gráficos de $\theta \times \ln$ $t$ para as profundidades de $20,30,40$ e $50 \mathrm{~cm}$, apresentando coeficientes mais baixos para as demais camadas $(60,70,80,90$ e $100 \mathrm{~cm})$ em relação aos apresentados para $\theta \times \ln t$. Estes resultados mostram a influência da maior variação temporal nas profundidades menores que nas profundidades maiores no cálculo da armazenagem pela umidade média.

O fluxo de água calculado para cada profundidade e para cada tempo de redistribuição é mostrado na Tabela 5.19. Utilizou-se para este cálculo as equações de regressão de $h_{z}$ versus in $t$ (Tabela 5.18). 

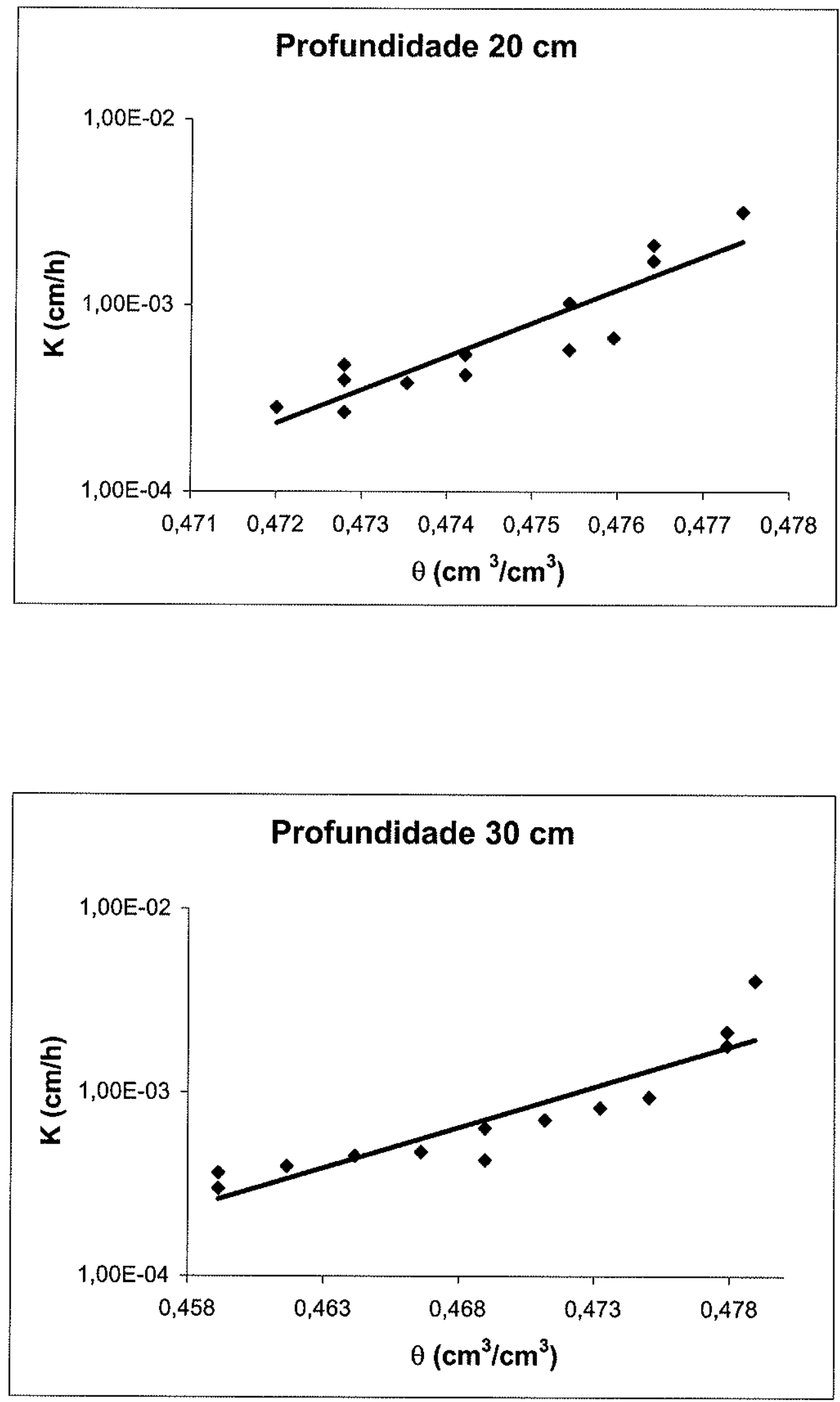

Figura 5.28 Gráficos de condutividade hidráulica $(K)$ pela umidade $(\theta)$, para as profundidades de 20 e $30 \mathrm{~cm}$, com dados obtidos pela curva de retenção. 

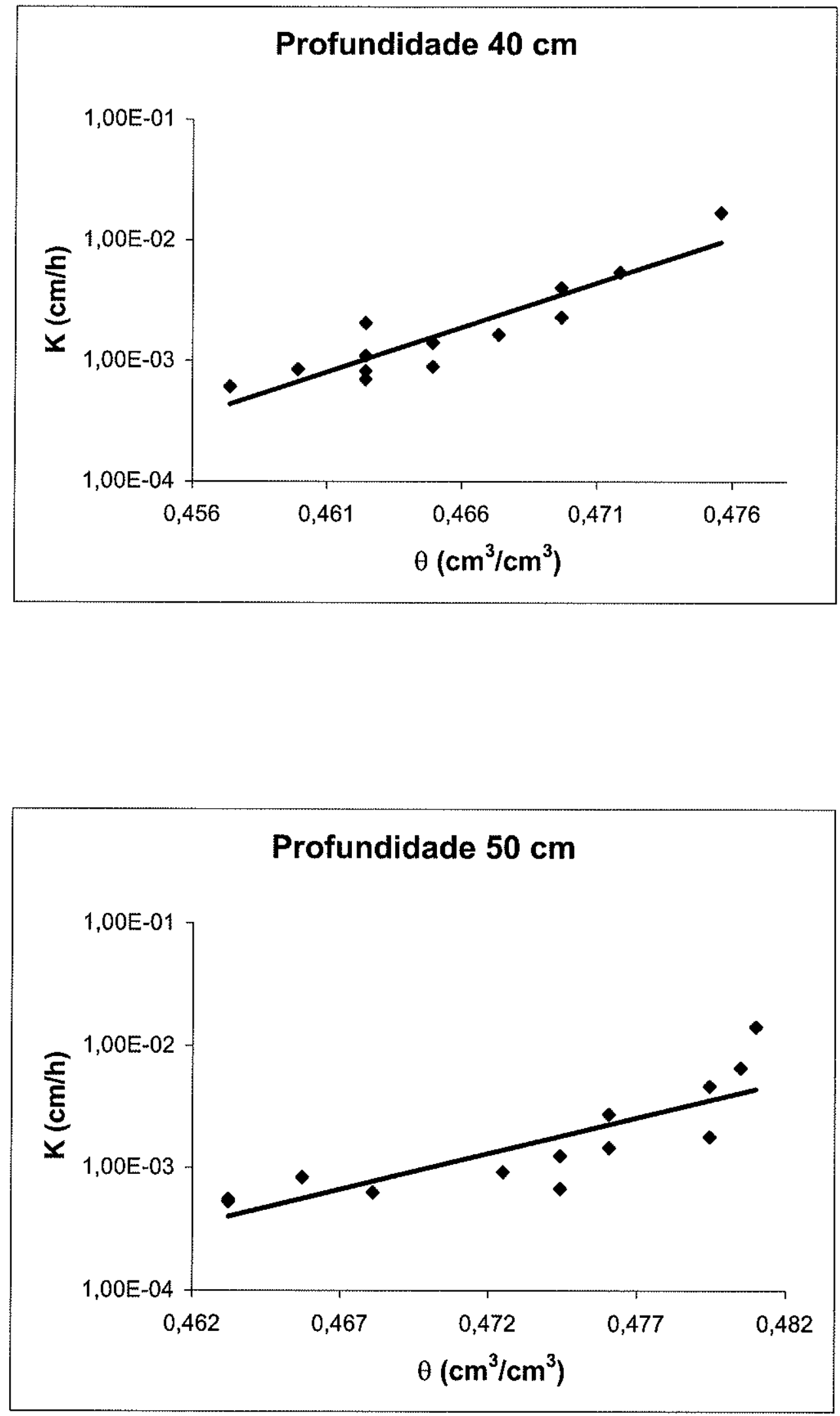

Figura 5.29 Gráficos de condutividade hidráulica $(K)$ pela umidade $(\theta)$, para as profundidades de 40 e $50 \mathrm{~cm}$, com dados obtidos pela curva de retenção. 

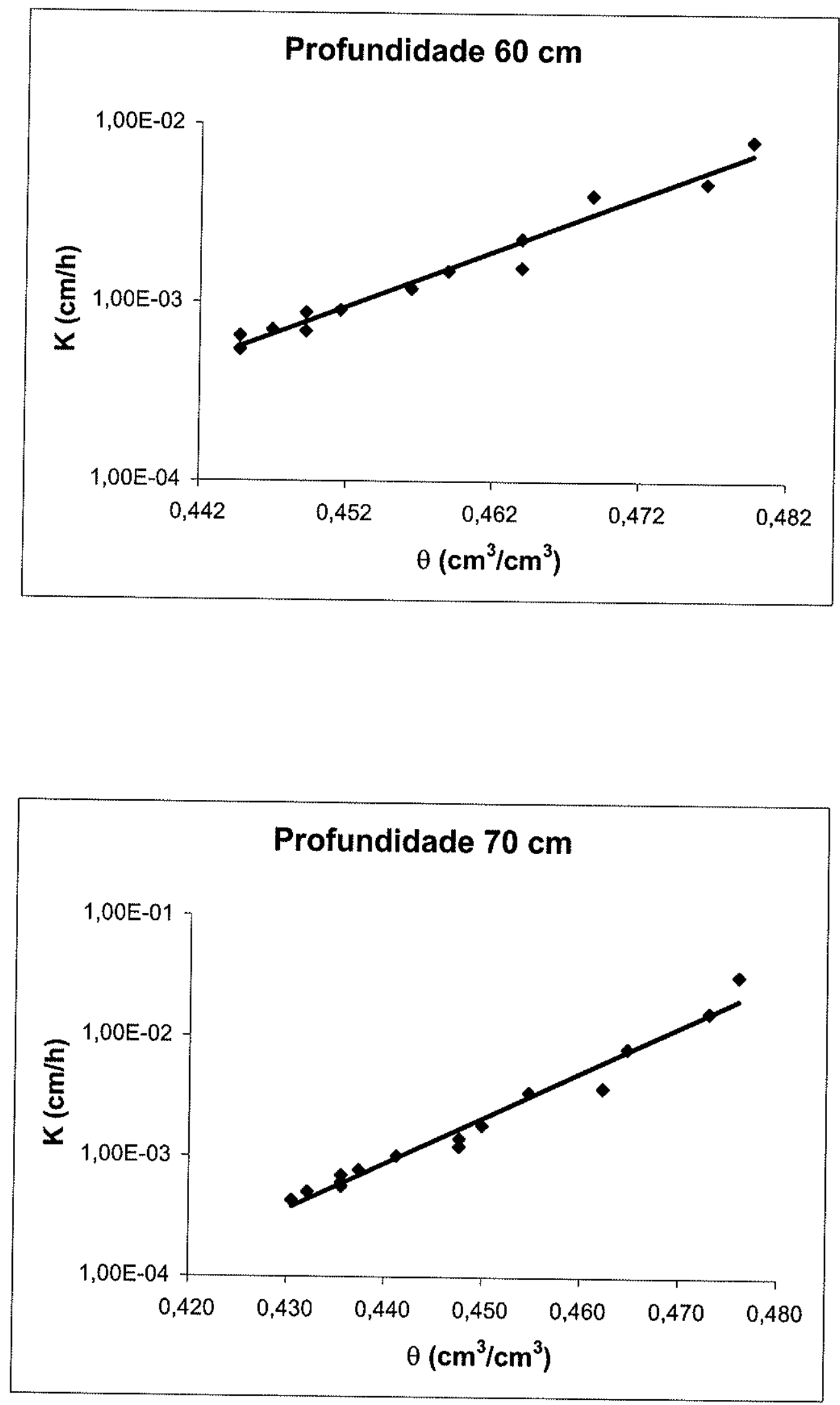

Figura 5.30 Gráficos de condutividade hidráulica $(K)$ pela umidade $(\theta)$, para as profundidades de 60 e $70 \mathrm{~cm}$, com dados obtidos pela curva de retenção. 

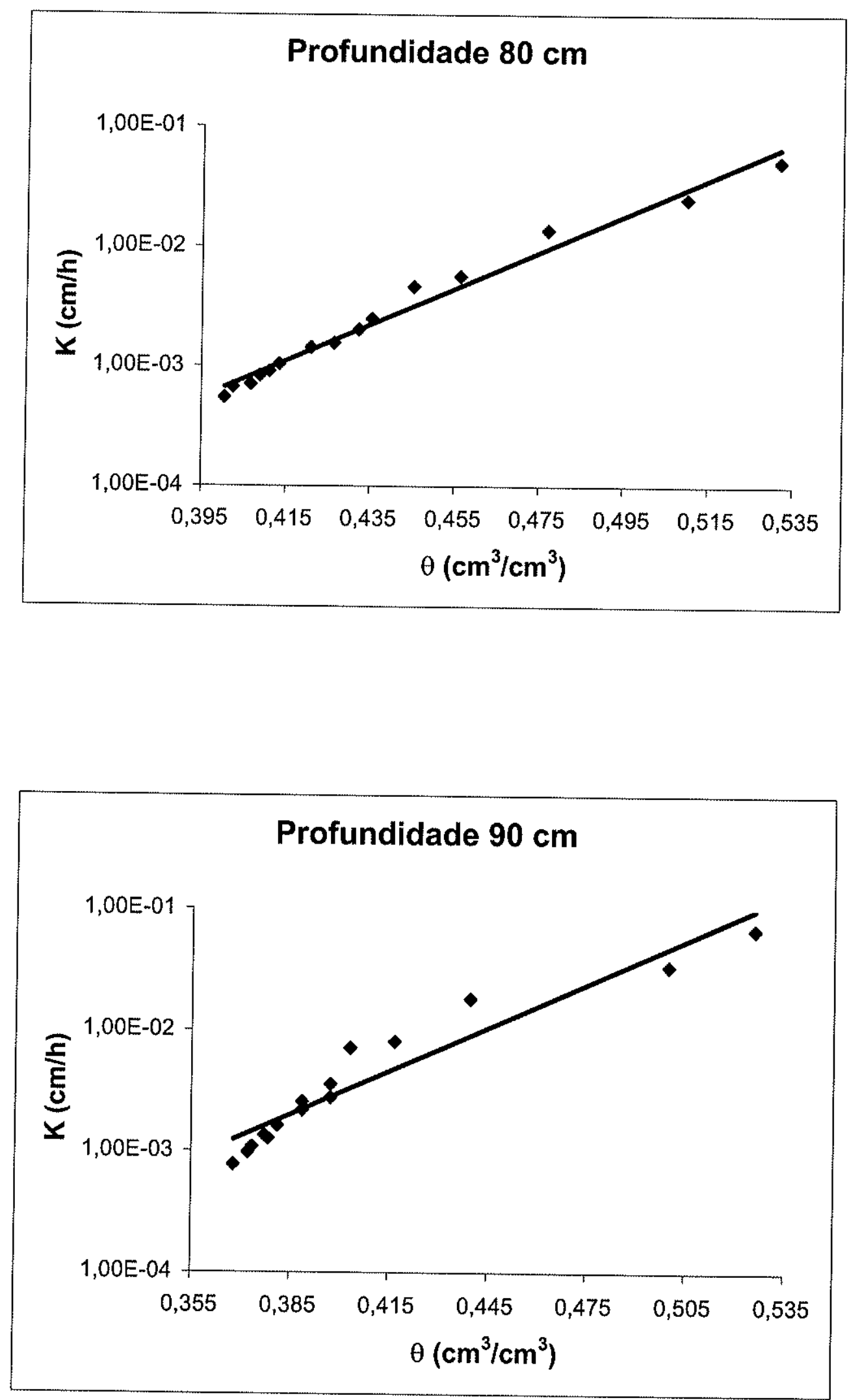

Figura 5.31 Gráficos de condutividade hidráulica $(K)$ pela umidade $(\theta)$, para as profundidades de 80 e $90 \mathrm{~cm}$, com dados obtidos pela curva de retenção. 
TABELA 5.15 Equações potenciais obtidas por regressão dos valores de condutividade hidráulica versus umidade.

\begin{tabular}{ccc}
\hline Profundidade $(\mathrm{cm})$ & $\begin{array}{c}\text { Equação } \\
\text { potencial }\end{array}$ & $\begin{array}{c}\text { Coeficiente de } \\
\text { correlação }\left(r^{2}\right)\end{array}$ \\
\hline 20 & $\mathrm{~K}(\theta)=2 \cdot 10^{-88} \cdot \mathrm{e}^{410,65 \theta}$ & 0,82 \\
30 & $\mathrm{~K}(\theta)=2 \cdot 10^{-24} \cdot \mathrm{e}^{101,06 \theta}$ & 0,83 \\
40 & $\mathrm{~K}(\theta)=9 \cdot 10^{-38} \cdot \mathrm{e}^{169,71 \theta}$ & 0,83 \\
50 & $\mathrm{~K}(\theta)=3 \cdot 10^{-31} \cdot \mathrm{e}^{134,74 \theta}$ & 0,69 \\
60 & $\mathrm{~K}(\theta)=1 \cdot 10^{-17} \cdot \mathrm{e}^{71,157 \theta}$ & 0,97 \\
70 & $\mathrm{~K}(\theta)=2 \cdot 10^{-20} \cdot \mathrm{e}^{87,494 \theta}$ & 0,97 \\
80 & $\mathrm{~K}(\theta)=6 \cdot 10^{-10} \cdot \mathrm{e}^{34,921 \theta}$ & 0,98 \\
90 & $\mathrm{~K}(\theta)=5 \cdot 10^{-8} \cdot \mathrm{e}^{27,638 \theta}$ & 0,91 \\
\hline
\end{tabular}


TABELA 5.16 Valores de condutividade hidráulica saturada $\left(K_{0}\right)$, calculada pelo procedimento da curva de retenção, para cada profundidade ao longo do tempo de redistribuição.

\begin{tabular}{cc}
\hline Profundidade $(\mathrm{cm})$ & $\mathrm{K}_{0}$ \\
\hline 20 & $2,35 \cdot 10^{-3}$ \\
30 & $2,11.10^{-3}$ \\
40 & $1,09 \cdot 10^{-2}$ \\
50 & $4,20 \cdot 10^{-3}$ \\
60 & $6,82 \cdot 10^{-3}$ \\
70 & $2,44 \cdot 10^{-2}$ \\
80 & $7,02 \cdot 10^{-2}$ \\
90 & $1,03 \cdot 10^{-1}$ \\
\hline
\end{tabular}


TABELA 5.17 Valores de condutividade hidráulica relativa experimental ( $K r$ Exp) obtidos pelo procedimento da curva de retenção da água no solo.

\begin{tabular}{ccccccccc}
\hline $\begin{array}{c}\text { Tempo } \\
\text { (h) }\end{array}$ & \multicolumn{7}{c}{ Profundidade $(\mathrm{cm})$} \\
\cline { 2 - 9 } & 20 & 30 & 40 & 50 & 60 & 70 & 80 & 90 \\
\hline 24,2 & 1,3424 & 1,9188 & 1,5473 & 3,4029 & 1,1847 & 0,3270 & 0,1950 & 0,1773 \\
48,2 & 0,7347 & 1,0109 & 0,4940 & 1,5651 & 0,6858 & 0,1541 & 0,0803 & 0,0781 \\
54,6 & 0,8915 & 0,8496 & 0,3689 & 1,1049 & 0,5828 & 0,1403 & 0,0658 & 0,0689 \\
99,3 & 0,4358 & 0,4460 & 0,1884 & 0,6510 & 0,3328 & 0,0748 & 0,0353 & 0,0345 \\
124,8 & 0,2837 & 0,3903 & 0,2098 & 0,4266 & 0,2295 & 0,0578 & 0,0288 & 0,0269 \\
144,7 & 0,2446 & 0,3366 & 0,1508 & 0,3474 & 0,2199 & 0,0498 & 0,0222 & 0,0248 \\
168,8 & 0,2306 & 0,3036 & 0,1292 & 0,2977 & 0,1754 & 0,0415 & 0,0203 & 0,0212 \\
216,5 & 0,1798 & 0,2249 & 0,1008 & 0,2199 & 0,1322 & 0,0314 & 0,0148 & 0,0158 \\
239,8 & 0,2030 & 0,2138 & 0,0780 & 0,1986 & 0,1279 & 0,0284 & 0,0128 & 0,0131 \\
265,9 & 0,1627 & 0,2034 & 0,0820 & 0,1620 & 0,1009 & 0,0249 & 0,0118 & 0,0123 \\
288,2 & 0,1689 & 0,1877 & 0,0757 & 0,1495 & 0,1028 & 0,0230 & 0,0101 & 0,0105 \\
312,2 & 0,1134 & 0,1733 & 0,0645 & 0,1317 & 0,0949 & 0,0207 & 0,0095 & 0,0095 \\
359,9 & 0,1202 & 0,1424 & 0,0559 & 0,1257 & 0,0796 & 0,0175 & 0,0078 & 0,0075 \\
\hline
\end{tabular}



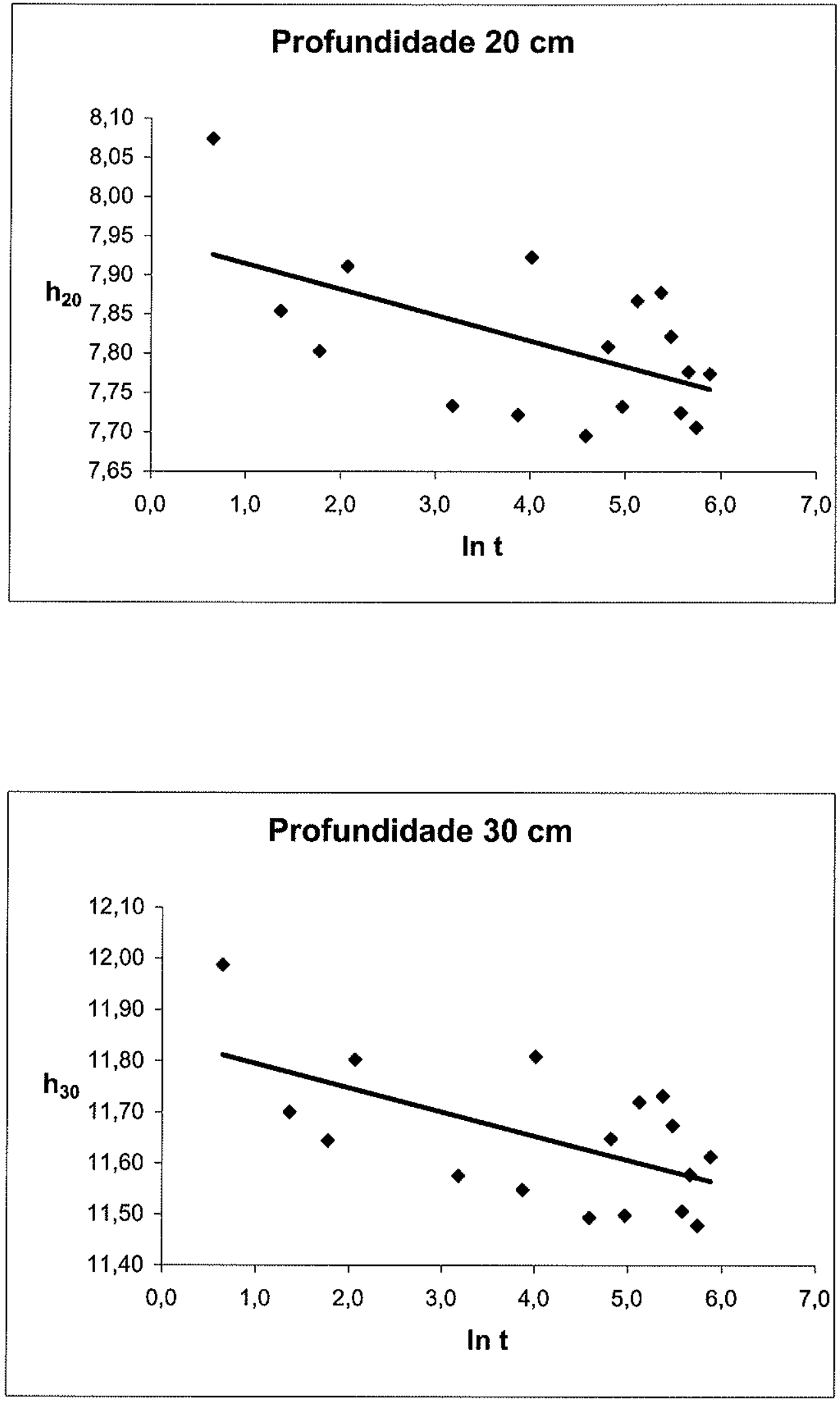

Figura 5.32 Gráficos de armazenagem $\left(h_{z}\right)$ por $\ln t$, para as profundidades de 20 e $30 \mathrm{~cm}$, com dados obtidos da sonda de nêutrons. 

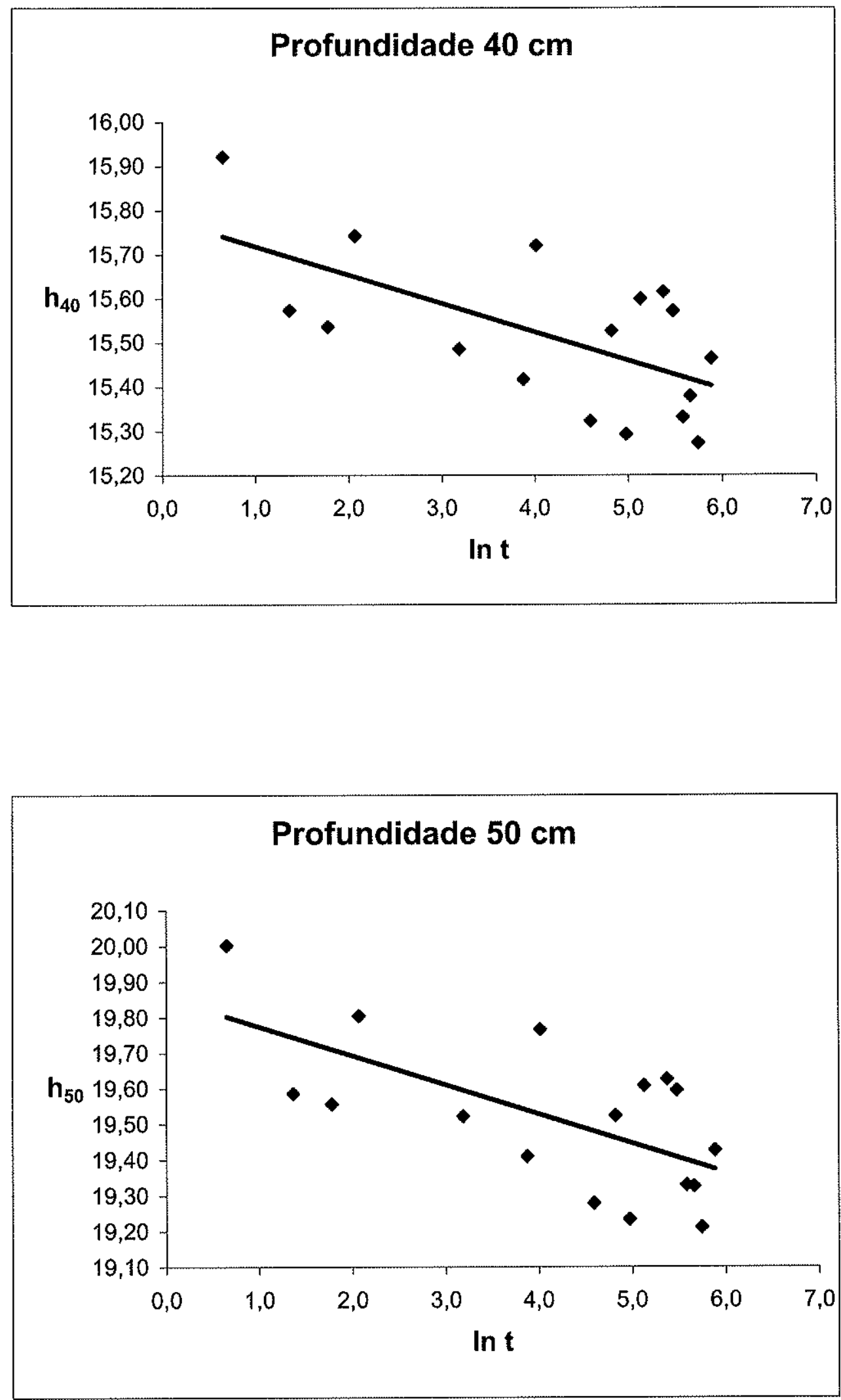

Figura 5.33 Gráficos de armazenagem $\left(h_{z}\right)$ por $\ln t$, para as profundidades de 40 e $50 \mathrm{~cm}$, com dados obtidos da sonda de nêutrons. 

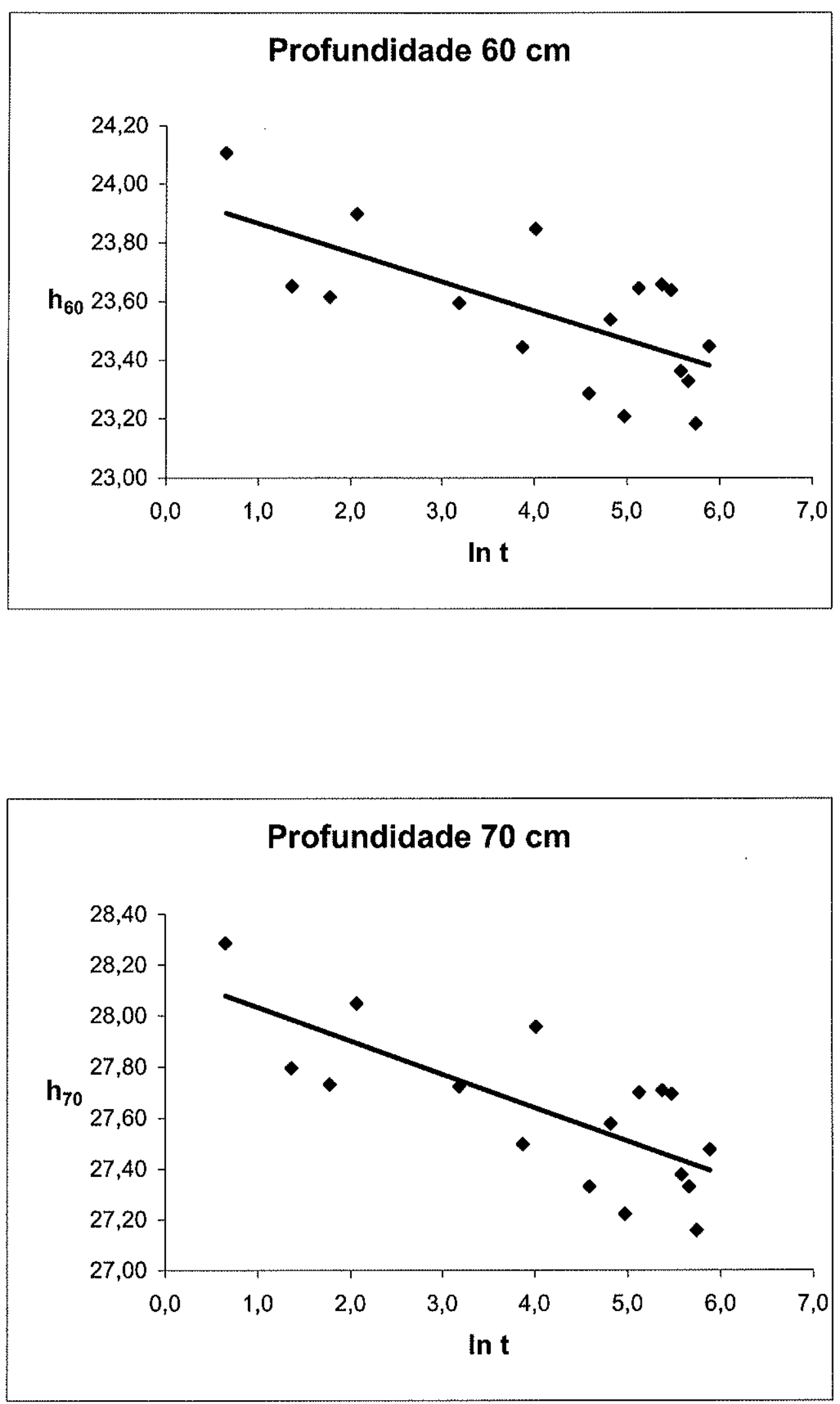

Figura 5.34 Gráficos de armazenagem $\left(h_{z}\right)$ por $\ln t$, para as profundidades de $60 \mathrm{e}$ $70 \mathrm{~cm}$, com dados obtidos da sonda de nêutrons. 

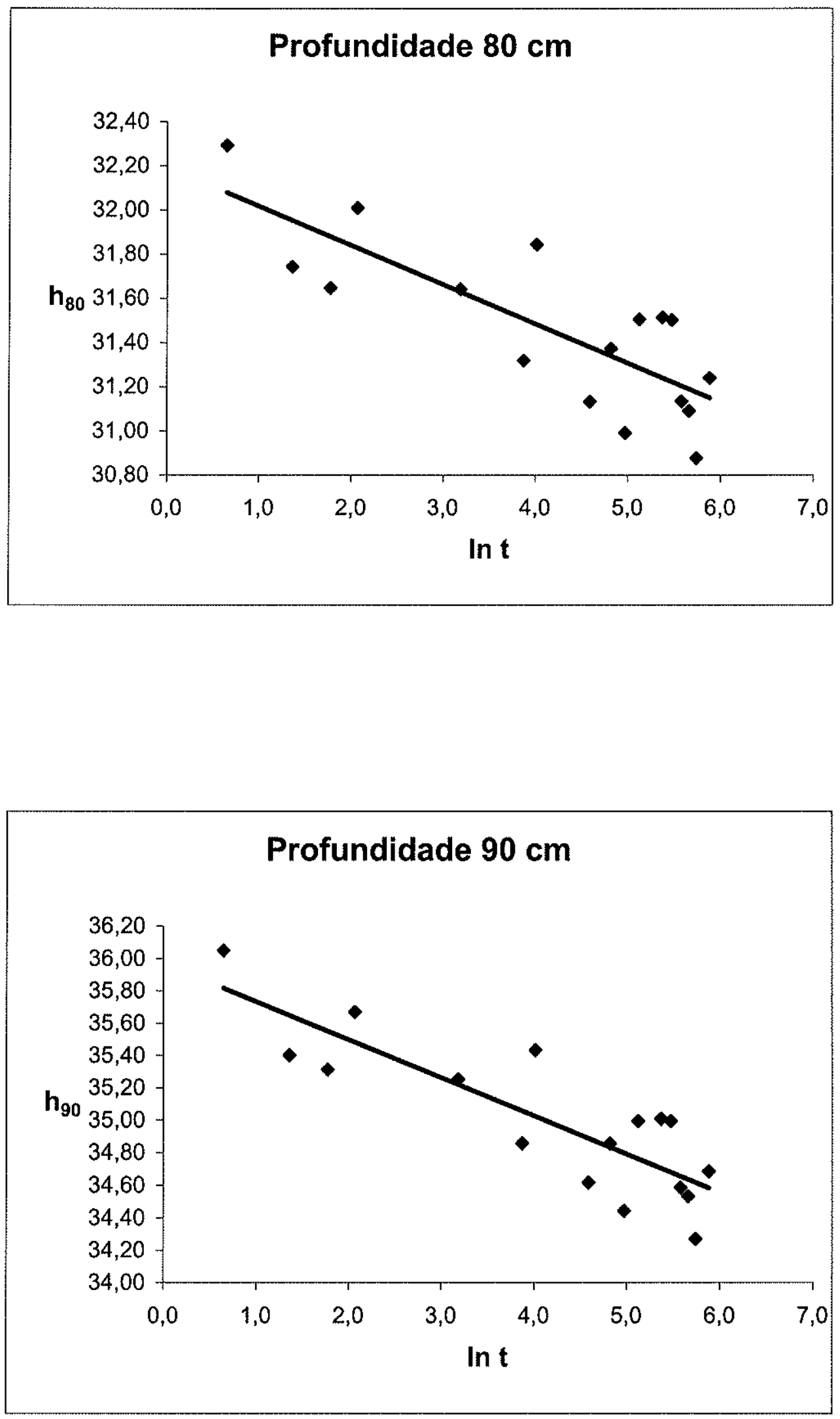

Figura 5.35 Gráficos de armazenagem $\left(h_{z}\right)$ por $\ln t$, para as profundidades de $80 \mathrm{e}$ $90 \mathrm{~cm}$, com dados obtidos da sonda de nêutrons. 


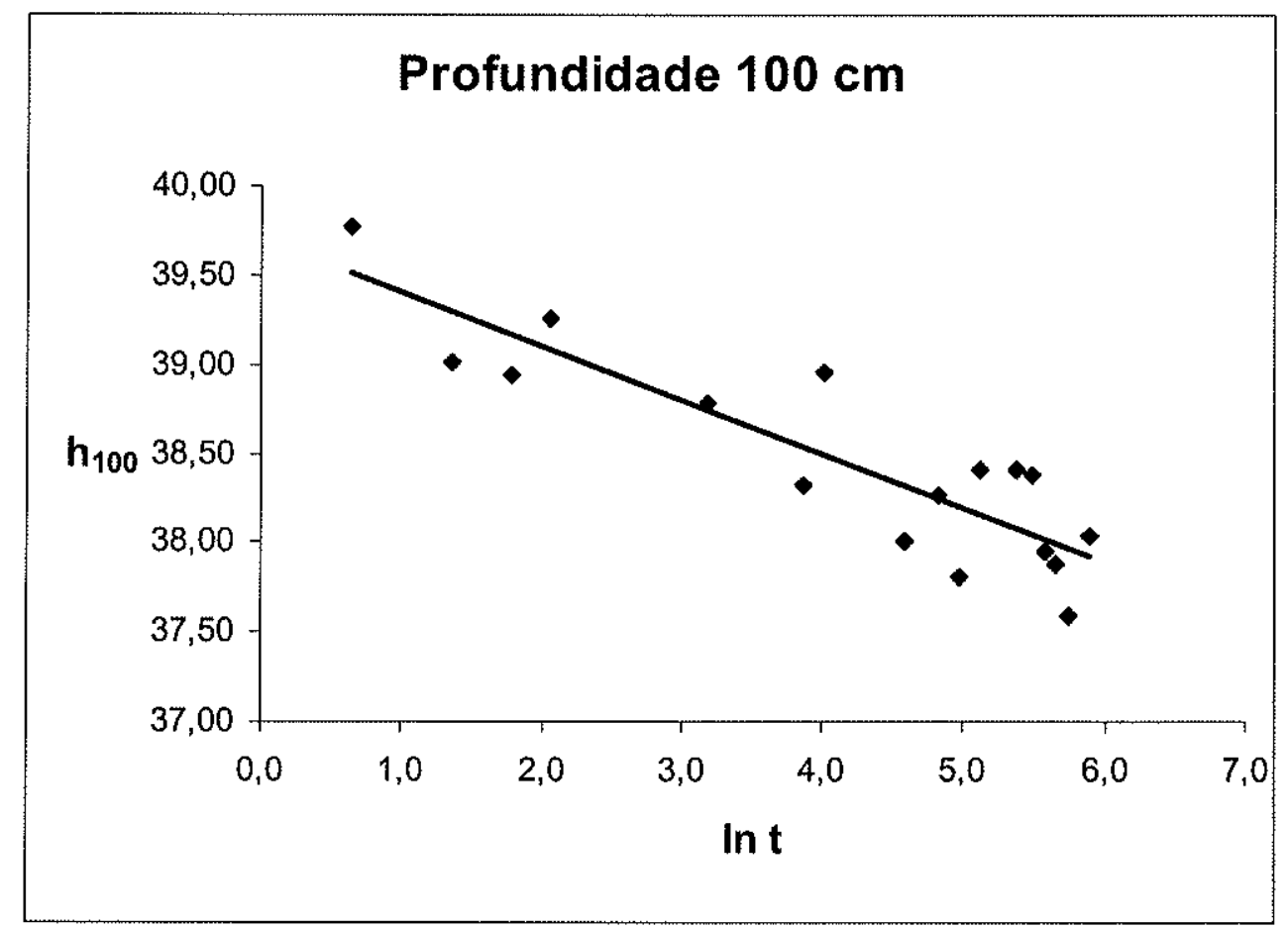

Figura 5.36 Gráfico de armazenagem $\left(h_{z}\right)$ por $I n t$, para a profundidade de $100 \mathrm{~cm}$, com dados obtidos pela sonda de nêutrons. 
TABELA 5.18 Equações lineares obtidas por regressão da armazenagem $\left(h_{z}\right)$ versus In t para a sonda de nêutrons.

\begin{tabular}{ccc}
\hline Profundidade $(\mathrm{cm})$ & $\begin{array}{c}\text { Equação } \\
\text { Linear }\end{array}$ & $\begin{array}{c}\text { Coeficiente de correlação }\left(\mathrm{r}^{2}\right) \\
\end{array}$ \\
\hline 20 & $h_{20}=-0,0327 \ln \mathrm{t}+7,947$ & 0,32 \\
30 & $h_{30}=-0,0472 \ln \mathrm{t}+11,843$ & 0,35 \\
40 & $h_{40}=-0,0647 \ln \mathrm{t}+15,783$ & 0,39 \\
50 & $h_{50}=-0,0818 \ln \mathrm{t}+19,856$ & 0,42 \\
60 & $h_{60}=-0,0991 \ln \mathrm{t}+23,965$ & 0,46 \\
70 & $h_{70}=-0,1305 \ln \mathrm{t}+28,163$ & 0,55 \\
80 & $h_{80}=-0,1773 \ln \mathrm{t}+32,194$ & 0,64 \\
90 & $h_{90}=-0,2353 \ln \mathrm{t}+35,97$ & 0,72 \\
100 & $h_{100}=-0,3039 \ln \mathrm{t}+39,709$ & 0,78 \\
\hline
\end{tabular}


$K(\theta)$ foi calculado, dividindo-se os valores do fluxo (Tabela 5.19) pelo gradiente de potencial (Tabela 5.12), e cujos valores podem ser encontrados na Tabela 5.20, as equações com os respectivos coeficientes de correlação na Tabela 5.21 , e os gráficos $K(\theta) \times \theta$ nas Figuras $5.37,5.38,5.39$ e 5.40 . Os valores de correlação foram muito baixos para as profundidades de $20,30,40,50$ e $60 \mathrm{~cm}$, variando de 0,08 a 0,32 , uma vez que a umidade medida pela sonda também variou muito pouco nessas camadas. Para as demais profundidades, 70,80 e $90 \mathrm{~cm}$, os coeficientes apresentaram-se mais elevados, ficando entre 0,70 e 0,80 . Em comparação com os valores obtidos a partir dos tensiômetros (Tabela 5.14), as equações de $K$ versus $\theta$ com a sonda de nêutrons apresentou coeficientes de correlação muito menores, notadamente até a profundidade de $60 \mathrm{~cm}$, no qual a variação de umidade com o tempo detectada pela sonda de nêutrons foi muito pequena. Este fato mostra a menor sensibilidade da sonda em relação ao tensiômetro para medir a variação da umidade nesse tipo de solo.

\subsection{Modelo de van Genuchten (1980)}

Baseado na teoria descrita no item 4.5, calculou-se a condutividade hidráulica relativa (Tabela 5.23), utilizando-se a equação 15 , a partir dos dados de potencial mátrico (Tabela 5.2), umidade (Tabela 5.4) e a saturação efetiva (Tabela 5.22). Com esses dados, e empregando-se a equação 13 , estimou-se a condutividade hidráulica pelo modelo de van Genuchten (Tabela 5.24).

Pelos valores de saturação efetiva calculados (Tabela 5.22 ) em relação ao tensiômetro, pode-se observar que as primeiras camadas $(20,30,40,50,60$ e 70 $\mathrm{cm}$ ) apresentam valores bem próximos à saturação, nas primeiras horas de redistribuição.

Os valores de condutividade hidráulica relativa (Tabela 5.23) também confirmam a maior saturação nas primeiras camadas, sendo que os valores chegam próximo a zero a partir de $60 \mathrm{~cm}$. 
TABELA 5.19 Fluxos calculados $(\mathrm{cm} / \mathrm{h}$ ) para cada profundidade ao longo do tempo de drenagem interna do perfil, com dados obtidos pela sonda de nêutrons.

\begin{tabular}{|c|c|c|c|c|c|c|c|c|c|}
\hline \multirow{2}{*}{$\begin{array}{c}\text { Tempo } \\
\text { (h) }\end{array}$} & \multicolumn{9}{|c|}{ Profundidade $(\mathrm{cm})$} \\
\hline & 20 & 30 & 40 & 50 & 60 & 70 & 80 & 90 & 100 \\
\hline 24,2 & $03.10^{-2}$ & $1,48.10^{-2}$ & $03.10^{-2}$ & $57.10^{-2}$ & 年, & $10.10^{-2}$ & $5,57.10^{-2}$ & $7,39.10^{-2}$ & $9,54.10^{-2}$ \\
\hline 48,2 & $8,44.10^{-3}$ & $1,22.10^{-2}$ & $1,67.10^{-2}$ & $2,11.10^{-2}$ & $2,56.10^{-2}$ & $3,37.10^{-2}$ & $4,58.10^{-2}$ & $6,07.10^{-2}$ & $7,84 \cdot 10^{-2}$ \\
\hline 55,6 & $8,18.10^{-3}$ & $1,18.10^{-2}$ & $1,62.10^{-2}$ & $2,05.10^{-2}$ & $2,48.10^{-2}$ & $3,26.10^{-2}$ & $4,43.10^{-2}$ & & \\
\hline 98,9 & $7,11.10^{-3}$ & $1,03.10^{-2}$ & $1,41.10^{-2}$ & $1,78.10^{-2}$ & $2,16 \cdot 10^{-2}$ & $2,84.10^{-2}$ & $3,86.10^{-2}$ & $5,12 \cdot 10^{-2}$ & $6,61 \cdot 10^{-2}$ \\
\hline 124,4 & $6,78.10^{-3}$ & $9,78.10^{-3}$ & $1,34.10^{-2}$ & $1,69.10^{-2}$ & $2,05.10^{-2}$ & $2,70.10^{-2}$ & $3,67.10^{-2}$ & $4,88.10^{-2}$ & $6,30 \cdot 10^{-2}$ \\
\hline 144,8 & $6,57.10^{-3}$ & $9,49.10^{-3}$ & $1,30.10^{-2}$ & $1,64.10^{-2}$ & $1,99.10^{-2}$ & $2,62.10^{-2}$ & $3,56.10^{-2}$ & $4,73.10^{-2}$ & $6,11 \cdot 10^{-2}$ \\
\hline 169,0 & $6,38.10^{-3}$ & $9,20.10^{-3}$ & $1,26.10^{-2}$ & $1,59.10^{-2}$ & $1,93.10^{-2}$ & $2,54.10^{-2}$ & $3,46.10^{-2}$ & $4,59.10^{-2}$ & $5,93 \cdot 10^{-2}$ \\
\hline 216,5 & & & & & & & & & \\
\hline 239,9 & $5,97.10^{-3}$ & $8,61.10^{-3}$ & $1,18.10^{-2}$ & $1,49.10^{-2}$ & $1,81.10^{-2}$ & $2,38.10^{-2}$ & $3,24.10^{-2}$ & $4,29.10^{-2}$ & $5,55.10^{-2}$ \\
\hline 266,1 & $5,86.10^{-3}$ & $8,45.10^{-3}$ & $1,16.10^{-2}$ & $1,47.10^{-2}$ & $1,77.10^{-2}$ & $2,34.10^{-2}$ & $3,18.10^{-2}$ & $4,21.10^{-2}$ & $5,44.10^{-2}$ \\
\hline 288,3 & $5,77.10^{-3}$ & $8,33.10^{-3}$ & $1,14.10^{-2}$ & $1,44.10^{-2}$ & $1,75.10^{-2}$ & $2,30.10^{-2}$ & $3,13.10^{-2}$ & $4,15.10^{-2}$ & $5,37.10^{-2}$ \\
\hline 312 & $5,69.10^{-3}$ & $8,22.10^{-3}$ & $1,13.10^{-2}$ & $1,42.10^{-2}$ & $1,73.10^{-2}$ & $2,27.10^{-2}$ & $3,09.10^{-2}$ & $4,10.10^{-2}$ & $5,29.10^{-2}$ \\
\hline 360,0 & $5,56 \cdot 10^{-3}$ & $8,02 \cdot 10^{-3}$ & $1,10.10^{-2}$ & $1,39.10^{-2}$ & $1,68 \cdot 10^{-2}$ & $2,22.10^{-2}$ & $3,01 \cdot 10^{-2}$ & $4,00.10^{-2}$ & $5,16 \cdot 10^{-2}$ \\
\hline
\end{tabular}


TABELA 5.20 Condutividade hidráulica calculada $(\mathrm{cm} / \mathrm{h})$ para cada profundidade ao longo do tempo de drenagem interna do perfil, com dados obtidos pela sonda de nêutrons.

\begin{tabular}{|c|c|c|c|c|c|c|c|c|}
\hline \multirow{2}{*}{$\begin{array}{c}\text { Tempo } \\
\text { (h) }\end{array}$} & \multicolumn{8}{|c|}{ Profundidade $(\mathrm{cm})$} \\
\hline & 20 & 30 & 40 & 50 & 60 & 70 & 80 & 90 \\
\hline 24 & $25.10^{-4}$ & $1,03.10^{-4}$ & $4,24.10^{-4}$ & $0,41,10$ & $1,02.10$ & $1,93.10^{-4}$ & $2,54.10^{-4}$ & $3,00.10^{-4}$ \\
\hline 48,2 &, $12.10^{-4}$ & $8,91.10^{-5}$ & $2,22.10^{-4}$ & $2,57.10^{-4}$ & $1,44.10^{-4}$ &, $49.10^{-4}$ & $1,72.10^{-4}$ & $2,17.10^{-4}$ \\
\hline 55,6 & $1,49.10^{-4}$ & $8,22.10^{-5}$ & $1,82.10^{-4}$ & $1,99.10^{-4}$ & $1,34.10^{-4}$ & $1,49.10^{-4}$ & & \\
\hline 9 & $1,16.10^{-4}$ & $6,82 \cdot 10^{-5}$ & $1,47.10^{-4}$ & $1,86.10^{-4}$ & & & & \\
\hline 124 & $9,01.10^{-5}$ & $7,15.10^{-5}$ & $1,96.10^{-4}$ & $1,46.10^{-4}$ & $1,00.10^{-4}$ & $1,16.10^{-4}$ & $1,28.10^{-4}$ & $1,55.10^{-4}$ \\
\hline 144,8 & $8,74.10^{-5}$ & $6,94.10^{-5}$ & $1,58.10^{-4}$ & $1,34.10^{-4}$ & $1,08.10^{-4}$ & $1,13.10^{-4}$ & $1,11.10^{-4}$ & $1,61.10^{-4}$ \\
\hline 169,0 & $9,32.10^{-5}$ & $7,08.10^{-5}$ & $1,54.10^{-4}$ & $1,30.10^{-4}$ & $9,74.10^{-5}$ & $1,06.10^{-4}$ & $1,15.10^{-4}$ & $1,56.10^{-4}$ \\
\hline 216,5 & $8,89.10^{-5}$ & $6,42.10^{-5}$ & $1,47.10^{-4}$ & $1,17.10^{-4}$ & $8,98.10^{-5}$ & $9,86.10^{-5}$ & $1,03.10^{-4}$ & $1,42.10^{-4}$ \\
\hline 239,9 & $1,09.1$ & & & & & & & \\
\hline 266,1 & $9,52.10^{-5}$ & $6,87.10^{-5}$ & $1,41.10^{-4}$ & $1,02.10^{-4}$ & $8,11.10^{-5}$ & $9,24.10^{-5}$ & $9,67.10^{-5}$ & $1,31.10^{-4}$ \\
\hline 288,3 & $1,06.10^{-4}$ & $6,77.10^{-5}$ & $1,39.10^{-4}$ & $1,01.10^{-4}$ & $8,82 \cdot 10^{-5}$ & $9,11.10^{-5}$ & $8,80 \cdot 10^{-5}$ & $1,19.10^{-4}$ \\
\hline 312,2 & $7,57.10^{-5}$ & $6,68.10^{-5}$ & $1,27.10^{-4}$ & $9,47.10^{-5}$ & $8,70.10^{-5}$ & $8,74.10^{-5}$ & $8,85.10^{-5}$ & $1,15.10^{-4}$ \\
\hline 360,0 & $9,03.10^{-5}$ & $6,17 \cdot 10^{-5}$ & $1,24.10^{-4}$ & $1,02.10^{-4}$ & $8,21.10^{-5}$ & $8,31.10^{-5}$ & $8,16 \cdot 10^{-5}$ & $1,03.10^{-4}$ \\
\hline
\end{tabular}


TABELA 5.21 Equações lineares obtidas por regressão da condutividade hidráulica $(K)$ versus umidade $(\theta)$, com dados obtidos pela sonda de nêutrons.

\begin{tabular}{ccc}
\hline Profundidade $(\mathrm{cm})$ & $\begin{array}{c}\text { Equação } \\
\text { linear }\end{array}$ & Coeficiente de correlação $\left(\mathrm{r}^{2}\right)$ \\
\hline 20 & $\mathrm{~K}(\theta)=0,1527 \theta-0,0491$ & 0,08 \\
30 & $\mathrm{~K}(\theta)=0,1117 \theta-0,0347$ & 0,22 \\
40 & $\mathrm{~K}(\theta)=0,7680 \theta-0,2859$ & 0,18 \\
50 & $\mathrm{~K}(\theta)=1,0935 \theta-0,4247$ & 0,25 \\
60 & $\mathrm{~K}(\theta)=0,4099 \theta-0,1543$ & 0,32 \\
70 & $\mathrm{~K}(\theta)=0,5435 \theta-0,2094$ & 0,78 \\
80 & $\mathrm{~K}(\theta)=0,7131 \theta-0,2399$ & 0,70 \\
90 & $\mathrm{~K}(\theta)=0,7165 \theta-0,2303$ & 0,80 \\
\hline
\end{tabular}



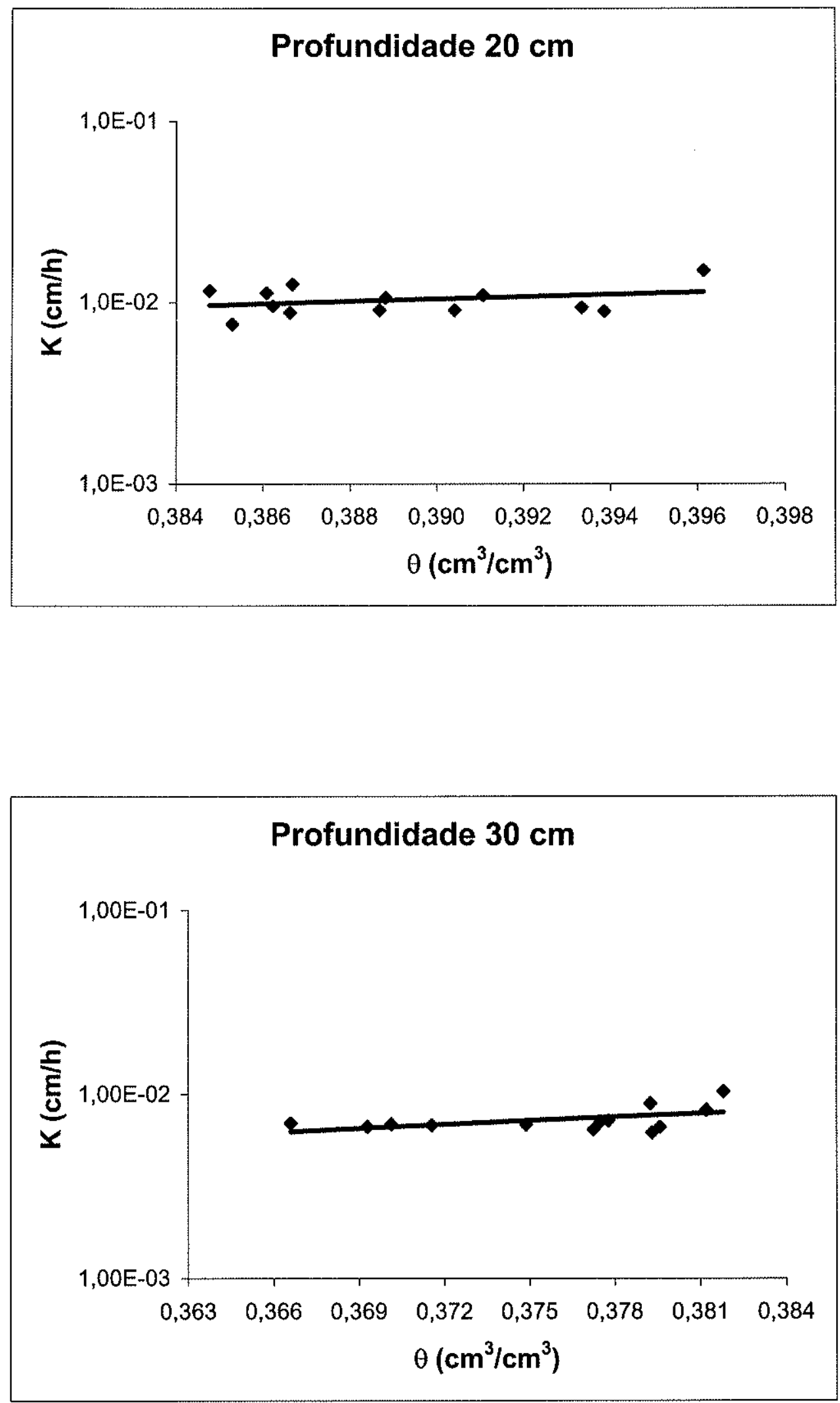

Figura 5.37 Gráficos de condutividade hidráulica $(K)$ pela umidade $(\theta)$, para as profundidades de 20 e $30 \mathrm{~cm}$, com dados obtidos pela sonda de nêutrons. 

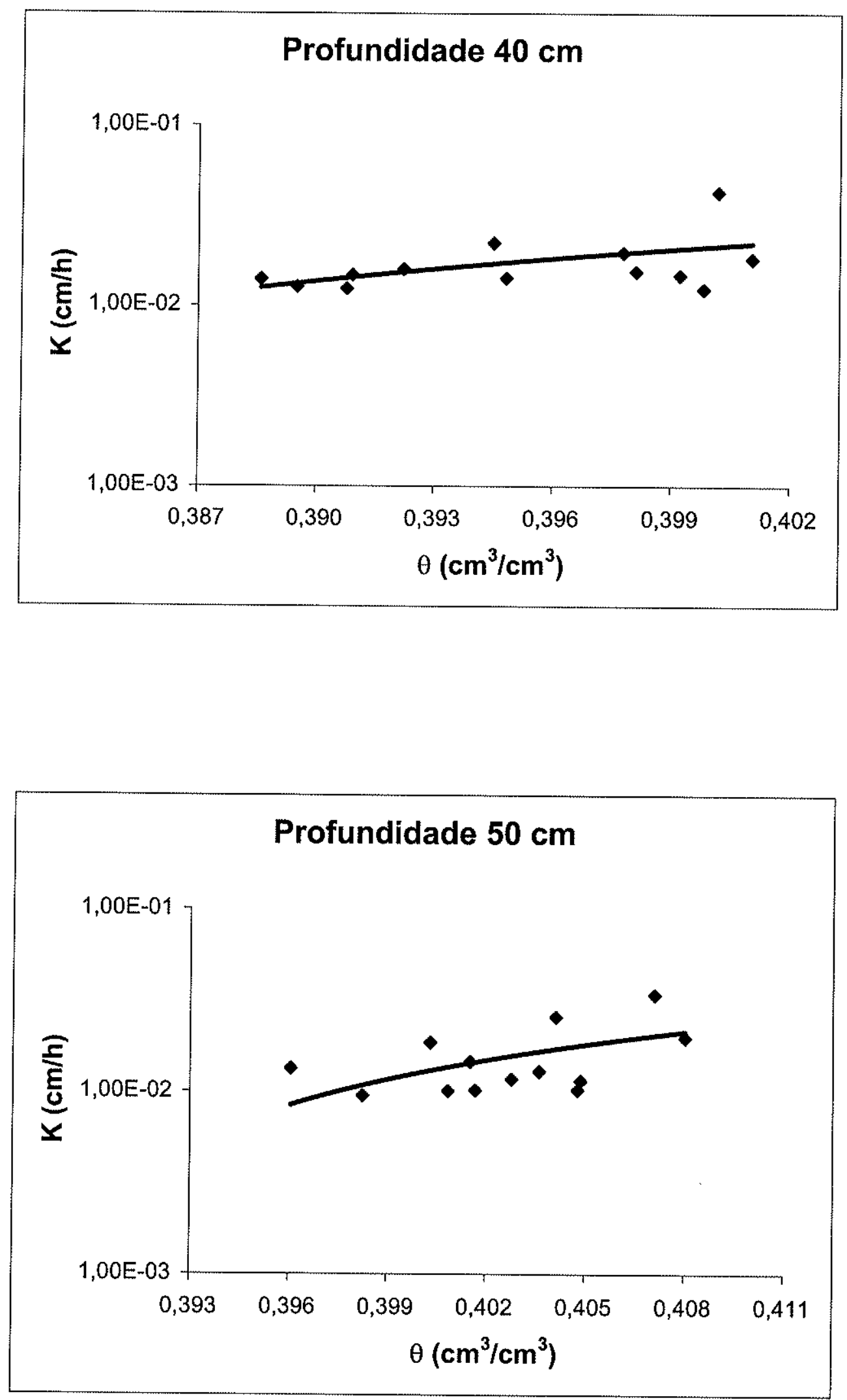

Figura 5.38 Gráficos de condutividade hidráulica $(K)$ pela umidade $(\theta)$, para as profundidades de 40 e $50 \mathrm{~cm}$, com dados obtidos pela sonda de nêutrons. 

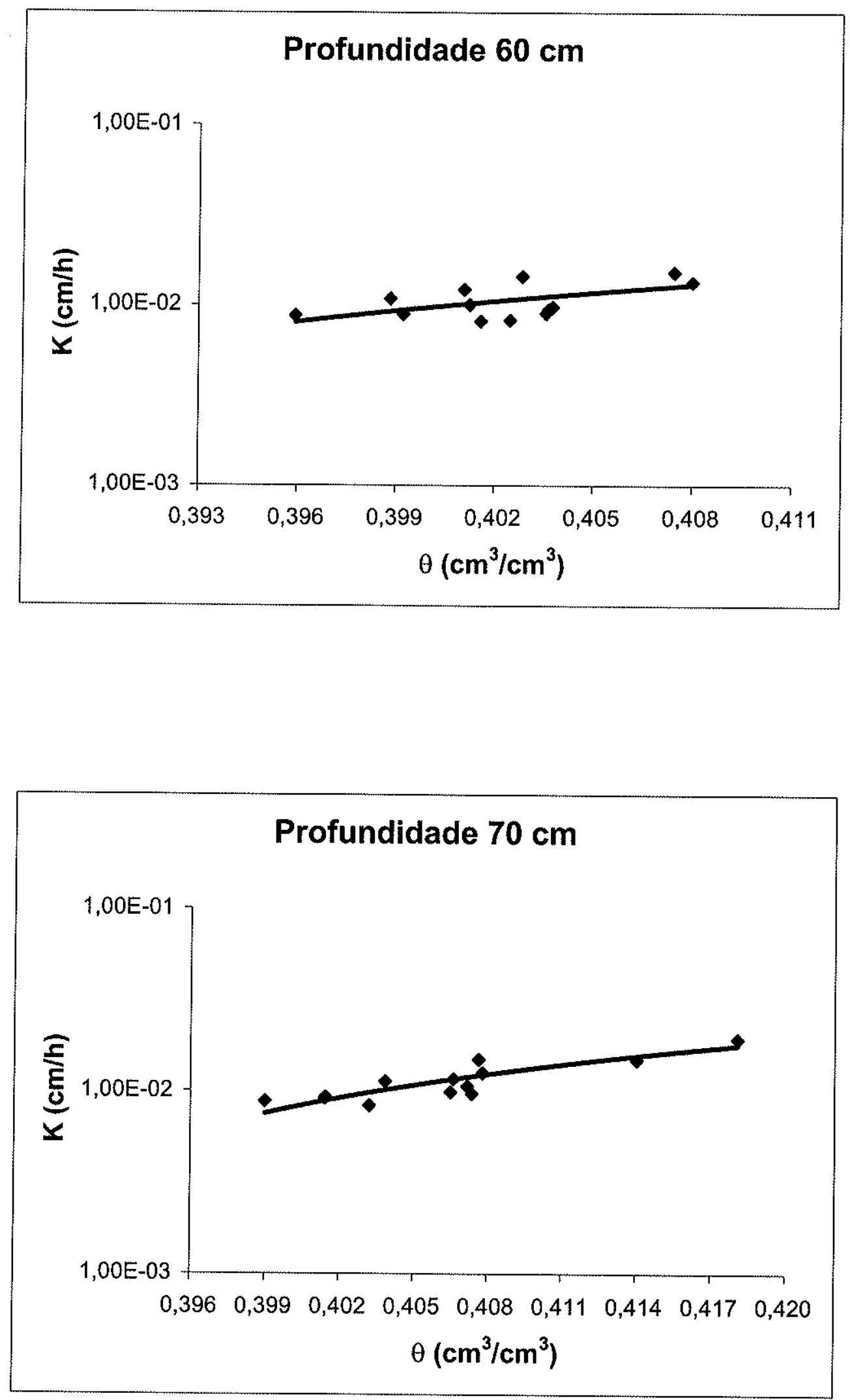

Figura 5.39 Gráficos de condutividade hidráulica $(K)$ pela umidade $(\theta)$, para as profundidades de 60 e $70 \mathrm{~cm}$, com dados obtidos pela sonda de nêutrons. 

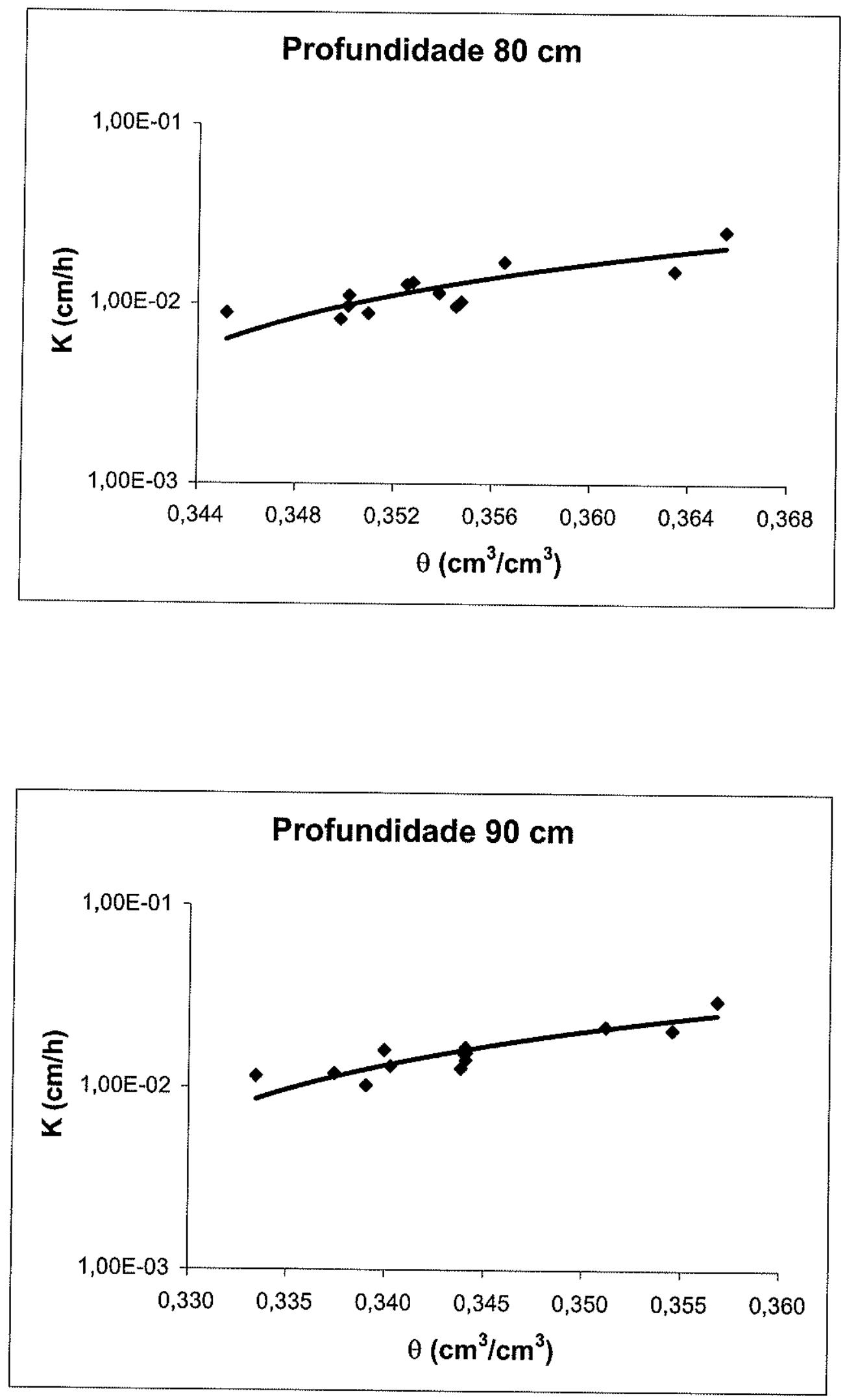

Figura 5.40 Gráficos de condutividade hidráulica $(K)$ pela umidade $(\theta)$, para as profundidades de 80 e $90 \mathrm{~cm}$, com dados obtidos pela sonda de nêutrons. 
TABELA 5.22 Saturação efetiva $\left(S_{\mathrm{e}}\right)$ calculada para cada profundidade ao longo do tempo de redistribuição.

\begin{tabular}{ccccccccccc}
\hline Tempo & \multicolumn{10}{c}{ Profundidade (cm) } \\
\cline { 2 - 10 }$(\mathrm{h})$ & 10 & 20 & 30 & 40 & 50 & 60 & 70 & 80 & 90 & 100 \\
\hline 24,2 & 0,9843 & 0,9974 & 0,9863 & 0,9639 & 1,0000 & 0,9911 & 0,8918 & 0,7176 & 0,5882 & 0,4795 \\
48,2 & 0,9779 & 0,9926 & 0,9795 & 0,9391 & 0,9966 & 0,9702 & 0,8751 & 0,6457 & 0,5093 & 0,4144 \\
54,6 & 0,9665 & 0,9926 & 0,9795 & 0,9246 & 0,9897 & 0,9189 & 0,8250 & 0,6078 & 0,4626 & 0,3983 \\
99,3 & 0,9623 & 0,9879 & 0,9604 & 0,8762 & 0,9671 & 0,8867 & 0,7930 & 0,5737 & 0,4425 & 0,3656 \\
124,8 & 0,9665 & 0,9904 & 0,9483 & 0,9246 & 0,9897 & 0,8867 & 0,7777 & 0,5631 & 0,4425 & 0,3573 \\
144,7 & 0,9623 & 0,9879 & 0,9347 & 0,9091 & 0,9671 & 0,8531 & 0,7777 & 0,5429 & 0,4127 & 0,3614 \\
168,8 & 0,9534 & 0,9822 & 0,9199 & 0,8929 & 0,9561 & 0,8364 & 0,7349 & 0,5242 & 0,4127 & 0,3533 \\
216,5 & 0,9487 & 0,9822 & 0,9041 & 0,8762 & 0,9434 & 0,8038 & 0,7090 & 0,4983 & 0,3868 & 0,3346 \\
239,8 & 0,9336 & 0,9755 & 0,8877 & 0,8594 & 0,8990 & 0,7881 & 0,6969 & 0,4902 & 0,3729 & 0,3180 \\
265,9 & 0,9487 & 0,9789 & 0,9199 & 0,8929 & 0,9561 & 0,7881 & 0,6969 & 0,4824 & 0,3774 & 0,3212 \\
288,2 & 0,9284 & 0,9755 & 0,8710 & 0,8762 & 0,9140 & 0,7730 & 0,6969 & 0,4749 & 0,3601 & 0,3060 \\
312,2 & 0,9388 & 0,9755 & 0,8542 & 0,8762 & 0,8815 & 0,7584 & 0,6740 & 0,4605 & 0,3560 & 0,2976 \\
359,9 & 0,9284 & 0,9717 & 0,8542 & 0,8426 & 0,8815 & 0,7584 & 0,6633 & 0,4536 & 0,3407 & 0,2822 \\
\hline
\end{tabular}


TABELA 5.23 Valores de condutividade hidráulica relativa ( $K r)$ obtidos pelo modelo de van Genuchten (1980).

\begin{tabular}{ccccccccccc}
\hline Tempo & \multicolumn{10}{c}{ Profundidade (cm) } \\
\cline { 2 - 10 } (h) & 10 & 20 & 30 & 40 & 50 & 60 & 70 & 80 & 90 & 100 \\
\hline 24,2 & 0,2854 & 0,5092 & 0,0854 & 0,0372 & 0,7037 & 0,1117 & 0,0066 & 0,0153 & 0,0035 & 0,0008 \\
48,2 & 0,2404 & 0,3827 & 0,0633 & 0,0191 & 0,1768 & 0,0454 & 0,0047 & 0,0069 & 0,0013 & 0,0003 \\
54,6 & 0,1867 & 0,3827 & 0,0633 & 0,0135 & 0,1023 & 0,0119 & 0,0017 & 0,0044 & 0,0007 & 0,0002 \\
99,3 & 0,1718 & 0,3200 & 0,0336 & 0,0048 & 0,0411 & 0,0060 & 0,0009 & 0,0029 & 0,0005 & 0,0001 \\
124,8 & 0,1867 & 0,3497 & 0,0241 & 0,0135 & 0,1023 & 0,0060 & 0,0007 & 0,0026 & 0,0005 & 0,0001 \\
144,7 & 0,1718 & 0,3200 & 0,0171 & 0,0096 & 0,0411 & 0,0030 & 0,0007 & 0,0020 & 0,0003 & 0,0001 \\
168,8 & 0,1457 & 0,2689 & 0,0122 & 0,0068 & 0,0297 & 0,0022 & 0,0003 & 0,0016 & 0,0003 & 0,0001 \\
216,5 & 0,1342 & 0,2689 & 0,0086 & 0,0048 & 0,0212 & 0,0011 & 0,0002 & 0,0011 & 0,0002 & 0,0001 \\
239,8 & 0,1052 & 0,2268 & 0,0061 & 0,0034 & 0,0075 & 0,0008 & 0,0001 & 0,0010 & 0,0002 & 0,0001 \\
265,9 & 0,1342 & 0,2469 & 0,0122 & 0,0068 & 0,0297 & 0,0008 & 0,0001 & 0,0009 & 0,0002 & 0,0001 \\
288,2 & 0,0971 & 0,2268 & 0,0043 & 0,0048 & 0,0107 & 0,0006 & 0,0001 & 0,0008 & 0,0001 & 0,0000 \\
312,2 & 0,1141 & 0,2268 & 0,0031 & 0,0048 & 0,0053 & 0,0005 & 0,0001 & 0,0006 & 0,0001 & 0,0000 \\
359,9 & 0,0971 & 0,2084 & 0,0031 & 0,0024 & 0,0053 & 0,0005 & 0,0001 & 0,0006 & 0,0001 & 0,0000 \\
\hline
\end{tabular}


TABELA 5.24 Condutividade hidráulica $(\mathrm{cm} / \mathrm{h})$ calculada pelo modelo de van Genuchten (1980).

\begin{tabular}{|c|c|c|c|c|c|c|c|c|}
\hline \multirow{2}{*}{$\begin{array}{c}\text { Tempo } \\
\text { (h) }\end{array}$} & \multicolumn{8}{|c|}{ Profundidade $(\mathrm{cm})$} \\
\hline & 20 & 30 & 40 & 50 & 60 & 70 & 80 & 90 \\
\hline 24,2 & $2,34.10^{-3}$ & $2,08 \cdot 10^{-3}$ & $1,05.10^{-2}$ & $4,20.10^{-3}$ & $2,42.10^{-2}$ & $6,08.10^{-3}$ & $5,04.10^{-2}$ & $6,06 \cdot 10^{-2}$ \\
\hline 48,2 & $2,33.10^{-3}$ & $2,07.10^{-3}$ & $1,02.10^{-2}$ & $4,19.10^{-3}$ & $2,37.10^{-2}$ & $5,97.10^{-3}$ & $4,53.10^{-2}$ & $5,25.10^{-2}$ \\
\hline 54,6 & $2,33.10^{-3}$ & $2,07.10^{-3}$ & $1,01.10^{-2}$ & $4,16 \cdot 10^{-3}$ & $2,24.10^{-2}$ & $5,63 \cdot 10^{-3}$ & $4,27.10^{-2}$ & $4,77.10^{-2}$ \\
\hline 99,3 & $2,32.10^{-3}$ & $2,03.10^{-3}$ & $9,55.10^{-3}$ & $4,06 \cdot 10^{-3}$ & $2,16.10^{-2}$ & $5,41.10^{-3}$ & $4,03 \cdot 10^{-2}$ & $4,56.10^{-2}$ \\
\hline 124,8 & $2,33.10^{-3}$ & $2,00.10^{-3}$ & $1,01.10^{-2}$ & $4,16 \cdot 10^{-3}$ & $2,16.10^{-2}$ & $5,30.10^{-3}$ & $3,95.10^{-2}$ & $4,56.10^{-2}$ \\
\hline 144,7 & $2,32.10^{-3}$ & $1,97.10^{-3}$ & $9,91 \cdot 10^{-3}$ & $4,06 \cdot 10^{-3}$ & $2,08.10^{-2}$ & $5,30.10^{-3}$ & $3,81.10^{-2}$ & $4,25 \cdot 10^{-2}$ \\
\hline 168,8 & $2,31.10^{-3}$ & $1,94.10^{-3}$ & $9,73.10^{-3}$ & $4,02.10^{-3}$ & $2,04.10^{-2}$ & $5,01.10^{-3}$ & $3,68.10^{-2}$ & $4,25.10^{-2}$ \\
\hline 216,5 & $2,31.10^{-3}$ & $1,91.10^{-3}$ & $9,55.10^{-3}$ & $3,96 \cdot 10^{-3}$ & $1,96.10^{-2}$ & $4,84 \cdot 10^{-3}$ & $3,50.10^{-2}$ & $3,98.10^{-2}$ \\
\hline 239,8 & $2,29.10^{-3}$ & $1,87.10^{-3}$ & $9,37.10^{-3}$ & $3,77.10^{-3}$ & $1,92.10^{-2}$ & $4,75.10^{-3}$ & $3,44.10^{-2}$ & $3,84.10^{-2}$ \\
\hline 265,9 & $2,30.10^{-3}$ & $1,94.10^{-3}$ & $9,73.10^{-3}$ & $4,02.10^{-3}$ & $1,92.10^{-2}$ & $4,75.10^{-3}$ & $3,39.10^{-2}$ & $3,89.10^{-2}$ \\
\hline 288,2 & $2,29.10^{-3}$ & $1,84 \cdot 10^{-3}$ & $9,55.10^{-3}$ & $3,84.10^{-3}$ & $1,89.10^{-2}$ & $4,75.10^{-3}$ & $3,33.10^{-2}$ & $3,71.10^{-2}$ \\
\hline 312,2 & $2,29.10^{-3}$ & $1,80.10^{-3}$ & $9,55.10^{-3}$ & $3,70.10^{-3}$ & $1,85.10^{-2}$ & $4,60.10^{-3}$ & $3,23.10^{-2}$ & $3,67.10^{-2}$ \\
\hline 359,9 & $2,28.10^{-3}$ & $1,80.10^{-3}$ & $9,18.10^{-3}$ & $3,70.10^{-3}$ & $1,85.10^{-2}$ & $4,52.10^{-3}$ & $3,18 \cdot 10^{-2}$ & $3,51 \cdot 10^{-2}$ \\
\hline
\end{tabular}




\subsection{Comparação entre Kr experimental e Kr por van Genuchten.}

Os gráficos de $\operatorname{Kr}(\operatorname{Exp}) \times \operatorname{Kr}(V G)$ são encontrados nas Figuras 5.41, 5.42, 5.43 e 5.44. Pode-se observar pelos gráficos que há uma boa correlação linear entre os valores estimados pelos dois métodos (Tabela 5.25), mas com subestimativa do método de van Genuchten para os valores de $K r$.

Embora o modelo de van Genuchten ajuste-se melhor para solos de textura média a arenosa (Libardi, 1995), o coeficiente de correlação obtido para $\operatorname{Kr}($ Exp) $\mathrm{x}$ $K r(V G)$ foi muito bom (entre 0,87 e 0,99 ), sugerindo que novos estudos devam ser realizados para verificar a possibilidade de correção do modelo de van Genuchten para solos de textura argilosa.

$\mathrm{Na}$ Tabela 5.26 observa-se valores de $K r$ (Exp) obtidos pela aplicação das equações de regressão apresentadas na Tabela 5.25 , e a relação $K r(\operatorname{Exp}) / K r(V G)$, na qual se quantificou a subestimativa dos valores de $K r$ por van Genuchten. As profundidades de 70 e $80 \mathrm{~cm}$ foram as que tiveram seu valor de $K r$ mais subestimado, enquanto as demais profundidades apresentaram razões entre 2 e 18. 

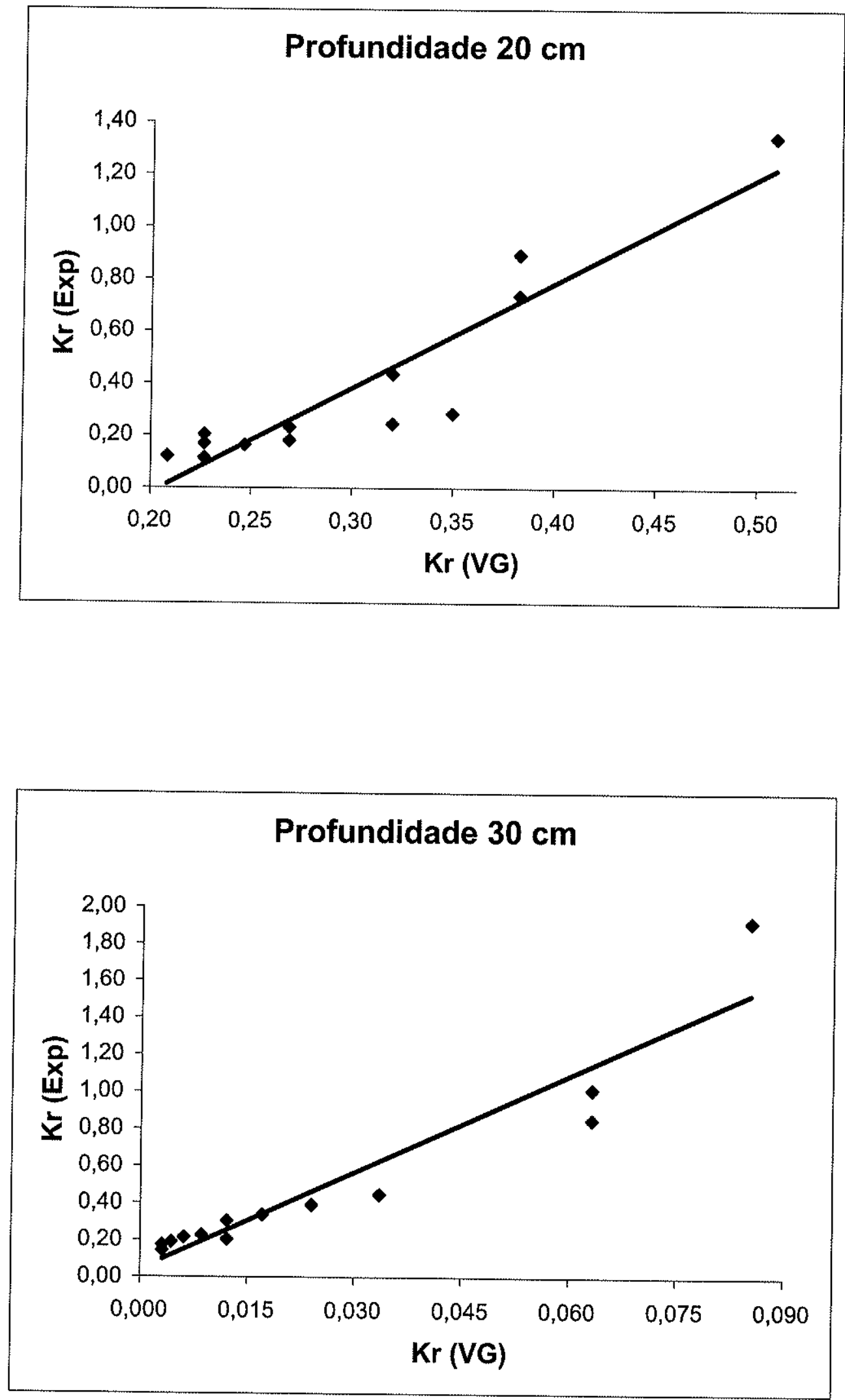

Figura 5.41 Gráficos de comparação entre $K r$ experimental $(K r(E x p))$ e $K r$ por van Genuchten $(K r(V G))$, para as profundidades de 20 e $30 \mathrm{~cm}$. 

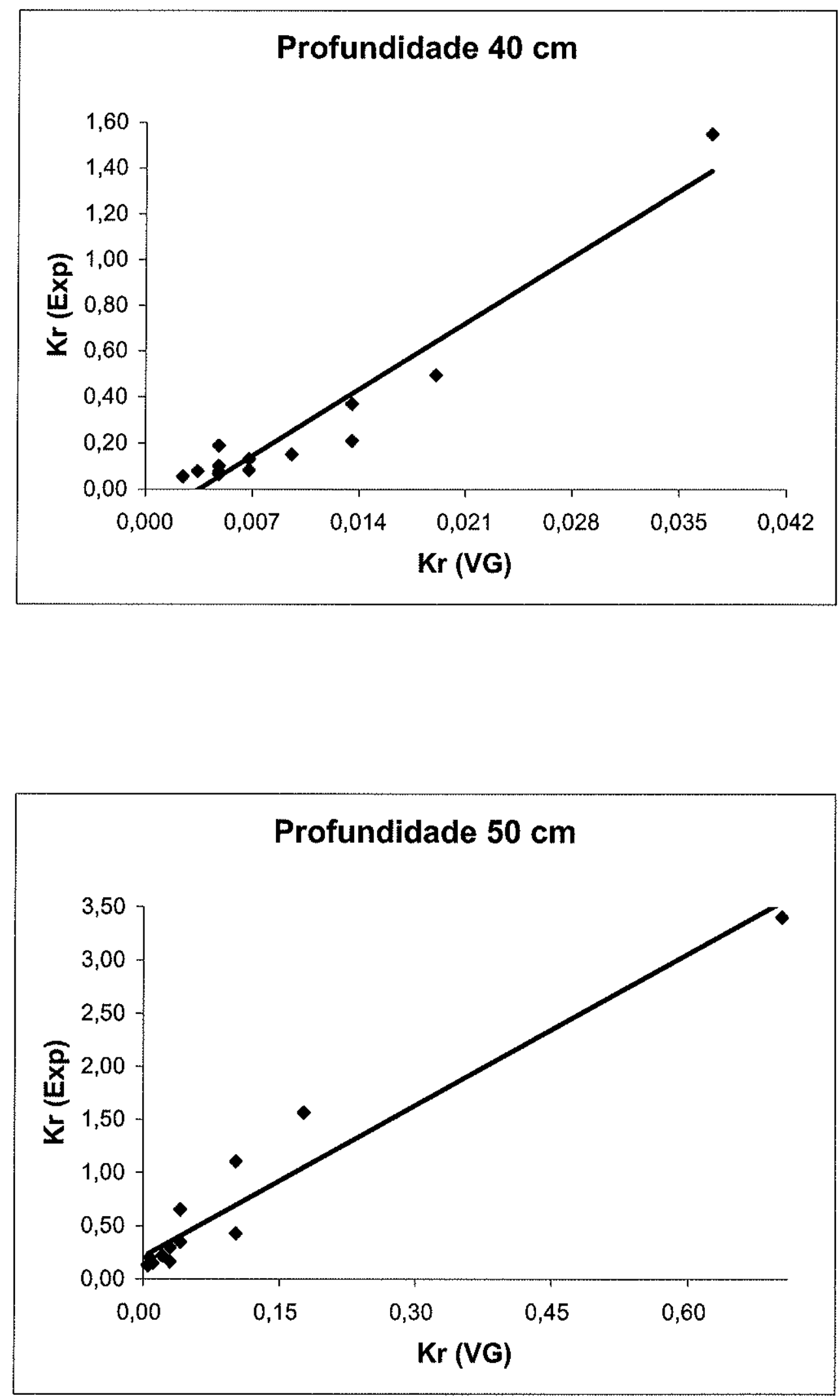

Figura 5.42 Gráficos de comparação entre $K r$ experimental $(K r(E x p))$ e $K r$ por van Genuchten $(K r(V G))$, para as profundidades de 40 e $50 \mathrm{~cm}$. 

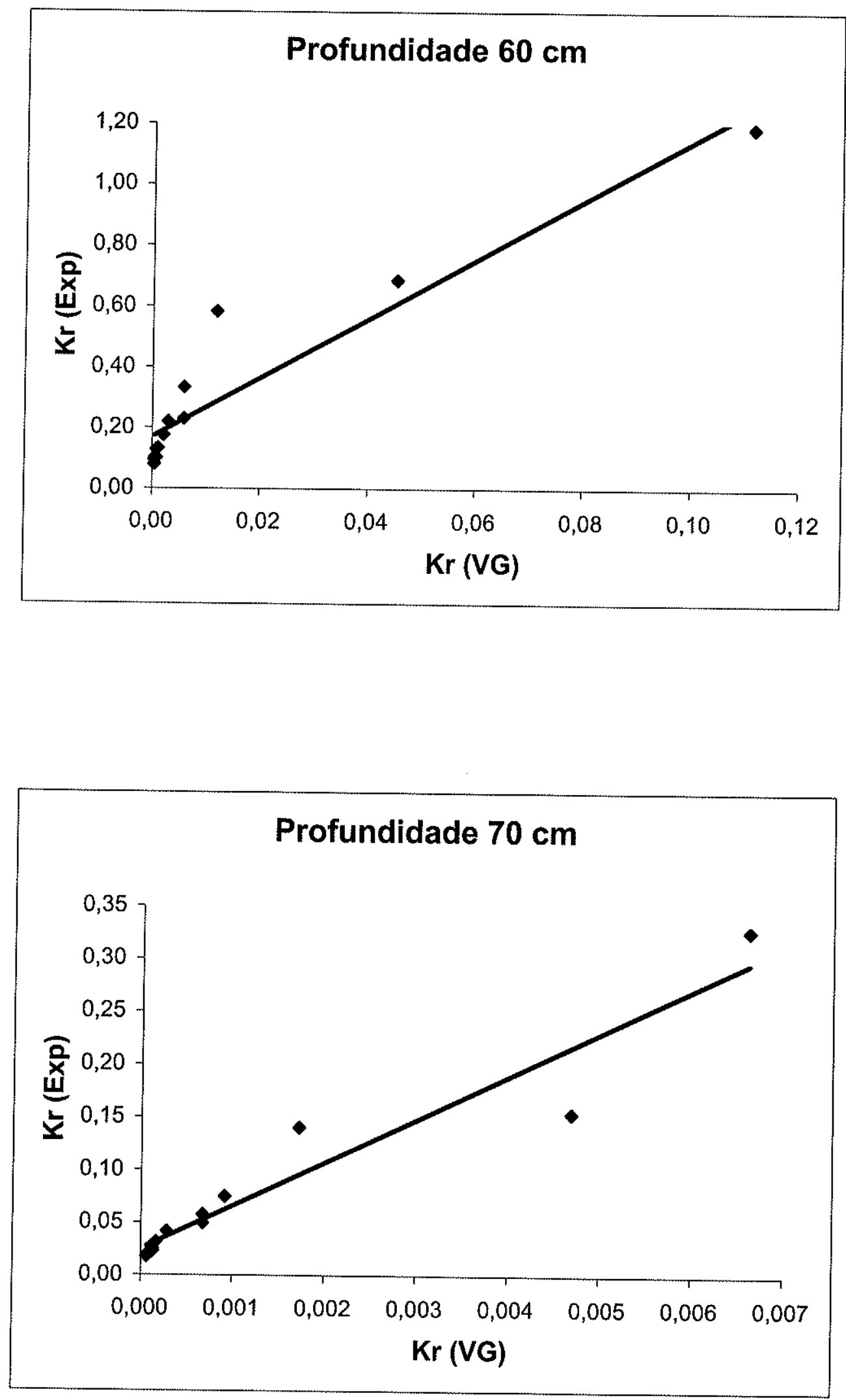

Figura 5.43 Gráficos de comparação entre $K r$ experimental $(K r(E x p))$ e $K r$ por van Genuchten ( $K r(V G))$, para as profundidades de 60 e $70 \mathrm{~cm}$. 

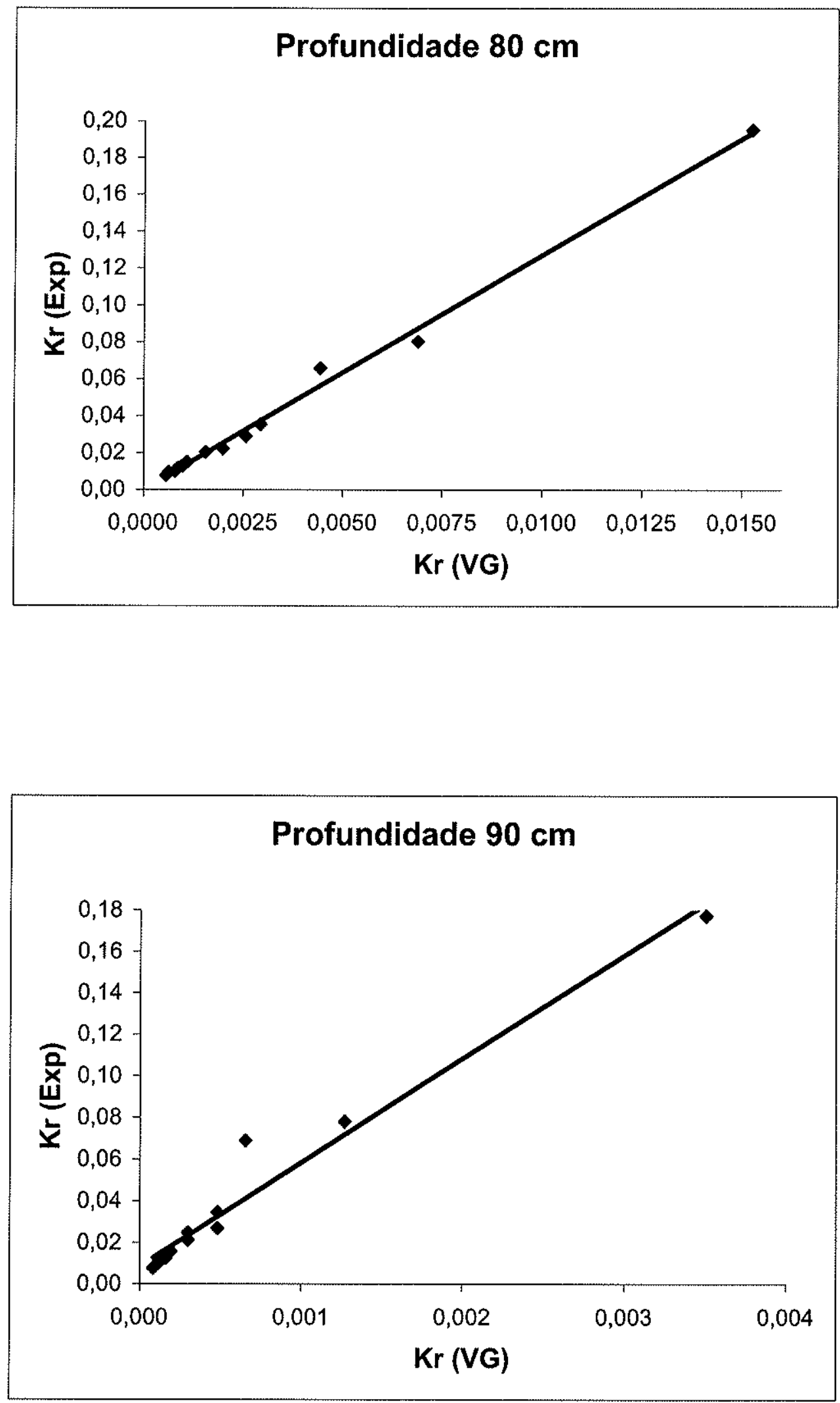

Figura 5.44 Gráficos de comparação entre $K r$ experimental $(K r($ Exp)) e $K r$ por van Genuchten $(K r(V G))$, para as profundidades de 80 e $90 \mathrm{~cm}$. 
TABELA 5.25 Equações lineares obtidas por regressão dos valores de $\mathrm{Kr}$ (Exp) versus $K r(V G)$.

\begin{tabular}{ccc}
\hline Profundidade $(\mathrm{cm})$ & $\begin{array}{c}\text { Equação } \\
\text { potencial }\end{array}$ & $\begin{array}{c}\text { Coeficiente de } \\
\text { correlação }\left(r^{2}\right)\end{array}$ \\
\hline 20 & $\operatorname{Kr}(\operatorname{Exp})=4,0096 \mathrm{Kr}(\mathrm{VG})-0,8214$ & 0,87 \\
30 & $\mathrm{Kr}(\operatorname{Exp})=17,379 \mathrm{Kr}(\mathrm{VG})+0,0428$ & 0,90 \\
40 & $\mathrm{Kr}(\operatorname{Exp})=41,171 \mathrm{Kr}(\mathrm{VG})-0,1439$ & 0,93 \\
50 & $\mathrm{Kr}(\operatorname{Exp})=4,7432 \mathrm{Kr}(\mathrm{VG})+0,2098$ & 0,93 \\
60 & $\mathrm{Kr}(\operatorname{Exp})=9,681 \mathrm{Kr}(\mathrm{VG})+0,1697$ & 0,89 \\
70 & $\operatorname{Kr}(\operatorname{Exp})=40,844 \mathrm{Kr}(\mathrm{VG})+0,025$ & 0,92 \\
80 & $\operatorname{Kr}(\operatorname{Exp})=12,672 \mathrm{Kr}(\mathrm{VG})+2.10^{-5}$ & 0,99 \\
90 & $\operatorname{Kr}(\operatorname{Exp})=49,809 \mathrm{Kr}(\mathrm{VG})+0,0086$ & 0,96 \\
\hline
\end{tabular}


TABELA 5.26 Valores escolhidos de $K r(V G)$ e aplicados às equações de regressão $\operatorname{Kr}(E x p) \times K r(V G)$ para obtenção da relação $\operatorname{Kr}(\operatorname{Exp}) / K r(V G)$.

\begin{tabular}{cccc}
\hline Profundidade $(\mathrm{cm})$ & $\mathrm{Kr}(\mathrm{VG})$ & $\mathrm{Kr}(\operatorname{Exp})$ & $\mathrm{Kr}(\mathrm{VG}) / \mathrm{Kr}(\operatorname{Exp})$ \\
\hline 20 & 0,5 & 1,18 & 2,37 \\
30 & 0,05 & 0,91 & 18,24 \\
40 & 0,005 & 0,062 & 12,39 \\
50 & 0,5 & 2,58 & 5,16 \\
60 & 0,05 & 0,654 & 13,08 \\
70 & 0,005 & 0,229 & 45,84 \\
80 & 0,005 & 0,063 & 12,68 \\
90 & 0,005 & 0,258 & 51,53 \\
\hline
\end{tabular}




\section{CONCLUSÕES E CONSIDERAÇÕES}

A análise dos resultados obtidos neste trabalho permitiu as seguintes conclusões:

i) A sonda de nêutrons mostrou-se pouco sensível à medida da variação de umidade no método do perfil instantâneo para o solo estudado, resultando em correlações muito baixas, provavelmente por estar operando dentro de sua resolução, o que não possibilitaria a percepção da pouca variação da umidade deste solo. Os valores de $K$ versus $\theta$, obtidos a partir da curva de retenção, ajustaram-se bem a uma equação exponencial, principalmente a partir dos $60 \mathrm{~cm}$ de profundidade (os valores de $r^{2}$ variaram de 0,69 para $z=50 \mathrm{~cm}, a$ máxima expressão do B textural, a 0,98 );

ii) O método do perfil instantâneo precisa ser analisado com mais cuidado para solos com presença de um horizonte $B$ textural, tanto com relação ao processo de saturação do perfil como ao processo de redistribuição de água;

iii) O modelo de van Genuchten subestimou, para todas as profundidades, os valores de condutividade hidráulica relativa $\left(K_{r}\right)$ em relação aos obtidos experimentalmente; entretanto, houve uma boa correlação linear entre os valores de $K_{r}$ obtidos por este modelo e os experimentais, o que pode confirmar a melhor aplicação deste modelo para solos de textura média a arenosa, como já abordado pela literatura; 
iv) As equações representativas da curva de retenção por horizonte pedológico, embora tenham se ajustado bem ao modelo de van Genuchten, podem não representar muito bem o comportamento hidráulico do horizonte como um todo. 


\section{REFEREANCIAS BIBLIOGRÁFICAS}

ALMEIDA, F.F.M. \& BARBOSA, O. (1953) Geologia das quadrículas de Piracicaba e Rio Claro, Estado de São Paulo. Boletim do $D G M$, n. 143. Rio de Janeiro, DNPM.

BACCHI, O.O.S. \& REICHARDT, K. (1990) A sonda de nêutrons e seu uso na pesquisa agronômica. Boletim Didático, n. 22. Piracicaba, SP, CENA. p.85.

BACCHI, O.O.S.; CORRENTE, J.E.; REICHARDT, K. (1991) Análise comparativa de dois métodos simplificados de determinação da condutividade hidráulica de solos. Revista Brasileira de Ciência do Solo, Campinas, v. 15, p. 249-252.

BLACK, C.A.; GARDNER, W.R.; THURTELL, G.W. (1969) The prediction of evaporation, drainage and soil water storage for a bare soil. Proceedings of Soil Science Society of America, Madison, v. 33, p. 655-660.

BRASIL. Serviço Nacional de Pesquisa Agronômica. Comissão de Solos. (1960) Levantamento de reconhecimento dos solos do Estado de São Paulo. Boletim 12. Ministério da Agricultura, CNEPA. 605p.

CAMPBELL, G.S. (1974) A simple method for determining unsaturated conductivity from moisture retention data. Soil Science, v. 117, n. 6, p. 311-314.

CASEY, F.X.M.; LOGSDON, S.D.; HORTON, R.; JAYNES, D.B. (1998) Measurement of field soil hydraulic and solute transport parameters. Soil Science Society of America Journal, v. 62, p. 1172-1178.

CHONG, S.K.; GREEN, R.E.; AHUJA, L.R. (1981) Simple in situ determination of hydraulic conductivity by power function descriptions of drainage. Water Resources Research, Washington, v. 17, n. 4, p. 1109-1114. 
DANE, J.H. (1980) Comparison of field and laboratory determined hydraulic conductivity values. Soil Science Society of America Journal, v. 49, p. 12-18.

DAVIDSON, J.M.; STONE, L.R.; NIELSEN, D.R.; LA RUE, M.E. (1969) Field measurement and use of soil water properties. Water Resources Research, v. 5 , p. $1312-1321$.

DOURADO NETO, D. \& JONG VAN LIER, Q. (1992) Curvaret versão 2.16. Piracicaba, Escola Superior de Agricultura Luiz de Queiroz, Universidade de São Paulo.

EUA Department of Agriculture. (1975) Soil taxonomy: a basic system of soil classification for making and interpreting soil surveys. Washington, Soil Cons. Service. $745 p$.

FREEZE, R.A. \& CHERRY, J.A. (1979) Groundwater. Englewood Cliffs, N.J., Prentice-hall International Inc. $604 \mathrm{p}$.

FREIRE, J.C. (1979) Condutividade hidráulica e capacidade de campo de latossolo roxo distrófico não saturado. Revista Brasileira de Ciência do Solo, v. 3, p. 73-77.

GARDNER, W.R. \& EHLIG, C.F. (1962) Some observations on the movement of water to plant roots. Agronomy Journal, v. 54, p. 453-456.

GARDNER, W.R. (1970) Field measurement of soil water diffusivity. Soil Science Society of America Proceedings, v. 34, p. 832.

GREEEN, R.E. \& COREY,J.C. (1971) Calculation of hydraulic conductivity: a further evaluation of some predictive methods. Soil Science Society of America Proceedings, Madison, v. 35, p. 3-8.

HAINSWORTH, J.M. \& AYLMORE, L.A.G. (1986) Water extraction by single plant roots. Soil Science Society of America Journal, v. 50, p. 841-848. 
HAINSWORTH, J.M. \& AYLMORE, L.A.G. (1989) Non-uniform soil water extraction by plant roots. Plant Soil, v. 113, p. 121-124.

HILLEL, D.; KRENTOS, V.D.; STYLIANOU, Y. (1972). Procedure and test of an internal drainage method for measuring soil hydraulic conductivity in situ. Science Society of America Proceedings, v. 114, p. 395-400.

INSTITUTO DE PESQUISAS TECNOLÓGICAS (1981) Mapa geomorfológico do Estado de São Paulo. São Paulo. (Escala 1:500.000).

JONG VAN LIER, Q. \& LIBARDI, P.L. (1997) Extraction of soil water by plants: development and validation of a model. Revista Brasileira de Ciência do Solo, v. 21, p. 535-542.

KLUTE, A. (1972) The determination of the hydraulic conductivity and diffusivity of unsaturated soils. Soil Science, v. 113, n. 4, p. 264-276.

KUNZE, R.J. \& NIELSEN, D.R. (1983) Comparison of soil water infiltration profiles obtained experimentally and by solution of Richards equation. Soil Science, v. 135, p. 342-349.

LIBARDI, P.L. (1978) Condutividade hidráulica do solo em condições de campo. Piracicaba, 142p. (Tese - Doutorado) - Escola Superior de Agricultura Luiz de Queiroz, Universidade de São Paulo.

LIBARDI, P.L., ed. (1999) Dinâmica da água no solo. $2^{a}$. ed. Piracicaba, São Paulo. 497p.

LIBARDI, P.L., ed. (1995) Dinâmica da água no solo. Piracicaba, São Paulo. 497p.

LIBARDI, P.L.; REICHARDT, K.; NIELSEN, D.R.; BIGGAR, J.W. (1980) Simplified methods for estimating soil hydraulic conductivity. Soil Science Society of America Proceedings, Madison, v. 44, p. 3-7. 
LIBARDI, P.L. \& SAAD, A.M. (1994) Balanço hídrico de uma cultura de feijão irrigada por pivô central em latossolo roxo. Revista Brasileira de Ciência do Solo, v. 18, p. 529-532.

LUXMORE, R.J.; GRIZZARD, T.; PATTERSON, M.R. (1981) Hydraulic properties of Fullerton Cherty Silt Loam. Science Society of America Journal, Madison, v. 45, p. 692-698.

MARSHALL, T.J. (1958) A relation between permeability and size distribution of pores. Journal of Soil Science, Oxford, v. 9, n. 1, p. 1-8.

MENEGON, V.A. (1990) Aspectos gerais sobre as minerações de calcário da Formação Irati e caracterização geotectônica do rejeito na região de Rio Claro e Piracicaba (SP). Rio Claro, 100p. (Dissertação - Mestrado) - Insatituto de Geociências - Universidade Estadual Paulista.

MILLINGTON, R.T.; QUIRK, J.P. (1959) Permeability of porous media. Nature, v. 183, n. 1, p. 387-388.

MORAES, S.O.; LIBARDI, P.L.; MARCIANO, C.R. (1998) Seleção da curva de calibração de sonda de nêutrons mais adequada ao longo do perfil do solo. Revista Brasileira de Ciência do Solo. (prelo, registro 976/98).

MUALEM, Y. (1976) A new model for predicting the hydraulic conductivity of unsaturated porous media. Water Resources Research, Washington, v. 12, n. 3 , p. $513-522$.

NIELSEN, D.R.; DAVIDSON, J.M.; BIGGAR, J.W.; MILLER, R.J. (1962) Water movement through Panoche clay soil. Hilgardia, Berkeley, v. 42, p. 491-506.

NIELSEN, D.R.; JACKSON, R.D.; CARY, J.W.; EVANS, D.D. (1972) Soil water. Madison, Wiscosin, American Society of Agronomy and Soil Science Society of America. 175p. 
NIELSEN, D.R.; BIGGAR, J.W.; ERTH, K.T. (1973) Spatial variability of field measured soil-water properties. Hilgardia, Berkeley, v. 42, n. 7, p. 215-259.

OGATA, G. \& RICHARDS, L.S. (1957). Water content changes following irrigation of a bare field soil that is protected from evaporation. Soil Science Society of America Proceedings, Madison, v. 21, p. 355-356.

PAULETTO, E.A. (1986) Determinação da condutividade hidráulica a partir da curva de retenção. Piracicaba, 133p. (Tese - Doutorado) - Escola Superior de Agricultura Luiz de Queiroz, Universidade de São Paulo.

PAULETTO, E.A.; LIBARDI, P.L.; MANFRON, P.A.; MORAES, S.O. (1988) Determinação da condutividade hidráulica de solos a partir da curva de retenção de água. Revista Brasileira de Ciência do Solo, v. 12, p. 189-195.

PREVEDELLO, C.L. (1987) Teoria do fluxo da água em solos não saturados: novos conceitos e aplicações. Piracicaba, 264p. (Tese - Doutorado) - Escola Superior de Agricultura Luiz de Queiroz, Universidade de São Paulo.

PREVEDELLO, C. L. (1994) Gradiente unitário do potencial hidráulico como fonte de erro na obtenção da condutividade hidráulica em solo não saturado. Pesquisa Agropecuária Brasileira, Brasília, v. 29, n. 2, p. 275-280.

PREVEDELLOO, B.M.S.; PREVEDELLO, C.L.; LIBARDI, P.L. (1981) Simplificação analítica do método do perfil instantâneo para a obtenção da condutividade hidráulica não saturada em condições de campo. Revista Brasileira de Ciência do Solo, Campinas, v. 5, p. 93-97.

PREVEDELLO, C.L.; LIBARDI, P.L.; REICHARDT, K. (1991) Modelo de difusão para quantificação e descrição do fluxo da água em solos. Revista Brasileira de Ciência do Solo, Campinas, v.15, p. 145-149.

REICHARDT, K. \& LIBARDI, P.L. (1974) Analysis of soil-water movement in the field: I. Hydrological Field Site Characterization. Piracicaba, SP. 21p. BC-021, CENA. 
RICHARDS, L.A. (1931) Capillary conduction of liquids through porous media. Physics, v. 1, p. 318-333.

RICHARDS, S.J. \& WEEKS, L.V. (1953) Capillary conductivity values from soil moisture, yield and tension measurements on soil columns. Soil Science Society of America Proceedings, v. 17, p. 206-209.

RICHARDS, L.A.; GARDNER, W.R.; OGATA, G. (1956) Physical processes determining water loss from soil. Soil Science Society of America Proceedings, $v$. 20, p. 310-314.

SAUNDERS, L.C.V.; LIBARDI, P.L.; REICHARDT, K. (1978) Condutividade hidráulica da terra roxa estruturada em condições de campo. Revista Brasileira de Ciência do solo, v. 2, p. 164-167.

SHAO, M. \& HORTON, R. (1998) Integral method for estimating soil hydraulic properties. Soil Science Society of America Journal, v. 62, p. 585-592.

SISSON, J.B.; FERGUSON, A.H.; VAN GENUCHTEN, M.TH. (1980) Simple method for predicting drainage from field plots. Soil Science Society of America Journal, v. 44 , p. $1147-1152$.

SOUZA, A.D.B. de (1993) Análise da variabilidade temporal da condutividade hidráulica de um latossolo vermelho amarelo. Piracicaba, 56p. (Dissertação Mestrado) - Escola Superior de Agricultura Luiz de Queiroz, Universidade de São Paulo.

SWARTZENDRUBER, D. (1987) A quasi-solution of Richards equation for the downward infiltration of water into soil. Water Resources Research, v. 23, p. 809817.

TALSMA, T. (1985) Prediction of hydraulic conductivity from soil water retention data. Soil Science, v. 140, n. 3, p. 184-188. 
TIMM, L.C. (1994) Avaliação de alguns modelos matemáticos para a determinação da condutividade hidráulica de solos não saturados. Viçosa, 74p. (Dissertação Mestrado) - Universidade Federal de Viçosa.

VAN BAVEL, C.H.M.; STIRK, G.G.; BRUST, K.J. (1968) Hydraulic properties of a clay loam soil and the field measurement of water uptake by roots. I. Interpretation of water content and pressure profiles. Soil Science Society of America Proceedings, v. 32, p. 310-317.

VAN GENUCHTEN, M.TH. (1980) A closed-form equation for predicting the conductivity of unsaturated soils. Soil Science Society of America Journal, Madison, v. 44, p. 892-898.

VAN GENUCHTEN, M.TH. \& NIELSEN, D.R. (1985) On describing and predicting the hydraulic conductivity of unsaturated soils. Ann. Geophys., v. 3, n. 5, p. 615628.

VILLA NOVA, N.A. (1989) Dados meteorológicos do município de Piracicaba. Estação meteorológica da Escola Superior de Agricultura Luiz de Queiroz, Universidade de São Paulo. Departamento de Física e Meteorologia.

WARRICK, A.W. \& NIELSEN, D.R. (1980) Spatial variability of soil physical properties in the field. In: Hillel, D., ed. Applications of Soil Physics. New York, Academic Press, p. 319-344.

WATSON, K.K. (1966) An instantaneous profile method for determining the hydraulic conductivity of unsaturated porous materials. Water Resources Research, v. 2, p. 709-715.

WOLFE, M.L.; LARSON, C.L.; ONSTAD, C.A. (1988) Hydraulic conductivity and Green-Ampt infiltration modeling for tilled soils. Transactions of ASAE, v. 31, p. $1135-1140$. 